Aus der Abteilung Psychiatrie und Psychotherapie

(Prof. Dr. med. P. Falkai)

im Zentrum Psychosoziale Medizin

der Medizinischen Fakultät der Universität Göttingen

\title{
Untersuchung genetischer und geschlechtlicher Einflüsse in der Alzheimerpathologie anhand des Maustiermodells 5XFAD
}

\author{
INAUGURAL - DISSERTATION \\ zur Erlangung des Doktorgrades \\ der Medizinischen Fakultät der Georg-August-Universität zu Göttingen
}

vorgelegt von

Kratz, Sebastian

aus

Weißenfels/Saale

Göttingen 2010 
Dekan: Prof. Dr. med. C. Frömmel

I. Berichterstatter: Prof. Dr. rer. nat. T. Bayer

II. Berichterstatter: Priv.-Doz. Dr. med. Merkler

Tag der mündlichen Prüfung: 29.11.2010 


\section{Inhaltsverzeichnis}

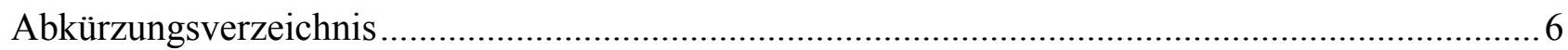

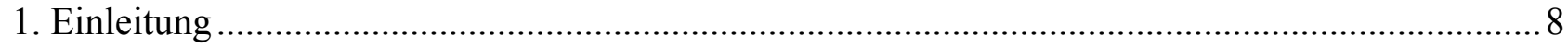

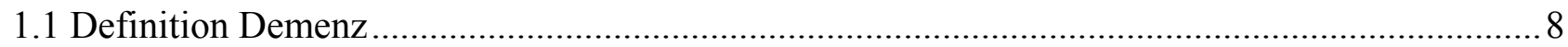

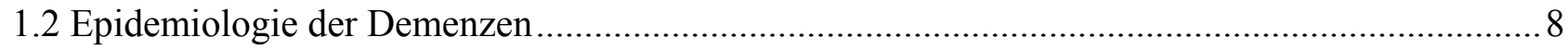

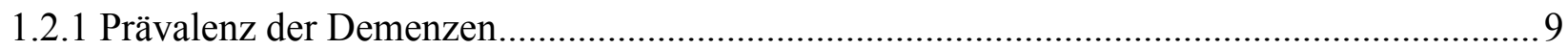

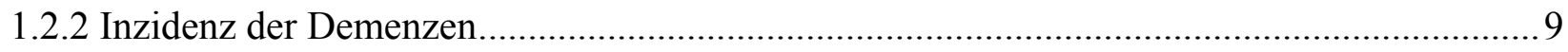

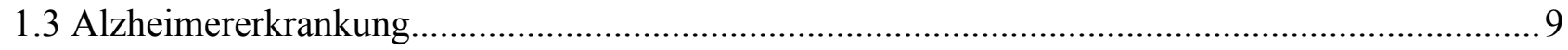

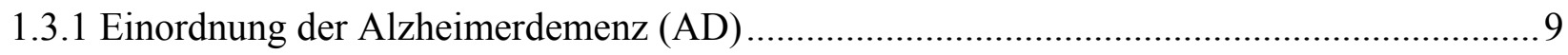

1.3.2 Prävalenz von Alzheimer und anderer Demenzen ....................................................... 11

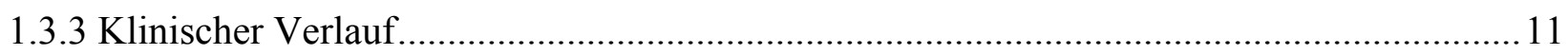

1.4 Geschichte der Alzheimer's schen Erkrankung................................................................... 12

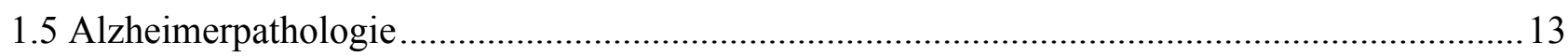

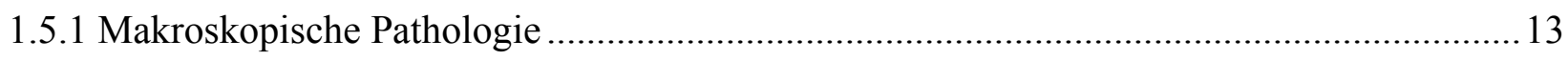

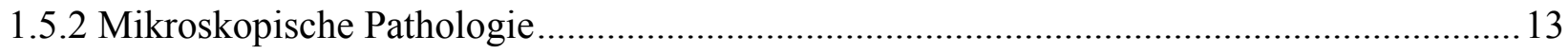

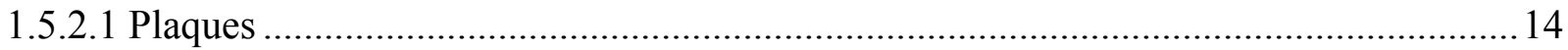

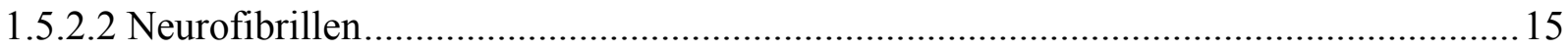

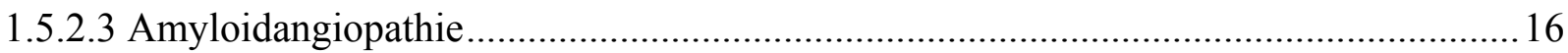

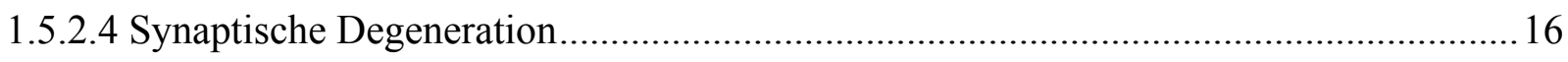

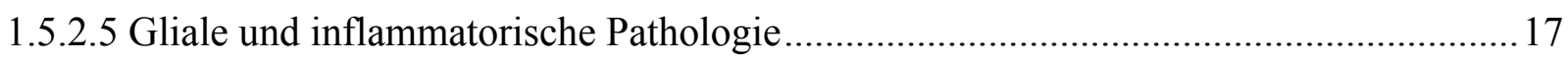

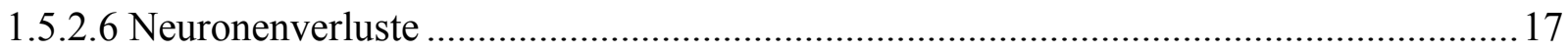

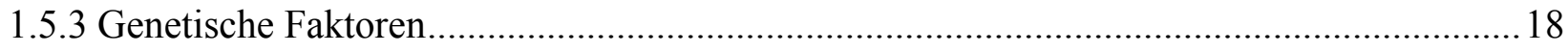

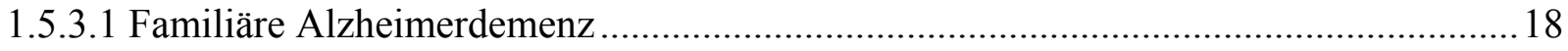

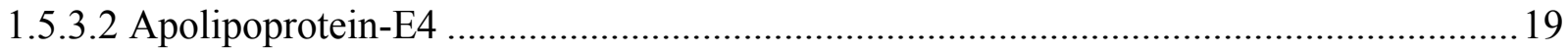

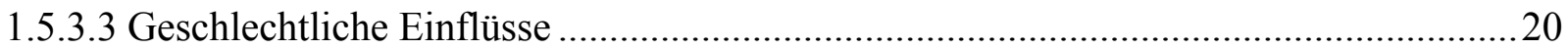

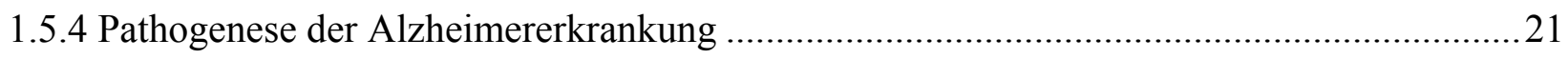

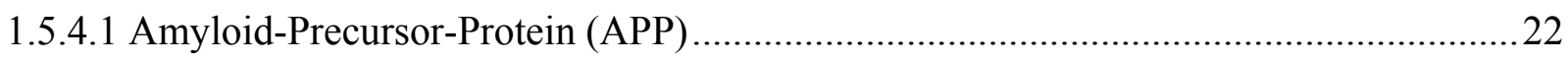

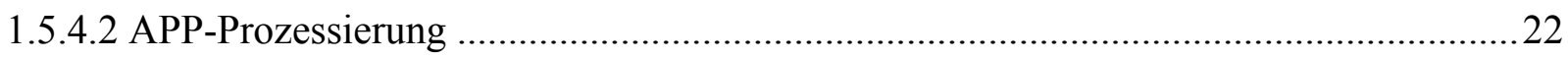

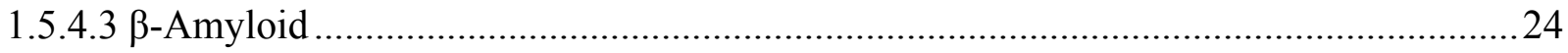




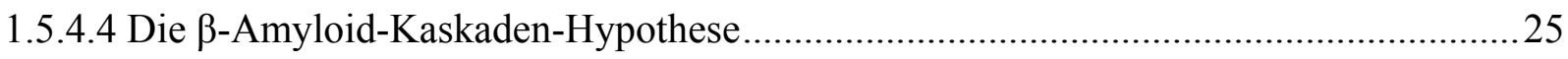

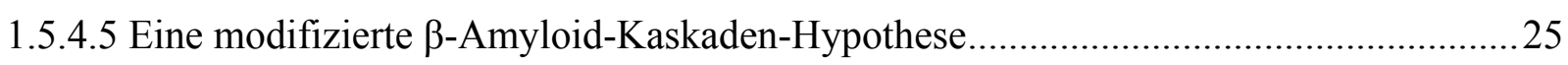

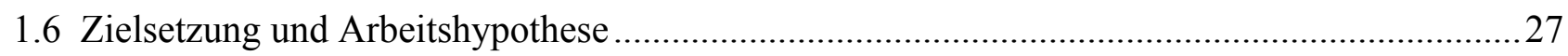

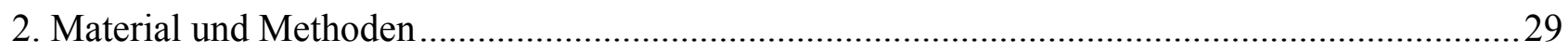

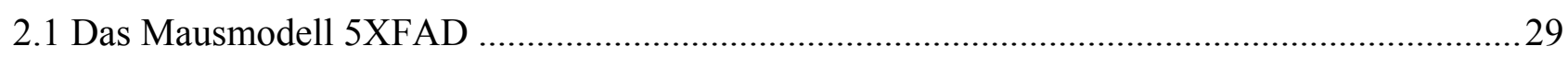

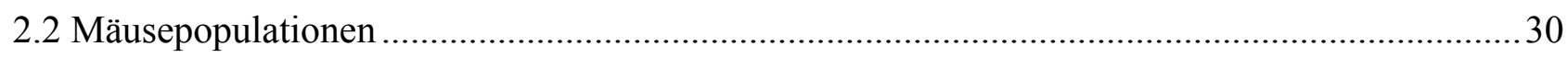

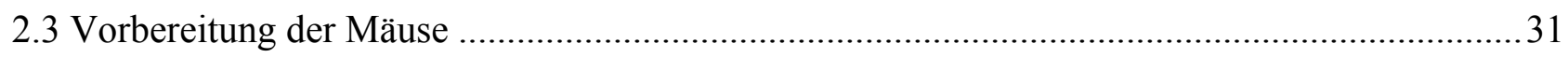

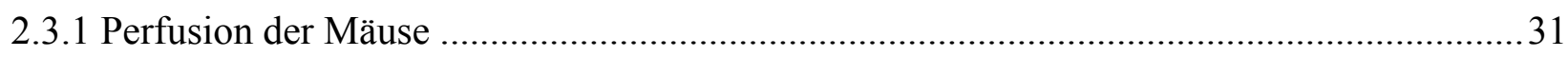

2.3.2 Herstellung der histologischen Schnitte für die Stereologie ........................................... 31

2.3.3 Cresylviolett-Färbung (Nissl-Färbung) für die Stereologie ............................................ 32

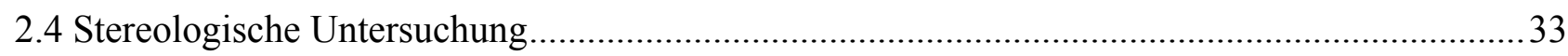

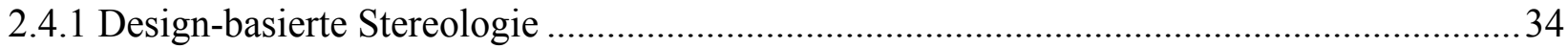

2.4.2 Berechnung der Neuronenzahl des Frontalkortex........................................................ 35

2.4.3 Berechnung des Volumens des Frontalkortex .............................................................. 36

2.5 Herstellung von histologischen Schnitten für den Plaqueload (quantitative A $\beta$-Bestimmung)

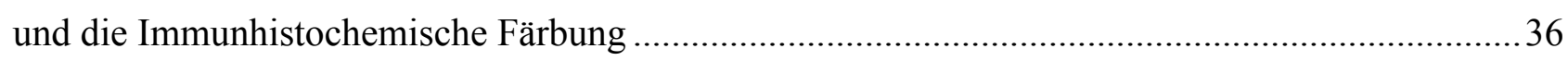

2.5.1 Bestimmung des Plaqueloads und der intraneuronalen $A \beta$-Aggregation ........................... 37

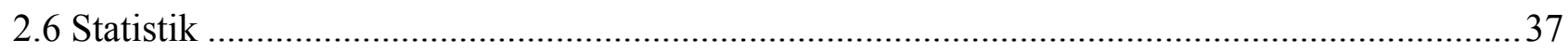

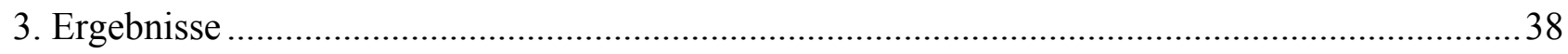

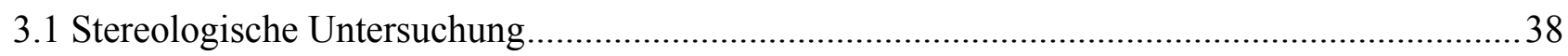

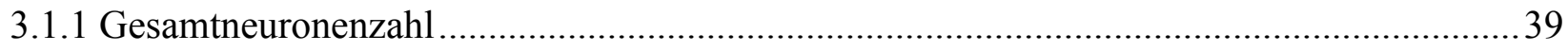

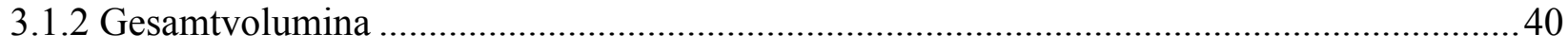

3.1.3 Vergleich der stereologischen Daten der Mausmodelle ................................................. 42

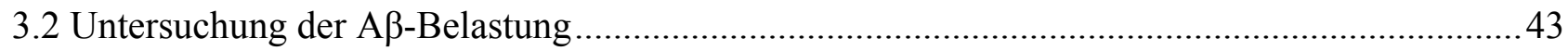

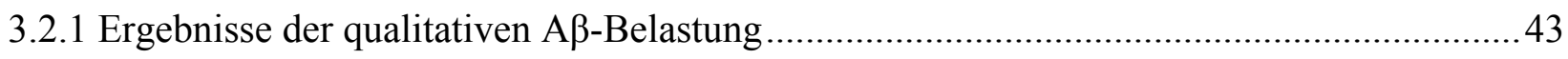

3.2.2 Ergebnisse der quantitativen Bestimmung der $A \beta$-Belastung (Plaqueload) ....................... 45

3.2.3 Vergleich der A $\beta$-Belastungen (Plaqueload) .............................................................. 46

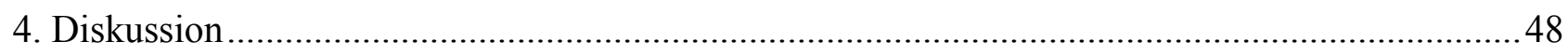


5 | I n h a l t s ve r ze i c h is

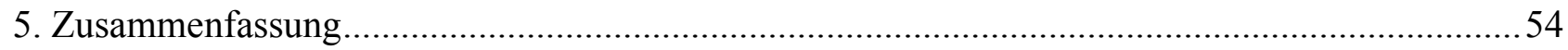

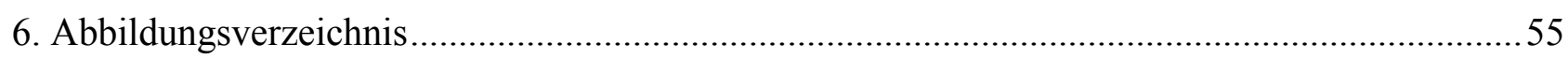

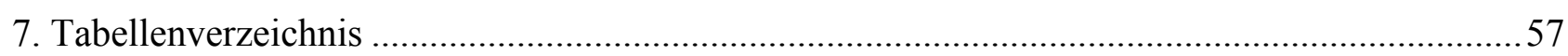

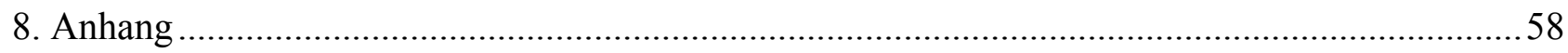

8.1 Altersspezifische Prävalenz (in Prozent) von Demenzerkrankungen ......................................58

8.2 Altersspezifische Inzidenz (in Prozent) von Demenzerkrankungen ........................................5 58

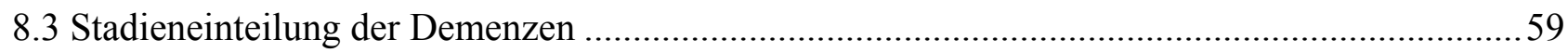

8.4 Klinische Diagnosekriterien für die Alzheimerdemenz nach NINCDSADRDA .....................60

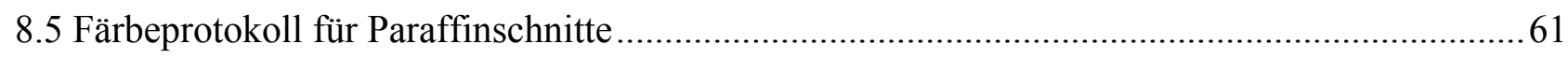

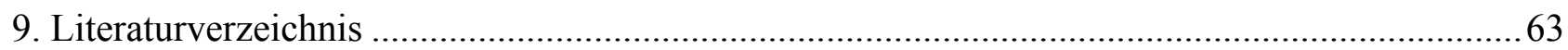




\section{Abkürzungsverzeichnis}

$\mathrm{A} \beta$

AD

ADAM

AICD

ANOVA

Aph

Apo

APP

APPs

BACE

bzw.

ca.

CAA

CT

DAB

EEG

EOAD

evtl.

FAD

FCS

$\mathrm{FSH}$

HIV

ICD

$\mathrm{kDa}$

LDL

LH

LOAD

LRP

MDI

Min

$\mathrm{n}$
$\beta$-Amyloid

Alzheimerdemenz

a disintegrin and metalloproteinase

APP intrazelluläre zytosolische Domäne

analysis of variance

anterior pharynx defective

Apolipoprotein

Amyloid-Precursor-Protein

soluble amyloid precursor protein

beta-site APP-cleaving enzyme

beziehungsweise

circa

kongophile Amyloidangiopathie

Computertomographie

3,3-Diaminobenzidin

Elektroenzephalogramm

early-onset Alzheimer's disease

eventuell

familiäre Alzheimerdemenz

fetal calf serum

follikelstimulierendes Hormon

Humanes Immundefizienzvirus

International Classification of Diseases

Kilodalton

low density lipoprotein

luteinisierendes Hormon

late-onset Alzheimer's disease

LDL receptor related Protein

mild cognitive impairment

Minute

number 
NFT(i/e)

NINCDSADRA

PBS

PHF

PS

S.

S.

SAE

TACE

VLDL

ZNS neurofibrillary tangles (intra-/extrazellulär)

The National Institute of Neurological and Communicative

Disorders and Stroke and the Alzheimer's Disease and Related

Disorders Association

phosphate buffered saline

paarig helikale Filamente

Presenilin

siehe

Seite

subkortikale arteriosklerotische Enzephalopathie

tumor necrosis factor converting enzyme

very low density lipoprotein

Zentralnervensystem 


\section{Einleitung}

\subsection{Definition Demenz}

Demenz ist eine erworbene, degenerative Erkrankung mit chronisch-progredientem Verlauf, die keine spezifische Krankheit oder Pathologie impliziert, sondern einen kognitiven Funktionsverlust bedeutet, der schwer genug ist, um die Alltagsfähigkeiten zu beeinträchtigen (Tang-Wai et al. 2005). Davon muss eine angeborene Intelligenzminderung und die altersentsprechende Hirninvolution abgegrenzt werden (Poeck und Hacke 2006).

Die entsprechenden Kriterien der ICD-10:

1. Eine Abnahme des Gedächtnisses und anderer kognitiver Fähigkeiten charakterisiert durch eine Verminderung der Urteilsfähigkeit und des Denkvermögens

2. Keine Bewusstseinstrübung

3. Verminderte Affektkontrolle mit mindestens einem der folgenden Merkmale: emotionale Labilität, Reizbarkeit, Apathie, Vergröberung des Sozialverhaltens

4. Dauer mindestens sechs Monate

Tabelle 1: ICD-10-Kriterien der Demenz (Ihl 2002)

\subsection{Epidemiologie der Demenzen}

In Deutschland sind bei den über 65-Jährigen ca. eine Million Menschen an Demenz erkrankt, damit gehört die Demenz zu den häufigsten psychiatrischen Erkrankungen. Es sind zu über zwei Drittel Frauen betroffen, was in Zusammenhang mit der höheren Lebenserwartung und dem damit höheren Erkrankungsrisiko gebracht wird. Sozioökonomisch zeigt die Demenz bedeutende Belastungen, da nach der Krankheitskostenrechnung 2002 des statistischen Bundesamtes auf psychische und Verhaltensstörungen 22,4 Milliarden Euro entfielen und ca. ein Viertel den Diagnosen nach ICD-10 für Demenz (F00-F03) zugerechnet wurden. Alle direkten und indirekten Kosten, die ein Demenzkranker im Mittel verursacht, belaufen sich auf circa 44.000 Euro pro Jahr.Die Familie muss im Durchschnitt 68 \% dieser Kosten tragen (Weyerer 2005). 


\subsubsection{Prävalenz der Demenzen}

Prognosen zufolge soll der Anteil der über 65-Jährigen von derzeit $20 \%$ auf 25-40 \% im Jahre 2030 ansteigen. Vor dem Hintergrund, dass die Prävalenzrate der Demenzen mit dem Alter exponentiell ansteigt (dies bedeutet angefangen bei den 60-Jährigen eine Verdopplung alle fünf bis sechs Jahre), muss insgesamt mit einem deutlichen Zuwachs an Demenzkranken gerechnet werden (Ihl 2002). Heute macht die Gesamtprävalenz in Deutschland circa 1,3 Millionen Menschen aus (s. Tabelle 12 im Anhang 8.1) (Poeck und Hacke 2006).

\subsubsection{Inzidenz der Demenzen}

Angaben zur Inzidenz sind schwieriger zu bewerten, da hier längere Zeiträume untersucht werden müssen und es durch Todesfälle, die nicht mehr mitgerechnet werden, zu einer Unterschätzung kommen kann. Es zeigt sich, dass sich die Inzidenz ab dem 65. Lebensjahr beinahe alle fünf Jahre verdoppelt. In der Metaanalyse von Bickel 2004 kam es zwischen den verschiedenen Autoren zu deutlicheren Schwankungsbreiten, als dies etwa bei der Prävalenz der Fall war (Bickel 2004) (s. Tabelle 13 im Anhang 8.2). Das Morbiditätsrisiko für eine schwere Demenz, berechnet aus den altersspezifischen Inzidenzraten, beträgt bis zum 80. Lebensjahr weniger als $10 \%$, bis zum Alter von 90 Jahren steigt es auf $40 \%$ und bis 100 Jahre auf $80 \%$. Rechnet man auch noch die mittelschweren Formen der Demenz dazu, kommt man auf Werte von beinahe $90 \%$ mit 100 Jahren. Da natürlich die Personenzahlen im höheren Altersbereich geringer werden, müssen diese Angaben auch kritisch gesehen werden (Bickel 1997).

\subsection{Alzheimererkrankung}

\subsubsection{Einordnung der Alzheimerdemenz (AD)}

Es gibt eine Vielzahl an Einteilungen von Demenzen, die verschiedene Vor- und Nachteile aufweisen. Ein sehr veranschaulichendes Schema ist die Einteilung in primär degenerative und sekundär symptomatische Demenzen. Primär neurodegenerative Erkrankungen sind beispielsweise die AD, die frontotemporale Demenz, wozu auch das Pick-Syndrom gehört, die Lewy-KörperchenDemenz und die Parkinsondemenz. Vaskuläre Demenzen, als weitere Gruppe der primären Demenzen sind unter anderem die Mikroangiopathie (SAE = subkortikale arteriosklerotische Enzephalopathie), die Makroangiopathie als Multiinfarktdemenz und strategisch bedeutsame 
Einzelinfarkte. Zu den sekundären Demenzen gehören die toxisch-metabolischen Enzephalopathien, wie die Demenz durch chronischen Alkoholabusus, HIV und Vitamin-B12-Mangel.

Andere Ursachen sind intrazerebrale Raumforderungen, Normdruckhydrozephalus oder ein chronisch-subdurales Hämatom (s. Tabelle 2) (Zeyfang et al. 2008).

\begin{tabular}{|c|c|c|c|}
\hline \multicolumn{2}{|l|}{ Primäre Demenzen } & \multicolumn{2}{|l|}{ Sekundäre Demenzen } \\
\hline $\begin{array}{l}\text { Neurodegenerative } \\
\text { Erkrankung }\end{array}$ & $\begin{array}{l}\text { Alzheimerkrankheit, } \\
\text { Frontotemporale Demenz, } \\
\text { Lewy-Körperchen-Demenz, } \\
\text { Parkinsondemenz }\end{array}$ & toxisch-metabolisch & $\begin{array}{l}\text { Chronische Intoxikation } \\
\text { (z.B. Alkohol), } \\
\text { HIV, } \\
\text { Stoffwechselstörungen, } \\
\text { Vit.-B12-Mangel, }\end{array}$ \\
\hline $\begin{array}{l}\text { Vaskuläre } \\
\text { Erkrankung }\end{array}$ & $\begin{array}{l}\text { SAE, } \\
\text { Makroangiopathie, } \\
\text { Einzelinfarkte in strategisch } \\
\text { bedeutsamen Lokalisationen }\end{array}$ & $\begin{array}{l}\text { Andere behandelbare } \\
\text { Ursachen }\end{array}$ & $\begin{array}{l}\text { Intrazerebrale } \\
\text { Raumforderung, } \\
\text { chron. subdurales } \\
\text { Hämatom, } \\
\text { Normdruckhydro- } \\
\text { zephalus }\end{array}$ \\
\hline
\end{tabular}

Tabelle 2: Einteilung der Demenzen (Zeyfang et al. 2008, S. 143)

Da die Demenz keine globale Hirnfunktionsstörung ist, können der Ausfallsymptomatik bestimmte Areale zugeordnet werden, die eine Einteilung in kortikale und subkortikale Demenzen erlaubt, die sich an klinisch-diagnostischen Aspekten orientiert. Selbstverständlich gibt es hier Überschneidungen und Ausnahmen, dennoch können Tendenzen ausgemacht werden, die schließlich zu weiteren diagnostischen Überlegungen führen sollen. Eine kortikale Demenz würde eher keine Veränderung in der Motorik zeigen. Die Patienten präsentieren sich zunächst in einem guten Allgemeinzustand. Bei näherer Betrachtung zeigt sich aber, dass die Patienten indifferent und teilweise enthemmt sind. Sie können aphasische, visuell-agnostische, apraktische Befunde und Störungen des Raumsinnes demonstrieren. Das Gedächtnis zeigt eine Speicherstörung und evtl. eine Amnesie.

Subkortikale Demenzen zeigen sich mit einer gestörten Motorik und psychischen Verlangsamung, wobei weniger die oben genannten kognitiven Störungen im Vordergrund stehen, als vielmehr eine verlangsamte Sprache und Handlung und eine Abrufstörung des Gedächtnisses. Motorische Defizite 
äußern sich durch extrapyramidale Störungen, wie eine Akinesie, einen Tremor, einen erhöhten Muskeltonus, ein abnormales Gangbild und eine gestörte Körperhaltung. Wie am Anfang bereits erwähnt, lässt sich keine absolute Trennung vornehmen, man kann aber sagen, dass kortikale Symptome wahrscheinlicher für eine AD sind und subkortikale Symptome eher für extrapyramidale Störungen, wie Parkinsondemenz und Chorea Huntington oder für symptomatische Erkrankungen sprechen (Schnieder 1999).

\subsubsection{Prävalenz von Alzheimer und anderer Demenzen}

In einer der größten europäischen Studien in einem Vorort von Rotterdam wurde ein Zusammenhang zwischen der Häufigkeit der AD und anderer demenzieller Subtypen und dem Bildungslevel untersucht. Es zeigte sich bei den TeilnehmerInnen im Alter von 56 bis 106 Jahren in $6,3 \%$ der Fälle eine Demenz. Von diesen 6,3\% hatten $72 \%$ eine AD, $16 \%$ eine vaskuläre Demenz und $6 \%$ eine Parkinsondemenz, die übrigen $6 \%$ verteilten sich auf andere Demenzsubtypen. Es konnte ein Zusammenhang zwischen einem niedrigeren Bildungsniveau und der Prävalenz der AD gezeigt werden, der sich nicht durch eine kardiovaskuläre Komorbidität erklären lässt, die auch häufig mit der $\mathrm{AD}$ und vaskulären Demenzen einhergeht (Ott et al. 1995). Überträgt man diese Prozentwerte auf die oben erwähnte Prävalenz der Demenz in Deutschland, muss man mit mehr als 900.000 Alzheimerkranken in der Bundesrepublik rechnen.

\subsubsection{Klinischer Verlauf}

Die ersten Anzeichen der AD sind schwierig erfassbar und damit ist auch der Krankheitsbeginn schwer festzulegen. In einer prospektiven Studie wurden verschiedene Frühsymptome der AD erkannt, wie beispielsweise leichte kognitive Einschränkungen (mild cognitive impairment = MDI), subjektive Gedächtnisstörungen und Depressionen nach dem 60. Lebensjahr (Heun et al. 2006). Ein sogenanntes Typ-A-Persönlichkeitsmuster mit Unruhe, sich selbst unter Druck setzen und Stress seien ebenfalls mit einem erhöhten Risiko verbunden, an einer AD zu erkranken (Baker et al. 1993)

Als manifestes Erstsymptom zeigt sich meistens die Gedächtnisstörung, aber auch Wortfindungsstörungen, Orientierungsstörungen oder Apathie können auftreten (Haupt et al. 1992). Eine Übersicht über den Verlauf und die Stadieneinteilung der Demenz gibt Tabelle 14 (s. Anhang 8.3). 
Einen weiteren Einblick in die Symptome der AD geben die klinischen Diagnosekriterien nach McKhann et al. (1984). Mit Hilfe einer klinischen Untersuchung kann zumindest eine wahrscheinliche Alzheimererkrankung diagnostiziert werden. Die definitive Diagnose ist erst post mortem anhand einer Hirnbiopsie möglich (s. Tabelle 14 im Anhang 8.3).

Die AD führt ungefähr acht Jahre nach Diagnosestellung zum Tod. Meistens treten Infektionen in Folge der Bettlägerigkeit auf wie beispielsweise Pneumonien oder Harnwegsinfekte (Ihl 2002).

\subsection{Geschichte der Alzheimer'schen Erkrankung}

Die Alzheimer'sche Erkrankung wurde erstmals vom Psychiater Alois Alzheimer, geb. 14.06.1864 bei Würzburg, auf der 37. Versammlung der süddeutschen Irrenärzte in Tübingen Ende 1906 vorgestellt. Damals fand sein Vortrag über seine mittlerweile verstorbene Patientin Auguste D. noch keinen großen Anklang.

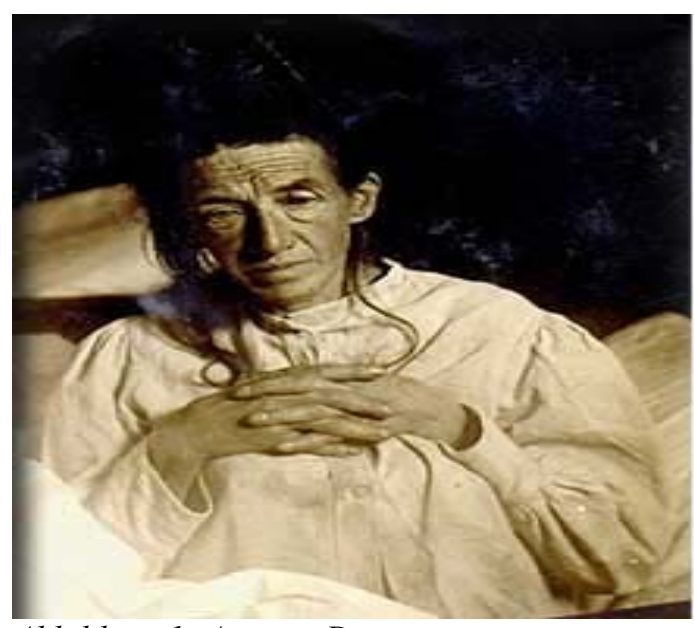

Abbildung 1: Auguste D.

(www.hirnliga.de/images/augusteD.jpg)

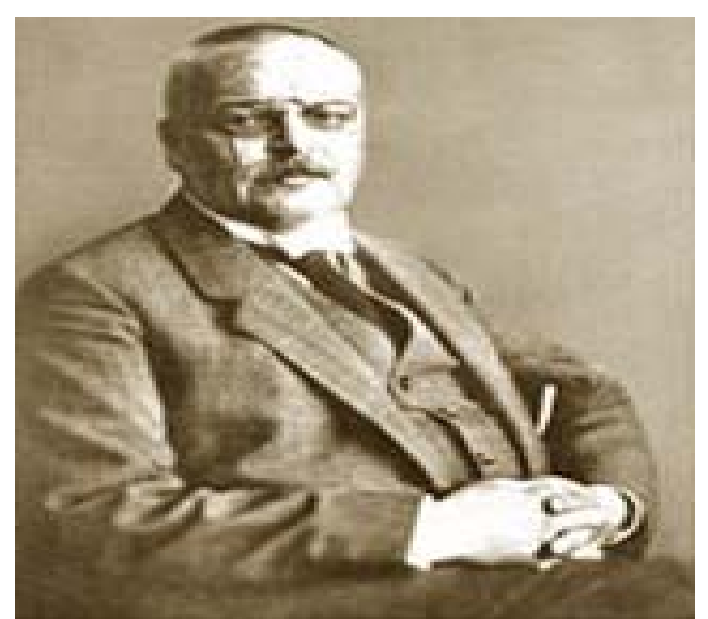

Abbildung 2: Alois Alzheimer (www.deutschealzheimer.de/fileadmin/alz/templates/template_im ages/Alois_Alzheimer.jpg)

Er hatte bei der noch relativ jungen Patientin, die unter „Schwachsinn“ litt, post mortem makroskopisch eine Hirnatrophie, mikroskopisch Fibrillenablagerungen in den Nervenzellen und extrazelluläre Ablagerungen im Hirnparenchym und damit erstmals die der Erkrankung zugrunde liegende Pathologie beschrieben. Erst ein Jahr später erschien sein Vortrag in der „Allgemeinen Zeitschrift für Psychiatrie und Psychisch-Gerichtliche Medizin“ mit dem Titel „Über eine eigenartige Erkrankung der Hirnrinde“. Es etablierte sich allmählich diese besondere Demenzform und fand erste Erwähnungen in Lehrbüchern (Eckert 2002). Heute gehört die Alzheimer'sche Erkrankung zu den häufigsten psychiatrischen Erkrankungen und ist die häufigste Demenzform. 


\subsection{Alzheimerpathologie}

Prinzipiell findet man, wie bereits durch Alois Alzheimer beschrieben, bei der Alzheimer'schen Pathologie makroskopische und mikroskopische Veränderungen. Diese sind von der normalen Hirninvolution abzugrenzen (Poeck und Hacke 2006), denn auch bei der normalen Hirnalterung finden sich Gehirnatrophie und möglicherweise Fibrillen bzw. Plaques (Hof et al. 1996). Im Zentrum der Pathologie steht sicherlich die Ablagerung von intra- und extraneuronalem AmyloidProtein (Kang et al. 1987).

\subsubsection{Makroskopische Pathologie}

Makroskopisch findet sich eine Atrophie bevorzugt im Parietal- und Temporallappen des Kortex, im Hippokampus und dem entorhinalen Kortex (s. Abbildung 3). Je nach Schwere und Chronologie zeigen sich verschieden starke Neuronenverluste in den einzelnen Hirnbereichen. Dies ist zurückzuführen auf eine Abnahme der kortikalen Dicke um bis zu 50-57 \% in den am schwersten betroffenen Bereichen im Vergleich zu 28 \% bei unauffälligen Gleichaltrigen. Die enorme Ab-

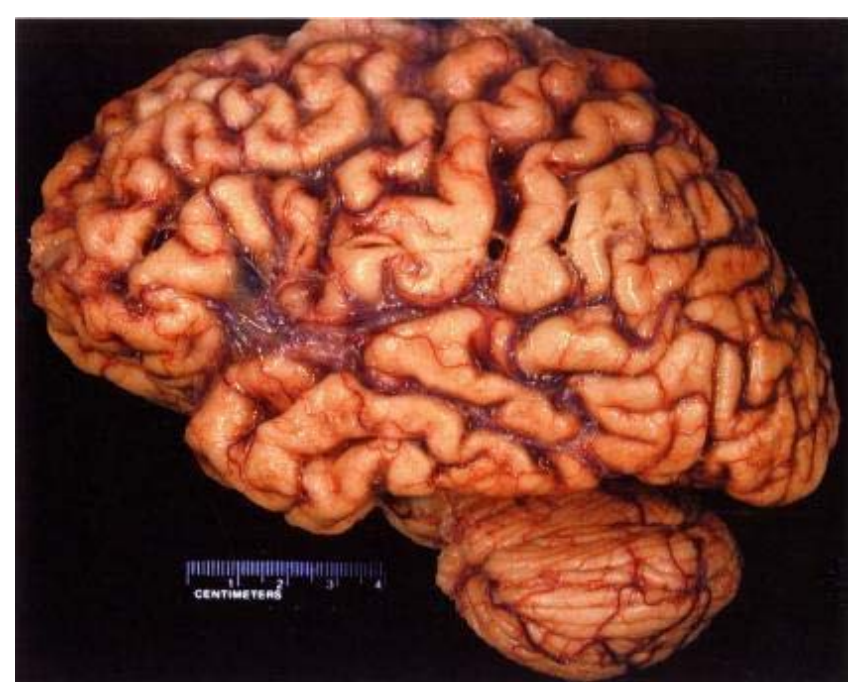

Abbildung 3: Hirnatrophie eines Alzheimerkranken (TangWai et al. 2005, S. 422) nahme der kortikalen Dicke ist in erster Linie Resultat eines Neuronenverlustes (Brun und Englund 1981; Morrison und Hof 1997; Shefer 1977). Weiterhin zeigen sich Veränderungen bzw. Verdickungen in den zerebralen und meningealen Blutgefäßen, die als kongophile Amyloidangiopathie bezeichnet werden, in denen sich mikroskopisch $\beta$-Amyloide ablagern, die sich aber von den intraparenchymalen $\beta$-Peptiden am N-Terminus unterscheiden (Masters et al. 1985b; Miller et al. 1989; Miller et al. 1993).

\subsubsection{Mikroskopische Pathologie}

Mittelpunkt der mikroskopischen Pathologie sind fibrilläre Amyloidablagerungen in Neuronen, extrazelluläre Plaques und die Amyloidangiopathie (Kang et al. 1987). Weiterhin spielen Synapsenverlust, endokrinologische, genetische und inflammatorische Veränderungen eine Rolle in 
der Entstehung der Alzheimererkrankung. Viele der Veränderungen kommen auch in normal alternden Gehirnen vor und sind nicht pathognomisch für die $\mathrm{AD}$, dennoch zeigen das Verteilungsmuster und die Intensität der Pathologien typische Merkmale für die Erkrankung (Morrison und Hof 1997).

\subsubsection{Plaques}

In extrazellulären Plaques, die früher auch als senile Plaques bezeichnet wurden, können vier verschiedene Bestandteile beschrieben werden: zentral-fibrilläres Kernstück, Perikarya, Axone und Dendriten mit Neurofibrillen, und Zellbestandteile mit dichten Körperchen (Terry et al. 1964).

Es gibt eine komplexe Einteilung der Plaques, je nachdem welche Bestandteile überwiegen. Prinzipiell kann man diffuse Plaques ohne Neuriten mit amorphem Amyloid von den neuritischen Plaques unterscheiden. Letztere können gekennzeichnet sein durch dystrophe Neuriten, die aus degenerierten Synapsen und lysosomalen „dense bodies“ bestehen, durch Neuriten, die paarig helikale Filamente enthalten (PHF-Neuriten) und durch ein Amyloid-Kernstück (s. Abbildung 4) (Dickson 1997; Wisniewski et al. 1989). Dystrophisch neuritische Plaques kommen auch bei normal alternden Menschen vor, wohingegen die PHF-Neuriten eher typisch für die AD sind (Dickson et al. 1988; Tekirian et al. 1996). Dystrophische Neuriten können durch die Aktivität lysosomaler Enzyme angezeigt werden, z.B. durch saure Phosphatase (Suzuki und Terry 1967) und Kathepsin (Cataldo et al. 1994) oder durch Marker, die glykolysierte Gruppen erkennen wie z.B.

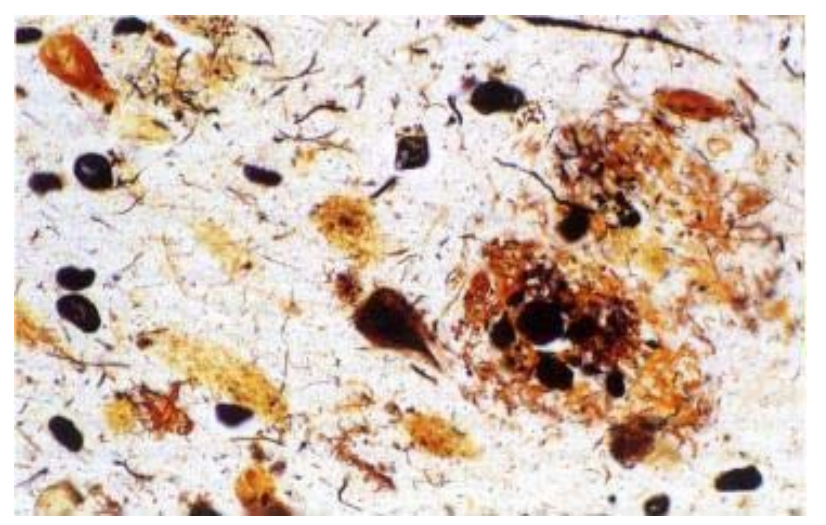

Abbildung 4: Neuritische Plaque mit Amyloid-Kern, umrandet von dystrophen Neuriten und Neurofibrillen (Tang-Wai et al. 2005, S. 422)
Concanavalin A (Mann et al. 1990). Des Weiteren können Antikörper gegen Chromogranin A, Synaptophysin und Ubiquitin degenerierte Neuriten bzw. Synapsen anzeigen (Brion et al. 1991; Munoz 1991; Perry et al. 1987). Die PHF-Neuriten werden im Kapitel Neurofibrillen besprochen. 


\subsubsection{Neurofibrillen}

Neurofibrillen bzw. „neurofibrillary tangles“(NFT) kommen intrazellulär in Neuronen und im Neuropil als „neuropil threads“ vor und sind charakteristisch (Braak et al. 1986), aber nicht spezifisch für die $\mathrm{AD}$, denn sie kommen auch bei der postenzephalitischen Parkinsonerkrankung und der subakuten sklerosierenden Panenzephalitis vor (Greenfield und Bosanquet 1953; Mandybur et al. 1977). Terry und Kollegen haben sogar gezeigt, dass die AD auch ohne Neurofibrillen vorkommt, wobei typisch Ablagerungen im Neokortex und Hippokampus fehlen; dennoch scheint das Vorkommen von Neurofibrillen tendenziell mit einem schwereren Verlauf zusammenzuhängen (Terry et al. 1987).

Yen et al. (1995) teilen die Neurofibrillen in intrazelluläre (NFTi) und nach Absterben der Zelle in extrazelluläre Fibrillen (,ghost tangles“, NFTe) ein und beziffern die Bestandteile der Filamente auf mindestens 20 Komponenten. Die wichtigsten Bestandteile sind Strukturproteine, Kinasen, Amyloid, ApoE und Ubiquitin (Yen et al. 1995). Sie können gepaarte Filamente (PHF) oder gerade Filamente enthalten (Kidd 1964).

Eine der bedeutendsten Komponenten der Filamente ist das Strukturprotein Tau, das zu den mikrotubuliassoziierten Proteinen gehört (Grundke-Iqbal et al. 1986). Das PHF-Tau unterscheidet sich vom normalen Tau durch einen höheren Glycin- und niedrigeren Lysingehalt (Liu et al. 1991), höhere saure isoelektrische Ladung (Ksiezak-Reding et al. 1990) und eine Hyperphosphorylierung (Hasegawa et al. 1992). Es konnte gezeigt werden, dass die Hyperphosphorylierung des Strukturproteins Tau früh bei der $\mathrm{AD}$ auftritt und sogar noch vor dem Nachweis von Neurofilamenten in Nervenzellen zu finden ist. Ähnlich hohe Werte für das veränderte Tau finden sich aber auch bei nicht dementen Vergleichsgruppen, nicht aber bei gesunden jungen Menschen (s. Abbildung 5) (Bancher et al. 1989).

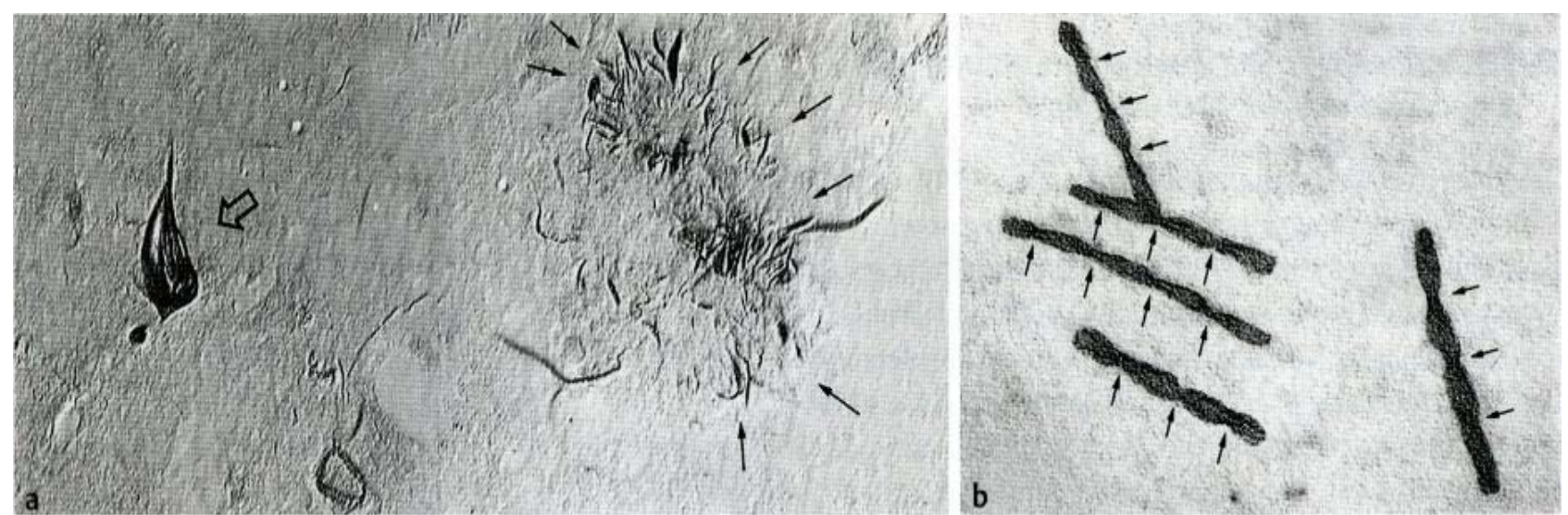

Abbildung 5:a) Lichtmikroskopische Aufnahme von intrazellulären Neurofibrillen (dicker Pfeil) und dystrophen Neuriten in einer neuritischen Plaque (kleine Pfeile); b) Elektronenmikroskopische Aufnahme von PHF (Arendt 2002, S. 114) 


\subsubsection{Amyloidangiopathie}

Das $\beta$-Peptid ( $\beta$-Amyloid) wurde ursprünglich aus meningealen Arteriolen und Venen von Patienten mit AD bzw. Down-Syndrom isoliert und ist Verursacher der kongophilen Amyloidangiopathie (CAA) (Glenner und Wong 1984a, 1984b).

Die Häufigkeit der CAA in Gehirnen von nicht dementen Patienten über 60 Jahre beträgt circa 36 \%, wohingegen Alzheimerpatienten in bis zu $85 \%$ der Fälle eine Amyloidangiopathie aufweisen. Dies könnte darauf hindeuten, dass auch Atherosklerose eine Rolle bei der Amyloidablagerung spielt (Ellis et al. 1996; Vinters und Gilbert 1983) und ist eine mögliche Ursache für die bereits erwähnte Überschneidung von vaskulärer Demenz und AD.

Selkoe fasste 2001 zusammen, dass erstaunlicherweise die Amyloidablagerungen, die man in meningealen und kortikalen Gefäßen findet, abrupt aufhören, sobald die Gefäße die weiße Substanz erreichen (Selkoe 2001). Die Amyloidablagerung ist begleitet von einem Untergang an Gefäßzellen, wie Perizyten und Muskelzellen, wofür insbesondere das A $\beta 1-40$ bzw. 1-42 verantwortlich gemacht wird (Suzuki N et al. 1994; Thomas et al. 2000; Verbeek et al. 2000).

Ungünstigerweise hat sich gezeigt, dass $\beta$-Amyloid die Fähigkeit besitzt, über einen intrazellulären proinflammatorischen Weg eine Vasokonstriktion zu verursachen (Paris et al. 2000). Dies kann eine Hirnblutung verursachen, wobei hier ein Zusammenhang zwischen der eigentlichen Ablagerung und bestimmten ApoE-Allelen besteht (Greenberg et al. 1998).

\subsubsection{Synaptische Degeneration}

Mit Hilfe von Synaptophysin-Antikörpern wurde gezeigt, dass im temporalen bzw. frontalen Kortex und im Hippokampus ein Synapsenverlust von bis zu 48-77 \% vorliegt. Der Synapsenverlust im Verhältnis zum Neuronenverlust beträgt im Vergleich zu Gesunden bis zu 38 \% (Davies et al. 1987; Honer et al. 1992). Dabei kommt es zu einem Synapsenverlust von lebenden Neuronen bzw. durch den Neuronenverlust selbst. Es wird vermutet, dass verändertes A $\beta$ bzw. Amyloid-PrecursorProtein (APP) im Zusammenhang mit einem gestörten axonalen Transport mittels KynesinMotorproteinen steht. Daraus könnte eine trophische Störung des Axons mit folgender Neurodegeneration resultieren (Kamal et al. 2001). Der Synapsenverlust bei der AD ist insgesamt der am besten korrelierte neurobiologische Faktor zum kognitiven Rückgang (Coleman und Yao 2003). 


\subsubsection{Gliale und inflammatorische Pathologie}

Mitte der Siebziger wurden erstmals Zusammenhänge zwischen inflammatorischen Prozessen und der Alzheimerpathologie festgestellt. Dementsprechend wurden mittels Elektronenmikroskop Immunglobulinablagerungen auf Amyloidfibrillen in senilen Plaques und Komplementablagerungen in Plaques mit einem Amyloidkern gefunden, sodass immunologischen Faktoren eine Rolle in der Pathologie der AD zugeordnet werden kann (Eikelenboom und Stam 1982; Ishii und Haga 1976, 1984). Auch gliale Veränderungen scheinen eine Rolle in der immunologischen Reaktion zu spielen. $\beta$-Amyloid ist in der Lage, gliale Zellen zur Produktion von Wachtstumsfaktoren und Zytokinen anzuregen. Diese Tatsache korreliert mit der Beobachtung, dass Astrozyten und Mikroglia in der Plaquekorona gefunden wurden (Araujo und Cotman 1992; Gitter et al. 1995). Inwiefern diese chronischen, inflammatorischen und glialen Veränderungen Ursache, Epiphänomen oder Begleitreaktion sind, ist wichtige Grundlage intensiver Forschung. Verschiedene Autoren weisen daraufhin, dass antiinflammatorische Medikamente einen zumindest verzögernden Effekt in der Progression der Alzheimerpathologie haben.

\subsubsection{Neuronenverluste}

Ältere Studien zeigen einen signifikanten Nervenzellverlust bei normalen Älteren im Vergleich zu jüngeren Gesunden ähnlich wie bei der AD im Bereich des Hippokampus, des Nucleus basalis Meynert und des Locus coeruleus (Ball 1977; Lowes-Hummel et al. 1989). Dahingegen zeigen neuere Untersuchungen, die die absolute Neuronenzahl mittels Stereologie gemessen haben, einen größeren Zusammenhang zwischen Geschlecht und Neuronenverlust als zwischen Alter und Neuronenverlust. Bei Letzterem konnte nur eine Abnahme der Neuronenzahl über die Lebensspanne von 20 bis 90 Jahre um $10 \%$ gemessen werden, während der durchschnittliche Unterschied zwischen Frauen und Männern circa $16 \%$ zu Gunsten der Männer betrug (Pakkenberg und Gundersen 1997; Pakkenberg et al. 2003). Die divergierenden Ergebnisse könnten an den unterschiedlichen Untersuchungsmethoden liegen.

In Bezug auf die AD haben Whitehouse und Kollegen einen Nervenzellverlust im Nucleus basalis Meynert von bis zu $75 \%$ gefunden und damit ein histologisches Korrelat zum bekannten Acetylcholinmangel aufgezeigt (Whitehouse et al. 1982). Der Nucleus basalis Meynert projiziert besonders in den Neokortex und das limbische System, sodass dessen Untergang die Minderung höherer kortikaler Funktionen und des Gedächtnisses forciert. Besonders hohe Nervenzellverluste finden sich auch im Locus coeruleus in der Formatio reticularis. Diese noradrenergen Neurone 
steuern insbesondere Wachheit und Aufmerksamkeit. Hier fanden Bondareff und Kollegen Verluste bis zu $80 \%$ und Tomlinson und Kollegen vermuten einen Zusammenhang zwischen der Schwere der AD bezüglich hoher neokortikaler Plaque-Anreicherung und dem Neuronenverlust im Nucleus coeruleus (Bondareff et al. 1982; Tomlinson et al. 1981).

Ein sehr früher und starker Neuronenverlust scheint im entorhinalen Kortex einzusetzen. Mittels stereologischer Verfahren wurde ein bis zu 32 \%iger Neuronenverlust im entorhinalen Kortex bei noch milder AD im Vergleich zu Kontrollgruppen gemessen. Bei schwerer AD beträgt der Verlust in einzelnen Schichten 70 bis $90 \%$ (Gomez-Isla et al. 1996). Da der entorhinale Kortex eine Schlüsselposition zwischen Neokortex und Hippokampus einnimmt, lassen sich hieraus die für die $\mathrm{AD}$ typischen Gedächtnisverschlechterungen ableiten.

\subsubsection{Genetische Faktoren}

Es gibt eine Reihe von Faktoren, die die Entstehung der Alzheimererkrankung beeinflussen. Wie schon zu Beginn dargestellt wurde, ist das Alter wohl der entscheidende Faktor bei der Entstehung der AD. Circa 3-4 \% der über 65 Jährigen und über $30 \%$ der über 90-Jährigen sind dement. Man kann davon ausgehen, dass zwei Drittel der Erkrankten eine AD haben.

\subsubsection{Familiäre Alzheimerdemenz}

Neben der AD, die mit dem Alter korreliert (late-onset Alzheimer's disease, LOAD), gibt es auch Formen, die gehäuft autosomal dominant in Familien auftreten. Die Erkrankung beginnt relativ früh (vor dem 65. Lebensjahr) und wird als „Early Onset Alzheimer Disease“ (EOAD) bezeichnet. Es gibt verschiedene Einschätzungen wie häufig diese Form ist, man kann aber sicherlich mit mindestens 1-5 \% rechnen (Rogaeva 2002). In 50 \% der Fälle mit EOAD sind die verantwortlichen Gene gefunden: Presenilin-1 (PS1), Presenilin-2 (PS2) und APP (Goate et al. 1991; Levy-Lahad et al. 1995; Sherrington et al. 1995).

Das APP-Gen ist auf Chromosom 21 lokalisiert und dessen Mutation wurde von Goate und Kollegen 1991 als erste spezifische genetische Ursache für die AD beschrieben. Das $\beta$-Amyloid wird aus dem Vorläufer APP von drei verschiedenen Sekretasen herausgeschnitten. Die Mutationen im APP-Gen führen zu veränderten Schnittstellen für die $\alpha$-/ $\beta$-/ oder $\gamma$-Sekretase und damit zu einer erhöhten bzw. veränderten Prozessierung (Haass et al. 1994). Schon 1993 haben Cai und Kollegen in Zellstudien gezeigt, dass APP-Mutationen zu einem deutlichen Anstieg von $\beta$-Amyloid führen 
können (s. Kapitel 1.5.4.2) (Cai et al. 1993).

Die Trisomie 21 (Down-Syndrom) ist eine weitere bedeutsame genetische Variante, die auf einer numerischen Chromosomenaberration beruht, bei der das Chromosom 21, auf dem das APP-Gen lokalisiert ist, in dreifacher und nicht zweifacher Anzahl vorliegt. Damit ist auch die Gendosis, die APP-Prozessierung und die Konzentration von A $\beta-40$ und 42 erhöht (Tokuda et al. 1997). Die Bedeutung der Gendosis wurde 1998 von Prasher und Kollegen unterstützt, die bei einer 78jährigen Patientin mit translozierter partieller Trisomie 21, die typische Zeichen des DownSyndroms aber kein vermehrtes APP-Gen hatte, autoptisch keine A $\beta$-Ablagerungen fanden (Prasher et al. 1998). Bei Down-Syndrom-Patienten wurden schon im Alter von 12 Jahren Amyloidablagerungen gefunden. Zunächst wird $A \beta-42$ und erst deutlich später $A \beta-40$ gebildet (Lemere et al. 1996).

Neben den APP-Gen-Mutationen, die zu einer veränderten Proteinprozessierung führen, gibt es noch zwei weitere bedeutende Genmutationen, die zur EOAD führen. Schellenberg und Kollegen haben 1992 Wolgadeutsche untersucht und eine genetische Verbindung der familiären Alzheimererkrankung zum Chromosom 14 gefunden (Schellenberg et al. 1992). Weitere Untersuchungen führten schließlich auf dessen langen Arm zum PS1-Gen (Sherrington et al. 1995). Kurz nach dieser Entdeckung wurde das PS2-Gen auf Chromosom 1 gefunden (Levy-Lahad et al. 1995). Beide Mutationen führen zu einem signifikanten Anstieg von A $\beta-42$ (Scheuner et al. 1996) durch eine veränderte katalytische Seite der $\gamma$-Sekretase, wobei Mutationen im PS1-Gen zu einer stärkeren $\beta$-Amyloid-Produktion führen als Mutationen im PS2-Gen (Bentahir et al. 2006; De Strooper et al. 1998). Beide Mutationen scheinen sich in ihrer Wirkung noch zu verstärken, denn in transgenen Mausmodellen mit PS1- und APP-Mutationen konnte eine beschleunigte und frühere Anreicherung von A $\beta-42-P$ laques gezeigt werden (Holcomb et al. 1998).

\subsubsection{Apolipoprotein-E4}

Ein weiterer bedeutender Risikofaktor für AD ist das Apolipoprotein-E- $\varepsilon 4$ (ApoE- $\varepsilon-4)$, das Anfang der Neunziger in Zusammenhang mit der LOAD gebracht wurde. ApoE ist auf dem langen Arm von Chromosom 19 lokalisiert. Bereits 1990 hat man mittels ApoE-Antikörpern herausgefunden, dass ApoE besonders mit Amyloid in extrazellulären Plaques, zerebralen Gefäßen und Neurofibrillen assoziiert war (Namba et al. 1991). Die Belastung mit $\beta$-Amyloid hängt deutlich mit

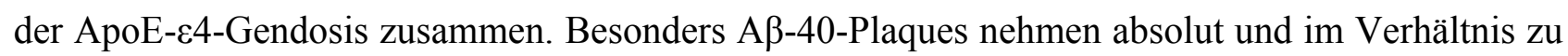
A $\beta$-42-Plaques zu (Gearing et al. 1996; Schmechel et al. 1993). 
Menschen die homozygot für das ApoE- $44-A l l e l$ sind, haben ein hohes Risiko an der AD zu erkranken (Corder et al. 1993; Saunders et al. 1993; Strittmatter et al. 1993). Dahingegen scheint das Risiko an der AD zu erkranken bei Menschen mit einem Apolipoprotein-E-e2-Genotyp am geringsten und führte $\mathrm{zu}$ der Vermutung, dass ApoE- $\varepsilon 2$ einen protektiven Effekt auf die Entwicklung einer LOAD hat (Corder et al. 1994).

Wie genau ApoE- $\varepsilon 4$ die Anreicherung von $\beta$-Amyloid beeinflusst bleibt weiterhin unklar. Jüngste Studien in Mausmodellen weisen daraufhin, dass das ApoE-e4-Allel dazu führt, dass freies $\beta$ Amyloid und ApoE-Amyloid-Komplexe an der Bluthirnschranke nicht vom schnelleren LRP1 (low density lipoprotein receptor related protein), sondern vom VLDL-Rezeptor (very low density lipoprotein), der sehr viel langsamer arbeitet, aus dem Hirnparenchym entfernt werden. Dahingegen werden bei ApoE-ع2/3-Allelen beide Rezeptoren benutzt und die Amyloidausscheidung erfolgt bedeutend schneller (Deane et al. 2008).

\subsubsection{Geschlechtliche Einflüsse}

Verschiedene Studien haben gezeigt, dass bei Frauen besonders im hohen Alter jenseits des 85 . Lebensjahres eine höhere Inzidenz für die Alzheimererkrankung vorliegt als bei Männern, das heisst Frauen haben ein höheres Lebensrisiko an einer AD zu erkranken (Andersen et al. 1999; Fratiglioni et al. 2000; Jorm und Jolley 1998). Dies könnte im Zusammenhang mit dem postmenopausalen Absinken des Östrogenspiegels stehen. Östrogene können antioxidativ wirken (Mooradian 1993) und die Überlebenszeit von Nervenzellen im Hippokampus und im MeynertBasalkern verlängern (McEwen et al. 1997). Eine Ovarektomie kann eine vermehrte Produktion von $\beta$-Amyloid zur Folge haben, welches sich aber unter dem Einfluss von Östrogenen wieder normalisiert (Xu et al. 1998). Hierzu passen auch die Ergebnisse von Tang und Kollegen, die 1996 gezeigt haben, dass eine Hormontherapie mit Östrogenen nach der Menopause das Risiko an einer AD zu erkranken signifikant senken und den Ausbruch verzögern kann (Tang et al. 1996). Neuere Untersuchungen der Women Health Initiative haben jedoch hervorgebracht, dass eine Hormontherapie mit Östrogenen nach dem 65. Lebensjahr nicht geeignet ist, das Risiko einer Demenz bzw. eines kognitiven Rückganges zu verhindern. Sie kann sogar das Morbiditätsrisiko erhöhen (Shumaker et al. 2004). Eine Östrogensubstitution als Therapie der AD konnte bisher keine signifikanten Unterschiede bezüglich der Progredienz der Erkrankung zeigen (Mulnard et al. 2000). In einer anderen Studie wurde auf eine positive Wirkung der Östrogeneinnahme im Zusammenhang mit Cholinesterasehemmern hingewiesen (Schneider et al. 1996). 
Trotz der widersprüchlichen Ergebnisse, zeichnet sich tendenziell ab, dass eine Hormonersatztherapie nicht die gewünschten Effekte erzielen kann. Marder et al. (2000) haben in ihrem Übersichtsartikel verschiedene Studien verglichen und vermutet, dass der Zeitpunkt der Therapie eine entscheidende Rolle spielen könnte. Eine früheinsetzende Hormontherapie perimenopausal könnte z.B. positivere Effekte haben als eine Hormonersatztherapie nach dem 60 . oder 70. Lebensjahr (Marder und Sano 2000).

Nach der Menopause findet neben dem Abfall des Gonadenhormons Östrogen ein Anstieg des follikelstimulierenden Hormons (FSH) und des luteinisierenden Hormons (LH) statt. Diese Effekte interagieren in einer Feedback-Schleife, bei der zuerst das Östrogen altersentsprechend abfällt und durch die fehlende negative Rückkopplung an die Hypophyse reaktiv FSH und LH nach der Menopause ansteigen. Bowen et al. $(2000,2002)$ vermuten, dass gerade der Anstieg des FSH und LH eine bedeutende Funktion in der Pathologie der AD hat. Beide Gonadotropine sind bei Alzheimerpatienten um das zweifache erhöht und könnten eine Rolle bei der Ablagerung von abnormalem Protein über den LDL-Rezeptor spielen. Erhöhte Werte von LH wurden auch in Pyramidenzellen des Hippokampus gezeigt, die besonders empfindlich bei der Alzheimer'schen Neurodegeneration reagieren (Bowen et al. 2000; Bowen et al. 2002). In einem KnockoutMausmodell wurden erhöhte LH-Werte bei einer LH-Rezeptor-kompetenten Maus versus einer Maus mit ausgeschaltetem LH-Rezeptor untersucht. Beide Mäuse hatten erhöhte LH-Werte, jedoch hatte nur die Maus mit funktionsfähigem LH-Rezeptor einen kognitiven Rückgang demonstriert (Casadesus et al. 2007).

Auch histopathologisch finden sich bedeutende Geschlechtsunterschiede, denn bei weiblichen Gehirnen finden sich insgesamt mehr alzheimertypische Veränderungen wie beispielsweise vermehrt Neurofibrillen (Barnes et al. 2005) oder mehr Plaques (Kraszpulski et al. 2001). Insgesamt zeigen sich bei der AD deutliche Geschlechtsunterschiede. Die Ursachen sind noch nicht eindeutig geklärt.

\subsubsection{Pathogenese der Alzheimererkrankung}

Wie schon beschrieben, spielt das A $\beta$ eine besondere Rolle bei der Entstehung von Plaques, inflammatorischen Prozessen und der Amyloidangiopathie. Es ist ein sehr wichtiger Bestandteil der Alzheimererkrankung und bedeutend für das Verständnis der gesamten Pathologie. Erstmals wurde das plaquebildende $\beta$-Peptid 1985 sequenziert und gab damit den Weg frei für die molekulare Erforschung der AD (Masters et al. 1985a). 


\subsubsection{Amyloid-Precursor-Protein (APP)}

Vorläuferprotein des $\beta$-Peptides ist das deutlich größere Amyloid-Precursor-Protein (APP), lokalisiert auf Chromosom 21. Das APP ist ein 110 bis $135 \mathrm{kDa}$ großes Transmembranprotein, wird ubiquitär im Körper exprimiert und wird durch mehrfache proteolytische Spaltung zum $A \beta$ geschnitten.

Das glykolisierte Transmembranprotein wird durch alternatives Spleißen in verschiedene Isoformen geschnitten. Die längste Isoform besteht aus 770 Aminosäuren. Es hat eine Transmembrandomäne, eine große N-terminale extrazelluläre Region und einen kürzeren $\mathrm{C}$-terminalen zytoplasmatischen Anteil. Die A $\beta$-Sequenz befindet sich zu einem Teil im extrazellulären sowie transmembranären Abschnitt (Kang et al. 1987; Sandbrink et al. 1994; Selkoe et al. 1988).

\subsubsection{APP-Prozessierung}

Das Transmembranprotein APP ist Ursprung des pathologischen $\beta$-Peptides. Es kann posttranslational prinzipiell durch zwei verschiedene Wege prozessiert werden. Dabei stehen die Enzyme $\alpha$ - und $\beta$-Sekretase im Zentrum. Die $\alpha$-Sekretase prozessiert den nicht amyloidogenen Weg, bei dem kein toxisches $\beta$-Peptid entsteht. Die $\beta$-Sekretase prozessiert den amyloidogenen Weg, bei dem $A \beta$ entsteht.

Das Schneiden des APP's durch die $\alpha$-Sekretase findet innerhalb der A $\beta$-Sequenz zwischen den Aminosäuren 16 und 17 statt. Es wird lösliches APPs- $\alpha$ gebildet und das membrangebundene C83 Fragment (Esch et al. 1990). Aus Letzterem wird noch einmal durch die $\gamma$-Sekretase das p53 Produkt herausgeschnitten (s. Abbildung 6 und 7). Bei diesem enzymatischen Weg ist es ausgeschlossen, dass aus genau diesem Vorläuferprotein noch toxisches $\beta$-Peptid entstehen kann. Es wurden bisher zwei Enzyme mit $\alpha$-Sekretase Aktivität aus der ADAM-Familie (a disintegrin and metalloproteinase) identifiziert: ADAM 10 und ADAM 17, welches auch als TACE (tumor necrosis factor converting enzyme) bekannt ist (Buxbaum et al. 1998; Lammich et al. 1999). 


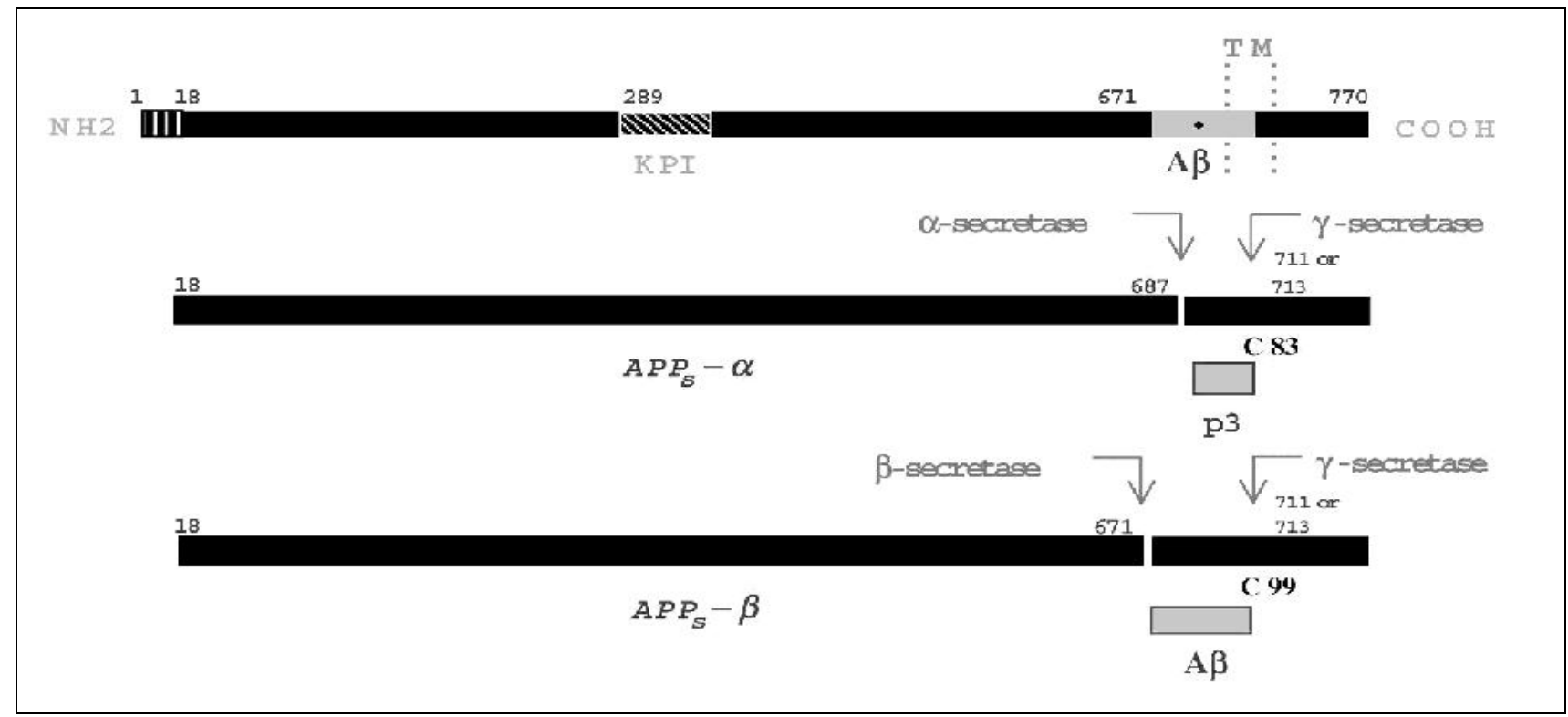

Abbildung 6: Schematische Darstellung der APP-Prozessierung, verändert nach Selkoe (Selkoe 2001, S. 746)

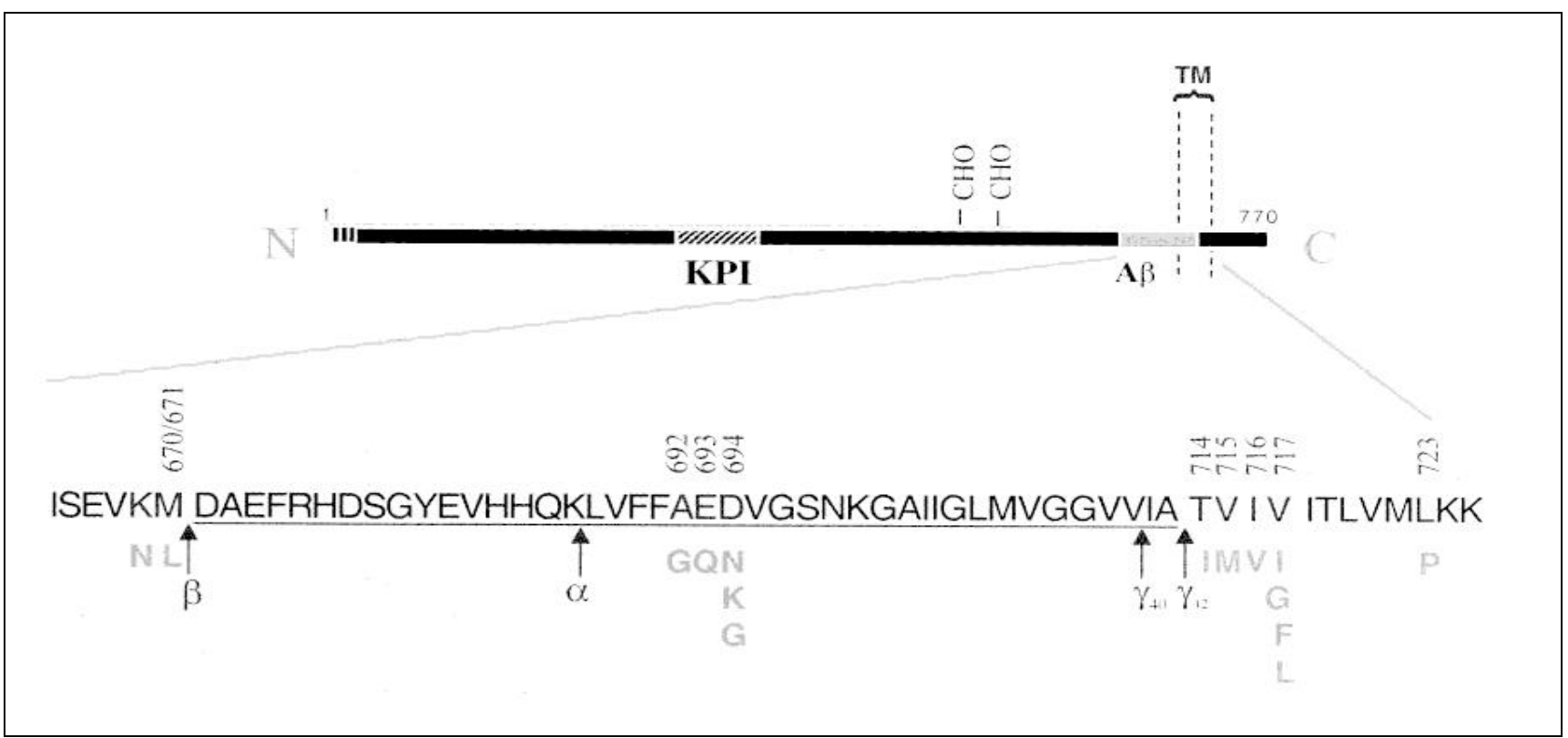

Abbildung 7: Schematische Darstellung der APP-Prozessierung, verändert nach Selkoe (Selkoe 2001, S. 749)

Bei dem amyloidogenen Prozessierungsweg des APP entsteht das neurotoxische $\beta$-Peptid, welches im Mittelpunkt der Alzheimer'schen Pathogenese steht. An dem N-terminalen Ende des APP werden durch die Aspartylproteasen BACE 1 und BACE 2 (beta-site APP-cleaving enzyme) lösliches APPs- $\beta$ herausgeschnitten. BACE 1 weist dabei die deutlich höhere Aktivität auf. Es hinterbleibt in der Membran ein C99-Fragment, welches durch die $\gamma$-Sekretase prozessiert wird. Es entstehen neben dem verbleibenden AICD (APP intrazelluläre zytosolische Domäne) das unlösliche B-Peptid-40 oder -42 (Blennow et al. 2006; Selkoe 2001; Vassar et al. 1999; Yan et al. 1999).

Die $\gamma$-Sekretase, die an beiden Schritten wesentlich beteiligt ist, besteht aus verschiedenen 
Proteinen, die einen großen Komplex bilden, der PS1 oder PS2, Nicastrin, Aph-1 (anterior pharynx defective) und Presenilin-Enhancer-2 enthält. Die Bedeutung der Preseniline wurde schon im Kapitel „Familiäre Alzheimerdemenz“ besprochen (s. Kapitel 1.5.3.1).

Wie gravierend eine Verschiebung des Gleichgewichts zu Gunsten der Bildung des $\beta$-Amyloids ist, verdeutlicht die Tatsache, dass die Fragmente der $\alpha$-Sekretase eine $100 \mathrm{fach}$ höhere neuroprotektive Wirkung bei glutamatinduzierter Exzitotoxizität haben als die Fragmente, die durch die $\beta$-Sekretase gebildet werden. Diese neuroprotektive Wirkung wird der Aminosäuresequenz 591-612 zugeordnet (Furukawa et al. 1996).

\subsubsection{3 $\beta$-Amyloid}

Das $\beta$-Amyloid kann verschiedene Wirkungen haben. Es kann in geringer Konzentration sogar neurotroph auf undifferenzierte Neurone, aber auch neurotoxisch in hoher Konzentration wirken (Yankner et al. 1990). Letzteres ist besonders dann stark ausgeprägt, wenn es eine Länge von 1-42 bzw. 1-43 Aminosäuren hat und in fibrillärer Form bzw. $\beta$-Faltblattstruktur vorliegt (Jarrett et al. 1993; Lorenzo und Yankner 1994). Takahashi und Kollegen haben gezeigt, dass A $\beta$ als Oligomer in endosomalen Vesikeln besonders prä- und postsynaptisch aggregiert (Takahashi et al. 2002).

Neben diesen N-terminal nicht trunkierten Amyloidformen, gibt es auch N-terminal trunkiertes $\beta$ Amyloid, welches generell stärker aggregiert (Pike et al. 1995).

2004 haben Casas und Kollegen bei APP ${ }^{\mathrm{SL}}$ PS1KI-Mäusen, die zwei Mutationen im PS1 und zwei Mutationen im APP (London und schwedische Mutation) haben, verschiedene trunkierte A $\beta \mathrm{x}-42-$ Spezies gefunden, die mit dem Alter zunehmen. Beispielsweise wurde bei vier Monate alten Mäusen unter anderem $\mathrm{A} \beta-3-42$ und zwei Monate später $\mathrm{A} \beta_{\mathrm{pE} 3-42}(\mathrm{~N}$-terminal trunkiertes $\mathrm{A} \beta$, das an dritter Stelle mit Pyroglutamat anstelle von Glutamat beginnt) gefunden (Casas et al. 2004). Gerade das $\mathrm{A} \beta_{\mathrm{pE} 3-42}$ hat eine größere Neigung zur Aggregation, eine höhere Stabilität und verstärkte Toxizität als A $\beta$ in voller Länge (He und Barrow 1999; Kuo et al. 1998; Russo et al. 2002; Schilling et al. 2006). $\mathrm{A} \beta_{\mathrm{pE} 3-42}$ scheint mit dem Alter zuzunehmen, wohingegen nicht trunkiertes $\mathrm{A} \beta$ abnimmt. Es wird vermutet, dass ein dynamischer Prozess während der Progression der AD zur proteolytischen Abspaltung der ersten beiden Aminosäuren führt (Wirths et al. 2010). Die hohe Stabilität des Amyloids wird durch eine Glutamatzyklase, die Glutamat in Pyroglutamat umwandelt, erreicht (Schilling et al. 2004). Inhibitoren dieser Zyklase haben bereits in vitro und in vivo eine verminderte $A \beta_{\mathrm{pE} 3-42}$-Bildung gezeigt (Cynis et al. 2006; Schilling et al. 2008). 


\subsubsection{Die $\beta$-Amyloid-Kaskaden-Hypothese}

Hardy und Allsop haben Anfang der Neunziger eine Kaskaden-Hypothese der Alzheimerpathogenese entwickelt in dessen Zentrum die Anreicherung von extrazellulärem $\beta$ Amyloid steht. Der Grund für die $\beta$-Peptid-Ablagerung ist der gestörte APP-Metabolismus, der beispielsweise durch APP-Gen-Mutationen, Trisomie 21 und Umweltfaktoren bedingt ist. Die Folge sind neuritische Plaques, vaskuläres Amyloid, Neurofibrillen und schließlich synaptische Degeneration und Neuronenverlust. Dies führt letztendlich zu den typischen klinischen Zeichen der Demenz (s. Abbildung 8) (Hardy und Allsop 1991).

\section{Die $\beta$-Amyloid-Kaskaden-Hypothese}

Risikofaktoren: Trisomie 21, APP-, PS1-/PS2-Mutationen, Alter

Veränderter APP-Metabolismus<smiles>[Te]C1CC1</smiles>

Erhöhtes extrazelluläres $A \beta-40 /-42$

Plaques, Neurofibrillen, vaskuläres Amyloid

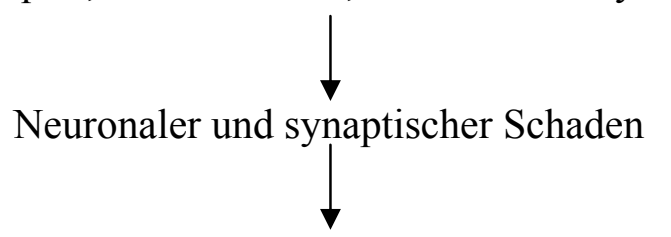

Neuronen- und Synapsenverlust

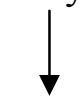

Gehirnatrophie

Klinik der Demenz

Abbildung 8: Die Amyloid-Kaskaden-Hypothese, verändert nach Hardy und Allsop (Hardy und Allsop 1991, S. 387)

\subsubsection{Eine modifizierte $\beta$-Amyloid-Kaskaden-Hypothese}

Die von Hardy und Allsop aufgestellte Kaskaden-Hypothese wurde kontrovers diskutiert. Es konnte gezeigt werden, dass es keine Korrelation zwischen der Anzahl der Plaques bzw. der $\beta$ Peptidablagerung und dem Fortschritt der Erkrankung gibt. Eine Stadieneinteilung anhand von Neurofibrillenablagerungen wies in diesem Zusammenhang eine höhere Genauigkeit auf (Braak 
und Braak 1991). Der Neuronenverlust im Hippokampus steht nicht im Zusammenhang mit extrazellulärem $\beta$-Amyloid, sondern korreliert ganz im Gegenteil mit der Anreicherung von intrazellulärem $\beta$-Peptid (Casas et al. 2004). Dass $\beta$-Peptide intrazellulär gebildet und erst dann nach extrazellulär abgegeben werden, haben Masters bzw. Wertkin und Kollegen bereits 1985 und 1993 gezeigt (Masters et al. 1985b; Wertkin et al. 1993). Immunhistochemische Untersuchungen bei menschlichen Gehirnen mit und ohne $\mathrm{AD}$, die mit Antikörpern gegen paarige helikale Filamente (PHF) und $\beta$-Amyloid angefärbt wurden, haben früh deutliche intrazelluläre Ablagerungen von $\mathrm{A} \beta$ hervorgebracht, bevor beispielsweise immunologische Reaktionen gegen PHF aufgetaucht sind (Fernandez-Vizarra et al. 2004). Besonders das stärker amyloidogene A $\beta-42$ kumuliert stark intrazellulär bei Down-Syndrom-Patienten. Das $A \beta-40$ reichert sich hingegen nur schwach in reifen Plaques an (Mori et al. 2002).

Aufgrund der zunehmenden Hinweise, dass intrazelluläres $A \beta-42$ entscheidend für die Alzheimer'sche Erkrankung ist, wurde eine neue „modifizierte $\beta$-Amyloid-Kaskaden-Hypothese“ formuliert. Nach dieser Hypothese wurde die intrazelluläre $A \beta$-Akkumulation als Auslöser für Synapsen- und Neuronendegeneration und schließlich deren Verlust als zentrales Element der Alzheimer'schen Pathogenese postuliert (s. Abbildung 9) (Wirths et al. 2004).

\section{Die modifizierte ß-Amyloid-Kaskaden-Hypothese}

Risikofaktoren: Trisomie 21, APP-, PS1-/PS2-

Mutationen, Alter

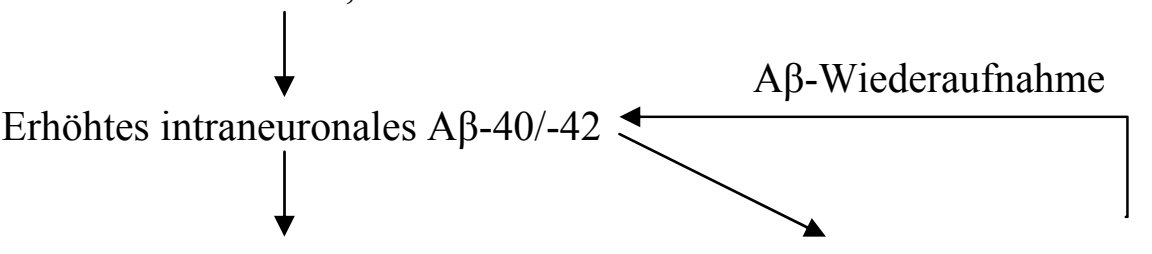

Akkumulation von intraneuronalem $A \beta-40 /-42$ Lösliches extraneuronales $A \beta-40 /-42$

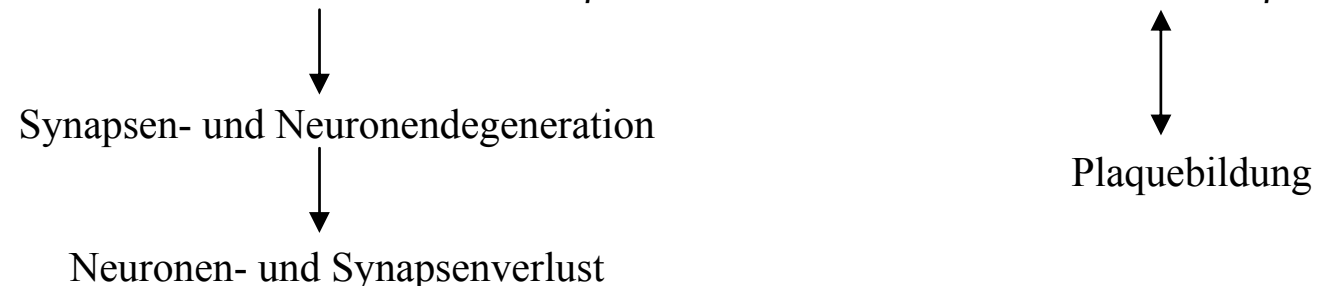

Atrophie bestimmter Hirnbereiche

Klinik der Demenz

Abbildung 9: Die modifizierte Amyloid-Kaskaden-Hypothese nach Wirths und Kollegen (Wirths et al. 2004, S. 515) 


\subsection{Zielsetzung und Arbeitshypothese}

Die von Alois Alzheimer Anfang des 20. Jahrhunderts beschriebene Erkrankung des Gehirns und seine Pathologien, haben sich zunehmend als komplexe Vorgänge dargestellt, die man nun seit 100 Jahren versucht $\mathrm{zu}$ ergründen und aufzuzeigen. Um bestimmte pathologische Abläufe besser nachzuvollziehen, wurde in den letzten Jahren auf verschiedene Mausmodelle zurückgegriffen, die typische Pathologien der Alzheimer'schen Erkrankung konzentrieren.

Das dieser Arbeit zugrunde liegende Mausmodell ist das transgene 5XFAD-Mausmodell, welches von Oakley et al. (2006) erstmals dazu benutzt wurde die wesentlichen mikroskopischen Merkmale der AD zu beschreiben. Die Arbeitsgruppe hatte damals qualitativ einen Neuronenverlust im Kortex und Subikulum im Vergleich zur nichttransgenen Mauspopulation beschrieben, sowie eine Ausdünnung der ersten und fünften Kortexschicht. Letzteres sei durch den Verlust an Pyramidenzellen in Schicht fünf und deren dendritischen Ausläufer in Schicht eins bedingt (siehe Abbildung 10) (Oakley et al. 2006).

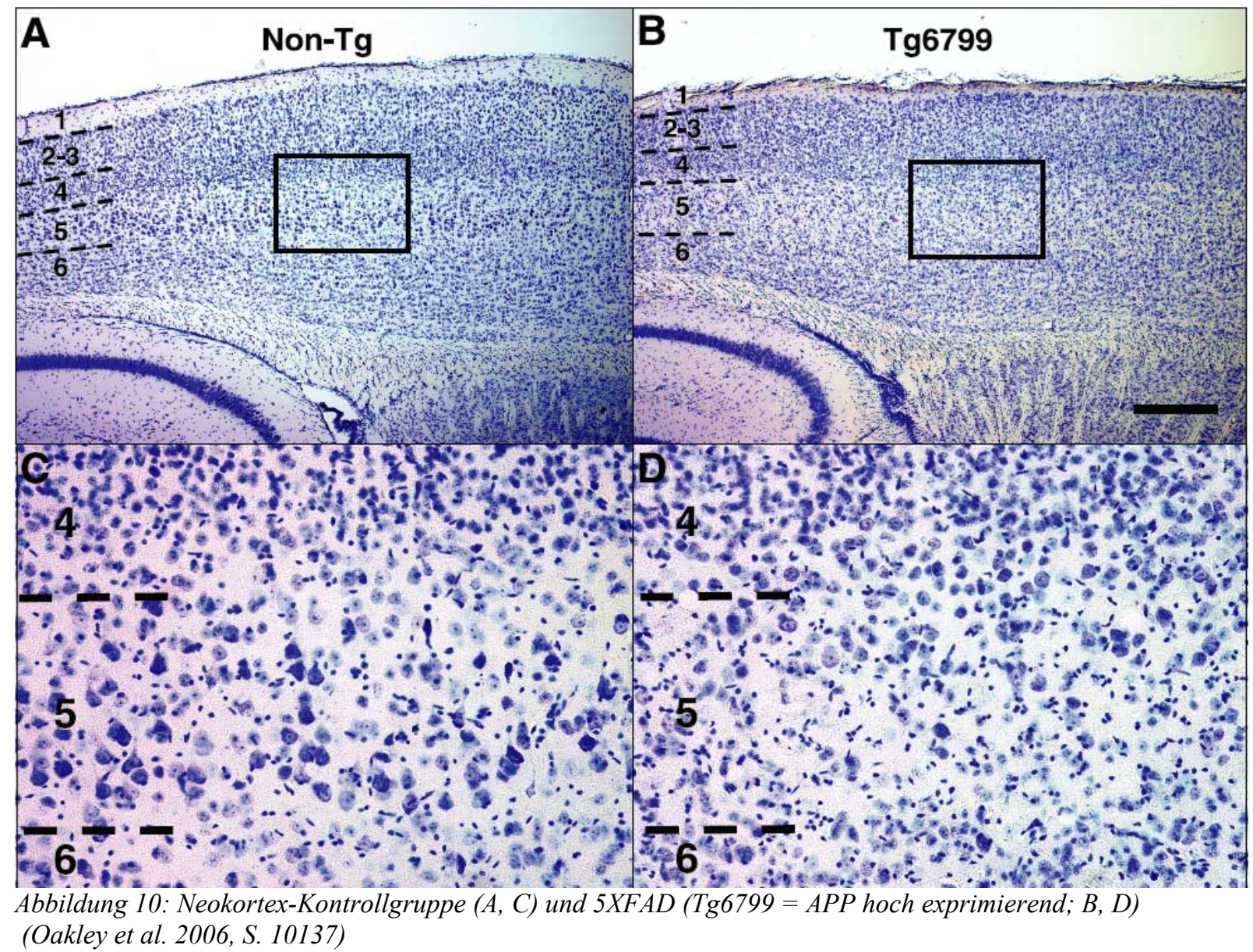




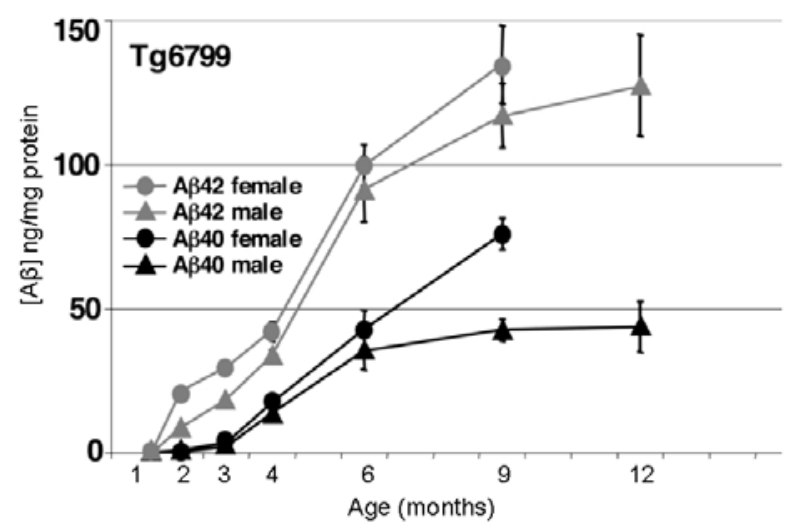

Abbildung 11: A -Level in 5XFAD-Mäusegehirnen (Tg6799 = APP hochexprimierend) (Oakley et al. 2006, S. 10132)
Weiterhin haben Oakley und Kollegen die bereits dargelegte Hypothese unterstützt, dass gerade die intraneuronale $\mathrm{A} \beta$-Aggregation $\mathrm{zu}$ Neurodegeneration führt. Sie haben auch gezeigt, dass die weiblichen Mausmodelle eine höhere Belastung mit $A \beta-40$ und $A \beta-42$ als die männlichen Mausmodelle haben (s. Abbildung 11). Ziel dieser Arbeit ist es, den von Oakley und Kollegen beschriebenen Neuronenverlust im Frontalkortex mittels stereologischer Ver-

fahren quantitativ zu verifizieren, einen Geschlechtseffekt bei der A $\beta$-Belastung zu überprüfen und der Hypothese nachzugehen, ob intraneuronale $A \beta$-Ablagerung bei dem Neuronenverlust eine Rolle spielen könnte. Zusätzlich soll in dieser Arbeit der Einfluss des genetischen Hintergrundes B6/SJL und B6 bei der AD überprüft werden. 


\section{Material und Methoden}

\subsection{Das Mausmodell 5XFAD}

Es wurde bereits dargelegt, dass es zur Analyse der AD verschiedene Mausmodelle gibt, in die unterschiedliche Mutationen und deren Kombinationen transgen eingebaut werden können. Das von Oakley et al. (2006) benutzte doppelt transgene Mausmodell hat fünf verschiedene Mutationen, wobei drei Mutationen im APP- und zwei Mutationen im PS1-Gen eingefügt sind. Um schneller und früher die Auswirkung von hohem Level an $A \beta-42$ überprüfen zu können, wurde gehofft, dass mehrere APP- und mehrere PS1-Mutationen einen additiven Effekt haben, der zu einer früheren Bildung von toxischem A $\beta-42$ führt. Das 5XFAD-Mausmodell überexprimiert APP in einer Länge von 695 Aminosäuren mit der schwedischen (K670N, M671L), der Florida- (I716V) und der London- (V717I) Mutation und zwei Mutationen im PS1-Gen: M146L und L286V (siehe Abbildung 12).

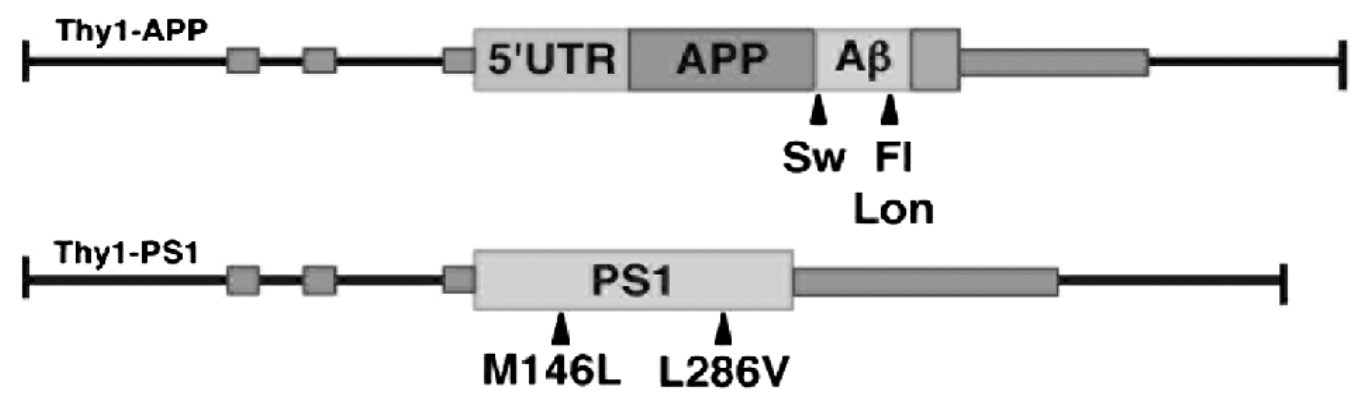

Abbildung 12: Schematische Darstellung der APP- und PS1-Transgene $(S w=$ swedish, Fl $=$ Florida, Lon $=$ London) (Oakley et al. 2006, S. 10131)

In dieser Arbeit wurde die Mauslinie Tg6799 zum Vergleich genommen, da sie die höchste Expression an APP hat (s. Abbildung 13). Die schwedische Mutation erhöht die Produktion des gesamten A $\beta$. Die Florida- und London-, sowie die beiden PS1-Mutationen (M146L und L286V)

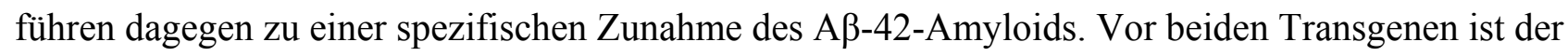
neuronenspezifische Mauspromotor Thyl gesetzt, um eine Überexpression zu forcieren (Moechars et al. 1996; Oakley et al. 2006; Selkoe 2001; Sisodia et al. 1999). 


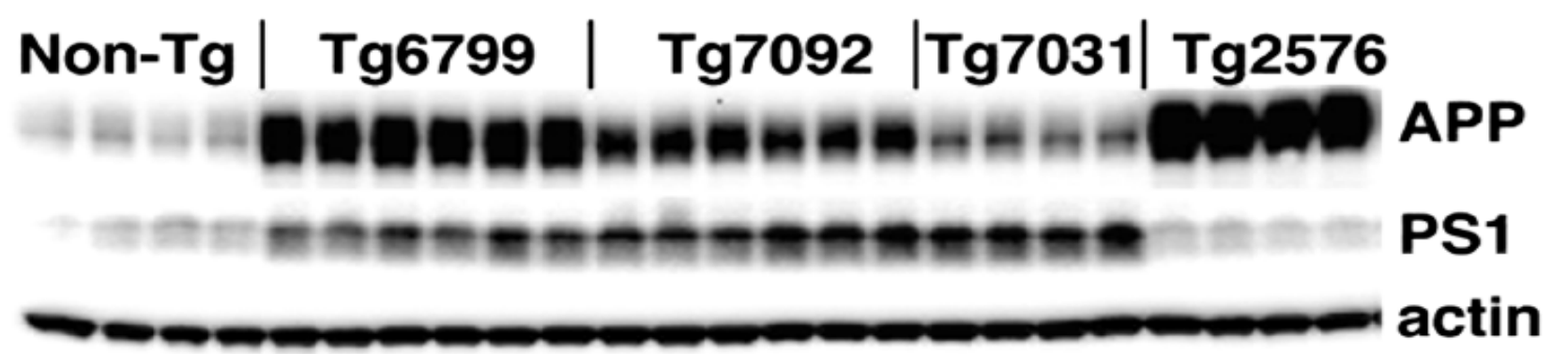

Abbildung 13: Immunoblot-Analyse der Expression von APP und PS1 der transgenen Mauslinien Tg6799, Tg7092, Tg7031 und zum Vergleich Tg2576, sowie einer nicht transgenen Vergleichsgruppe (Non-Tg). Actin-Bestimmung zur Funktionskontrolle (Oakley et al. 2006, S. 10131).

Eine der zwei transgenen 5XFAD-Mauslinien beruht in dieser Arbeit auf dem hemizygoten B6/SJLF1-Hybrid-Hintergrund (bestellt bei Jackson Laboratories, Bar Harbor, Maine, USA). Die andere basiert auf einer Rückkreuzung mit C57B16-(B6)-Wildtyp-Mäusen. Oakley und Kollegen haben bei dem transgenen Mausmodell auf dem Hintergrund B6/SJL eine massive Akkumulation von A $\beta-42$ beginnend schon im jungen Alter von anderthalb Monaten gefunden und eine deutlich höhere $A \beta$ 42- als A $\beta-40$-Produktion. Diesen Ergebnissen folgend, fanden sich bereits im Alter von zwei Monaten die ersten Amyloid-Plaques, also kurz nach dem ersten Nachweis von A $\beta$-42-Peptid. Auch intraneuronale $A \beta$-Ablagerungen manifestierten sich bevor sich Amyloid-Plaques gebildet haben. Damit wird die Hypothese unterstützt, dass intraneuronale A $\beta$-Ablagerungen zum Zelluntergang und Plaqueformation führen (,,inside-out process“). Im Alter von vier Monaten äußern die Mäuse im hippokampusabhängigen räumlichen Arbeitsgedächtnis im Vergleich zu einer gesunden Population Defizite (sogenanntes Y-Maze $=$ Y-Labyrinth). Ebenso haben die Mäuse im Morris Water-Maze (Morris Wasserlabyrinth) Defizite im Alter von vier bis fünf Monaten im Bereich Gedächtnis und Konditionierung demonstriert (Oakley et al. 2006).

\subsection{Mäusepopulationen}

Es standen insgesamt 13 Mäuse mit je sechs Monaten für die Bestimmung der A $\beta$-Belastung zur Verfügung und 23 Mäuse wurden parallel stereologisch untersucht. Es gab insgesamt fünf verschiedene Gruppen an Mäusepopulationen: drei Gruppen hatten die 5XFAD-Mutationen, wobei es eine männliche B6/SJL- und je eine weibliche und eine männliche B6-Population gab. Zwei weitere Gruppen waren Wildtypmäuse mit weiblichem und männlichem Geschlecht auf dem B6Hintergrund (siehe Tabelle 3). 


\begin{tabular}{|l|l|l|}
\hline Stereologie/Plaqueload(*) & Männlich & weiblich \\
\hline 5XFAD 6 Monate B6/SJL & $4\left(5^{*}\right)$ & - \\
\hline 5XFAD 6 Monate B6 & 4 & 4 \\
\hline Wildtyp 6 Monate B6 & $6^{* *}$ & $5^{* *}$ \\
\hline
\end{tabular}

Tabelle 3: Übersicht über die verwendeten Mäuse; *=hier eine Maus mehr untersucht für Plaqueload, ** da Wildtyp, hier keine Plaques

Anhand der Mäusepopulationen konnte man, wie bereits in Kapitel 1.6 beschrieben, jeweils Plaqueload und Stereologie getrennt, den Geschlechtseffekt untersuchen, die Auswirkungen der 5XFAD-Mutationen zur Wildtypkontrollgruppe zeigen und einen Einfluss des genetischen Hintergrundes analysieren. Alle untersuchten Tiere wurden gemäß der deutschen Richtlinien für Tierschutz behandelt. Der transgene Status der Mäuse wurde mittels PCR aus einer Ohrbiopsie ermittelt.

\subsection{Vorbereitung der Mäuse}

\subsubsection{Perfusion der Mäuse}

Die Mäuse wurden mittels eines Narkotikums betäubt und anschließend transkardial mit ca. 5-10 ml eiskaltem 0,01 M PBS (phosphate buffered saline) perfundiert. Danach wurde über selbige Kanüle 5-10 $\mathrm{ml} 4$ \%iges Paraformaldehyd gelöst in PBS eingespritzt, bis die Maus fixiert war. Der Kopf wurde mit einem Schnitt entlang der atlanto-axialen Verbindung abgetrennt und der Schädel in anteriorer Richtung eröffnet. Nach vorsichtiger Öffnung der Schädeldecke wurde das Gehirn behutsam entnommen und der Mittellinie zwischen den Hemisphären folgend, die Hirnhälften voneinander getrennt. Die jeweiligen linken Gehirnhälften wurden anschließend zwei Stunden bei 4 ${ }^{\circ} \mathrm{C}$ in Paraformaldehyd inkubiert und über Nacht bei $4{ }^{\circ} \mathrm{C}$ in eine $30 \%$ ige Saccharoselösung überführt. Am nächsten Tag wurden die linken Hemisphären bis zur Verwendung bei $-80{ }^{\circ} \mathrm{C}$ eingefroren. Die jeweiligen rechten Hemisphären wurden gleich nach Entnahme auf Trockeneis eingefroren und bei $-80{ }^{\circ} \mathrm{C}$ gelagert.

\subsubsection{Herstellung der histologischen Schnitte für die Stereologie}

Die jeweils bei $-80{ }^{\circ} \mathrm{C}$ tiefgefrorene linke Hemisphäre wurde mindestens 24 Stunden vor dem Schneiden in einen Kühlschrank mit $-20{ }^{\circ} \mathrm{C}$ übertragen. Am Arbeitstag wurde das Gehirn auf den Schneideblock im $-20{ }^{\circ} \mathrm{C}$ vorgekühlten Kryostat (Microtom-Kryostat MICROM HM550) gelegt, 
wobei vorher das Cerebellum koronar zur Hälfte entfernt wurde. Auf dem Schneideblock wurde das Gehirn stufenweise pyramidenförmig mit einem Gewebekleber fixiert (Tissue-Tek ${ }^{\circledR}$ O.C.T. ${ }^{\mathrm{TM}}$ Compound SAKURA Finetek Europe B.V.). Es wurden nun 10er Serien geschnitten, sodass am Ende in jedem Gefäß jeder zehnte Schnitt lag (Straight-Side Wide-Mouth Jar PC, Size 15ml, Nalge Nunc International). Die Schnittdicke betrug jeweils $30 \mu \mathrm{m}$ bei einem Schnittwinkel von $12^{\circ}$. Nach Beendigung wurden alle Gefäße bei $-80^{\circ} \mathrm{C}$ eingefroren.

\subsubsection{Cresylviolett-Färbung (Nissl-Färbung) für die Stereologie}

Pro Maus wurde immer das gleiche Gefäß ausgewählt, welches vorsichtig mittels der free-floatingMethode mit eiskaltem PBS gespült wurde, sodass alle Schnitte auf elektrostatischen Objektträgern (,SuperfrostPlus“, 25 x 75x 1,0 mm, Menzel GmbH \& Co KG, Braunschweig) vorsichtig sortiert werden konnten. Die Schnitte wurden mindestens zwei Stunden bei Raumtemperatur getrocknet und anschließend entsprechend der folgenden Färbeanleitung mit Cresylviolett gefärbt.

\section{Färbeanleitung:}

\section{1) Puffer:}

1A (Stocklösung): $1 \mathrm{M}$ Natriumacetat (136,08 g Na-Acetat-Trihydrat in 1 Liter Milli-Q)

1B (Arbeitslösung): $40 \mathrm{ml} 1 \mathrm{M}$ Natriumacetat (1A) + 9,6 ml konzentrierte Essigsäure, auffüllen auf 1 Liter mit Milli-Q

\section{2) Färbelösung (am Vortag herstellen):}

0,1 g Cresylviolett in 1 Liter der Lösung 1B lösen

30 min rühren,

über Nacht stehen lassen, kurz vor Gebrauch filtern.

\section{3) Entfettungslösung:}

3A (Stocklösung): 2 \%ige Triton X-100 (980 ml Milli-Q + 20 ml Triton X-100), ungefähr 1 Stunde rühren (lange haltbar).

3B (Arbeitslösung): 2,5 ml 3A + $50 \mathrm{ml}$ Milli-Q + $150 \mathrm{ml} \mathrm{100 \%} \mathrm{Ethanol}$

\section{Färbeprotokoll:}

1.) $2 \times 10$ min in $1 \mathrm{~B}$ (2 verschiedene Küvetten)

2.) $20 \mathrm{~min}$ in $3 \mathrm{~B}$

3.) $2 \times 10$ min in $1 \mathrm{~B}$ (2 verschieden Küvetten) 
4.) $2 \times 8$ min in 2 (2 verschiedene Küvetten)

5.) $3 \times 1 \mathrm{~min}$ in $1 \mathrm{~B}$ (3 verschiedene Küvetten)

6.) $3 \mathrm{~min}$ in $100 \%$ Ethanol

7.) $1 \times 10 \mathrm{~min}$ in Isopropanol (=2-Propanol)

8.) $2 \times 5$ min in Xylol

9.) mit Corbit-Balsam einschließen und über Nacht trocknen lassen

\subsection{Stereologische Untersuchung}

Grundlage der stereologischen Untersuchung waren die wie in Kapitel 2.3.2 und 2.3.3 beschriebenen $30 \mu \mathrm{m}$ dicken histologischen Schnitte, die mit Cresylviolett angefärbt wurden. Alle Schnitte entstammen einer definierten Region des Frontalkortex. Die Region des Frontalkortex wurde anhand des Mäusebildatlas von Paxinos und Franklin bestimmt und von Bregma $3.08 \mathrm{~mm}$ bis Bregma 0.26 mm festgelegt (s. Abbildung 14) (Paxinos und Franklin 2001).

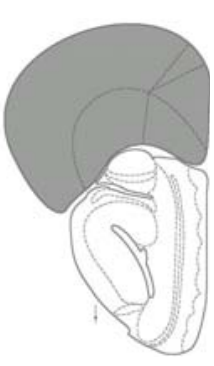

Bregma 3.08

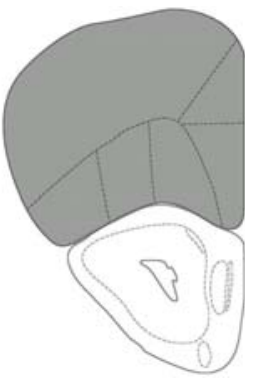

Bregma 2.58

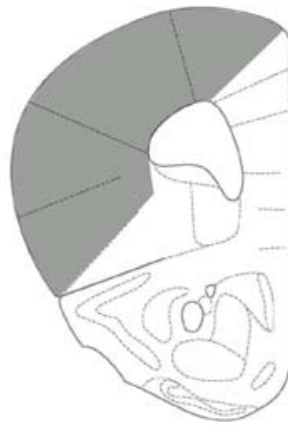

Bregma 1.98

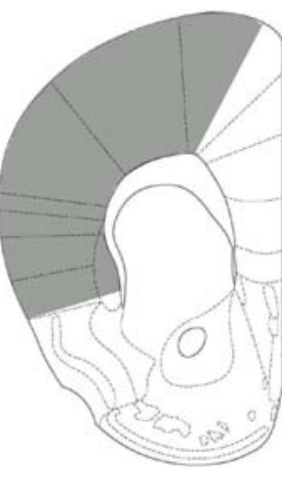

Bregma 1.54

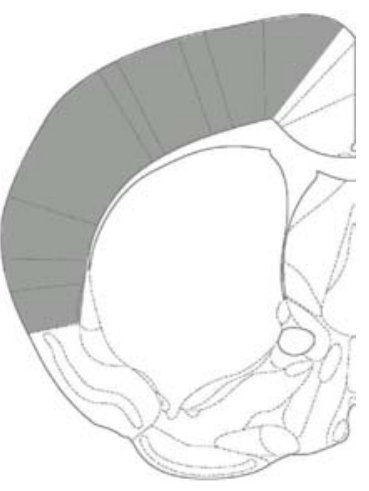

Bregma 0.38

Abbildung 14: Darstellung des Frontalkortex der linken Hemisphären, grau unterlegt ist der untersuchte Bereich, Zwischenstufen sind nicht dargestellt. Verändert nach dem Mäusebildatlas von Paxinos und Franklin (Paxinos und Franklin 2001)

Für die stereologische Untersuchung wurde das Mikroskop BX51 von Olympus und das Programm Stereoinvestigator 7 (Micro Brightfield) benutzt. Es wurden mittels der design-basierten Stereologie (,design based stereology“) die Gesamtneuronenzahl und das Volumen jeder Maus ermittelt.

Um die Region des Frontalkortex zu markieren, die untersucht werden sollte, wurde eine vierfache Vergrößerung gewählt. Zur Auszählung der Neuronen wurde eine 100fache Vergrößerung benutzt. Die Distanz zwischen den einzelnen Stichproben betrug $300 \mu \mathrm{m}$, da wie bereits in Kapitel 2.3.2 dargestellt, nur jeder zehnte Schnitt bei einer Dicke von $30 \mu \mathrm{m}$ genommen wurde.

Zum Zählen der Neurone wurden vorher Zählregeln festgelegt, wie sie im nächsten Kapitel beschrieben sind. 
Die eingestellten Parameter im Stereoinvestigator waren folgende:

- $\quad$ Counting Frame: 27,00 $\mu \mathrm{m}(\mathrm{X})$ x 27,00 $\mu \mathrm{m}(\mathrm{Y})$

- $\quad$ Counting Frame Area (XY): $729 \mu \mathrm{m}^{2}$

- $\quad$ Disector Height (Z): $6 \mu \mathrm{m}$

- $\quad$ Disector Volume (XYZ) $\left(\mu \mathrm{m}^{3}\right): 4374 \mu \mathrm{m}^{3}$

- $\quad$ Sampling Grid (X): $500 \mu \mathrm{m}$

- $\quad$ Sampling Grid (Y): $350 \mu \mathrm{m}$

- $\quad$ Sampling Grid Area (XY) $\left(\mu \mathrm{m}^{2}\right): 175000 \mu \mathrm{m}^{2}$

- Distance from section top to 3D counting frame: $2,00 \mu \mathrm{m}$

- $\quad$ Section thickness: $30,00 \mu \mathrm{m}$

- Grid Rotation: 0,00 Degrees

- $\quad$ Section Periodicity 10

- $\quad$ Focus method: manual focus

- Refocus to top of section at each grid site

- Measure section thickness at every 10th grid site

- $\quad$ Desired sampling sites: 1

\subsubsection{Design-basierte Stereologie}

Die design-basierte Stereologie (design-based stereology) ist eine Methode, um bestimmte Fragestellungen, die das ZNS betreffen zu quantifizieren. Sie ist geeignet, um die Volumina, Zellzahl, Längen von beispielsweise Gefäßen, durchschnittliche Dicke von Zellen und Zellarchitekturen zu bestimmen. Die Ergebnisse der design-basierten Stereologie sind repräsentativ für die gesamte Hirnregion, die im Mittelpunkt des Interesses steht. Sie sind unabhängig von der Lage oder Verteilung im Raum und der Form der Objekte. Systematische Fehler können auf ein Minimum reduziert werden. Schmitz und Hof haben 2005 in einem Übersichtsartikel ausführlich das Prinzip der stereologischen Untersuchung zusammengefasst.

Das Prinzip der stereologischen Untersuchung ist das sogenannte „Systematic Random Sampling“. Diese Stichprobenerhebung besteht aus Schnitten, die einen definierten Abstand zueinander haben und systematisch erhoben werden. Bei dieser Arbeit wurden Schnitte benutzt, die einen Abstand von $300 \mu \mathrm{m}$ zueinander haben. Auf den Schnitten wählt das Programm mit den oben genannten Einstellungen Bereiche aus (counting frames), die ausgezählt werden. Diese Bereiche haben den gleichen Abstand zueinander und verteilen sich gleichmäßig auf den Schnitt. Mit den gewonnenen 
Daten wird die Gesamtneuronenzahl und das Volumen des untersuchten Gehirns errechnet.

Die Zählrahmen (counting frames) werden mittels eines Rasters auf den vom Benutzer vorher festgelegten Bereich des Gehirnschnittes projiziert. Der Zählrahmen hat eine X-, Y- und ZKoordinate. Der nun entstandene Würfel hat sechs Seiten. Um die Neuronen auszuzählen und unter Berücksichtigung der Tatsache, dass die Würfel nicht direkt nebeneinander liegen und dass Zellfragmente beim Schneiden hängenbleiben, werden vorher strenge Zählregeln festgelegt (,counting rules"). Sie definieren genau, wann eine Zelle mitgezählt werden darf. Damit wird vermieden, dass Zellen doppelt gezählt werden. Wenn Zellen direkt auf der Linie liegen und auf allen Seiten mitgezählt werden würden, käme es zu einer verzerrten Extrapolation der Neuronenzahl für das gesamte Gehirn. Im Nachfolgenden sind die Zählregeln aufgeführt:

- $\quad$ Es werden nur Nucleoli von Neuronen gezählt, die sich innerhalb des Zählrahmens oder an der unteren Grenze des Zählrahmens scharf stellen lassen bzw. diese berühren. Nucleoli, die sich oberhalb der oberen Grenze scharfstellen oder diese berühren, werden nicht mitgezählt.

- Berührt ein Nucleolus im Zählrahmen ausschließende Grenzen (excluding lines), dann darf er nicht mitgezählt werden. Das Berühren einer Einschlussgrenze (including lines) führt zum Mitzählen.

Wurden alle Neurone ausgewählt, wechselt man zum nächsten Zählrahmen, bis alle Zählrahmen eines Schnittes fertig sind und schließlich alle Schnitte einer Maus ausgezählt wurden. Mittels der nachfolgend beschriebenen Formeln, kann man dann die Gesamtneuronenzahl und die Volumina errechnen.

\subsubsection{Berechnung der Neuronenzahl des Frontalkortex}

Die Neuronenzahl errechnet sich gemäß der „optical fractionator methode“ (West et al. 1991):

$N=$ "total markers counted" $x$ asf $x$ ssf $x$ tsf

asf $=$,sampling grid area $(\mathrm{XY})^{“} /$, ,counting frame area $(\mathrm{XY})^{“}$

$\rightarrow 175000 \mu \mathrm{m}^{2} / 729 \mu \mathrm{m}^{2}$

$\mathbf{s s f}=10$ (jeder zehnte Schnitt) 
tsf $=$,number weighted mean section thickness“ / ,disector height $(Z)$ “

$\rightarrow$ jeweilige aktuelle Schnittdicke in $\mu \mathrm{m} / 6 \mu \mathrm{m}$

„total markers counted“: ermittelte Neuronenzahl in den Zählrahmen

$\mathbf{N}=$ Gesamtneuronenzahl des Frontalkortex einer Hemisphäre

\subsubsection{Berechnung des Volumens des Frontalkortex}

Das Volumen des Frontalkortex der jeweiligen Hemisphäre wurde mittels der Formel „Cavalieri`s Estimator of Morphometric Volume“" berechnet (Rosen und Harry 1990):

$V c=d\left[\sum_{i=1}^{n}\left(y_{i}\right)\right]-(t) y_{\max }$

$d=$ Abstand zwischen den analysierten Schnitten $=300 \mu \mathrm{m}$

$y_{i}=$ Fläche von Schnitt i $\left[\mu \mathrm{m}^{2}\right]$

$t=$ jeweilige Schnittdicke $[\mu \mathrm{m}]$

$y_{\max }=$ größte gemessene Fläche $\left[\mu \mathrm{m}^{2}\right]$

\subsection{Herstellung von histologischen Schnitten für den Plaqueload (quantitative A $\beta$ -} Bestimmung) und die Immunhistochemische Färbung

Die Herstellung der Schnitte für den Plaqueload erfolgte an den jeweiligen in Paraffin eingebetteten rechten Hemisphären, die wie in Kapitel 2.3.1 beschrieben gleich nach Entnahme auf Trockeneis eingefroren und bei $-80^{\circ} \mathrm{C}$ gelagert wurden. Die Schnitte wurden am Microm HM 335 E mit einem Schnittwinkel von $6^{\circ}$ und einer Dicke von $4 \mu \mathrm{m}$ hergestellt und anschließend auf Objektträger gezogen („SuperfrostPlus“, 25 x 75x 1,0 mm, Menzel GmbH \& Co KG, Braunschweig).

Nach Inkubation bei $37{ }^{\circ} \mathrm{C}$ über Nacht wurden die Schnitte der 5XFAD-Mäuse mit folgenden Antikörpern nach dem Färbeprotokoll im Anhang (s. Tabelle 16 im Anhang 8.5) behandelt: 4G8 (Covance) in einer Konzentration von 1:10.000, der reaktiv gegen die Aminosäuren 17-24 des $\beta$ Amyloids ist, $A \beta[N]$ (IBL, Hamburg, Germany) in einer Konzentration von 1:500, 23850 gegen humanes APP (Gerd Multhaup) in einer Konzentration von 1:500 und mab2-48 (Synaptic Systems, Göttingen, Germany) in einer Konzentration von 1:500 gegen N-terminal trunkiertes A $\beta$, das mit Pyroglutamat an dritter Stelle der Aminosäuresequenz startet. Zum Sichtbarmachen diente das 3,3- 
Diaminobenzidin (DAB), das eine bräunliche Färbung verursachte. Es wurde mit Hämatoxylin gegengefärbt, um einen Kontrast zu schaffen.

\subsubsection{Bestimmung des Plaqueloads und der intraneuronalen A $\beta$-Aggregation}

Die Bestimmung des Plaqueloads erfolgte anhand von Fotos des Frontalkortex in zehnfacher Vergrößerung, die mittels eines Olympus BX-51 Mikroskops mit einer Olympus DP-50 Kamera angefertigt wurden. Die Bilder wurden mit der Software ImageJ (Version 1.40g, NIH, USA) in 8-bit schwarzweiß umgewandelt und durch die Anwendung eines Schwarzweiß-Schwellenwertes, der möglichst wenig Hintergrundrauschen und hauptsächlich Plaques zeigte, ausgewertet. Es wurden der prozentuale Anteil der Anfärbung durch die Antikörper ausgewertet und verglichen. Im Nachfolgenden noch eine Übersicht über die verwendeten Mäuse und Antikörper.

\begin{tabular}{|c|c|c|c|c|}
\hline Mausmodell Antikörper & $\begin{array}{l}\text { APP } \\
\text { (Konzentration) }\end{array}$ & $\begin{array}{l}\mathrm{A} \beta[\mathrm{N}] \\
\text { (Konzentration) }\end{array}$ & $\begin{array}{l}4 \mathrm{G} 8 \\
\text { (Konzentration) }\end{array}$ & $\begin{array}{l}\text { mab2-48 } \\
\text { (Konzentration) }\end{array}$ \\
\hline $\begin{array}{l}\text { 5XFAD } 6 \text { Monate } \\
\text { B6/SJL männlich }\end{array}$ & $1: 500$ & $1: 500$ & $1: 10.000$ & $1: 500$ \\
\hline $\begin{array}{l}\text { 5XFAD } 6 \text { Monate B6 } \\
\text { männlich }\end{array}$ & $1: 500$ & $1: 500$ & $1: 10.000$ & $1: 500$ \\
\hline $\begin{array}{l}\text { 5XFAD } 6 \text { Monate B6 } \\
\text { weiblich }\end{array}$ & $1: 500$ & $1: 500$ & $1: 10.000$ & $1: 500$ \\
\hline
\end{tabular}

Tabelle 4: Übersicht über verwendete Mäuse und Antikörper für den Plaqueload

\subsection{Statistik}

Die statistische Auswertung erfolgte mit dem Programm GraphPad Prism Version 4.03 für Windows (GraphPad Software, San Diego, CA, USA).

Die stereologischen Untersuchungen und der Plaqueload wurden mittels der einfaktoriellen Varianzanalyse (ANOVA) und einem t-Test durchgeführt. Alle Daten werden als Mittelwert \pm Standardabweichung $\sigma$ präsentiert. Die Signifikanzniveaus der t-tests werden folgend definiert: ** $=$ $\mathrm{p}<0,01 ; *=\mathrm{p}<0,05$. 


\section{Ergebnisse}

\subsection{Stereologische Untersuchung}

Wie bereits dargestellt, wurden design-basierte stereologische Untersuchungen mit dem Ziel der Quantifizierung von Volumen und Neuronenzahl an vier männlichen sechs Monate alten 5XFADMäusen mit dem genetischen Hintergrund B6/SJL, an je vier männlichen und weiblichen sechs Monate alten 5XFAD-B6-Mäusen und an sechs männlichen und fünf weiblichen sechs Monate alten B6-Wildtypmäusen durchgeführt.

Zusätzlich wurden Übersichtsaufnahmen von den 5XFAD-B6 und den B6-Wildtypen angefertigt, die einen qualitativen Eindruck abbilden sollen, wie es schon zum Vergleich von Oakley und Kollegen durchgeführt wurde (s. Kapitel 1.6). In vierfacher Vergrößerung wurde der vollständige Frontalkortexquerschnitt inklusive einer darübergelegten Markierung der sechs Schichten der grauen Substanz (s. Abbildung 15; a, b, c, d), soweit dies sicher beurteilbar war, dargestellt.

\section{XFAD B6 männlich 5XFAD B6 weiblich Wildtyp B6 männlich Wildtyp B6 weiblich}

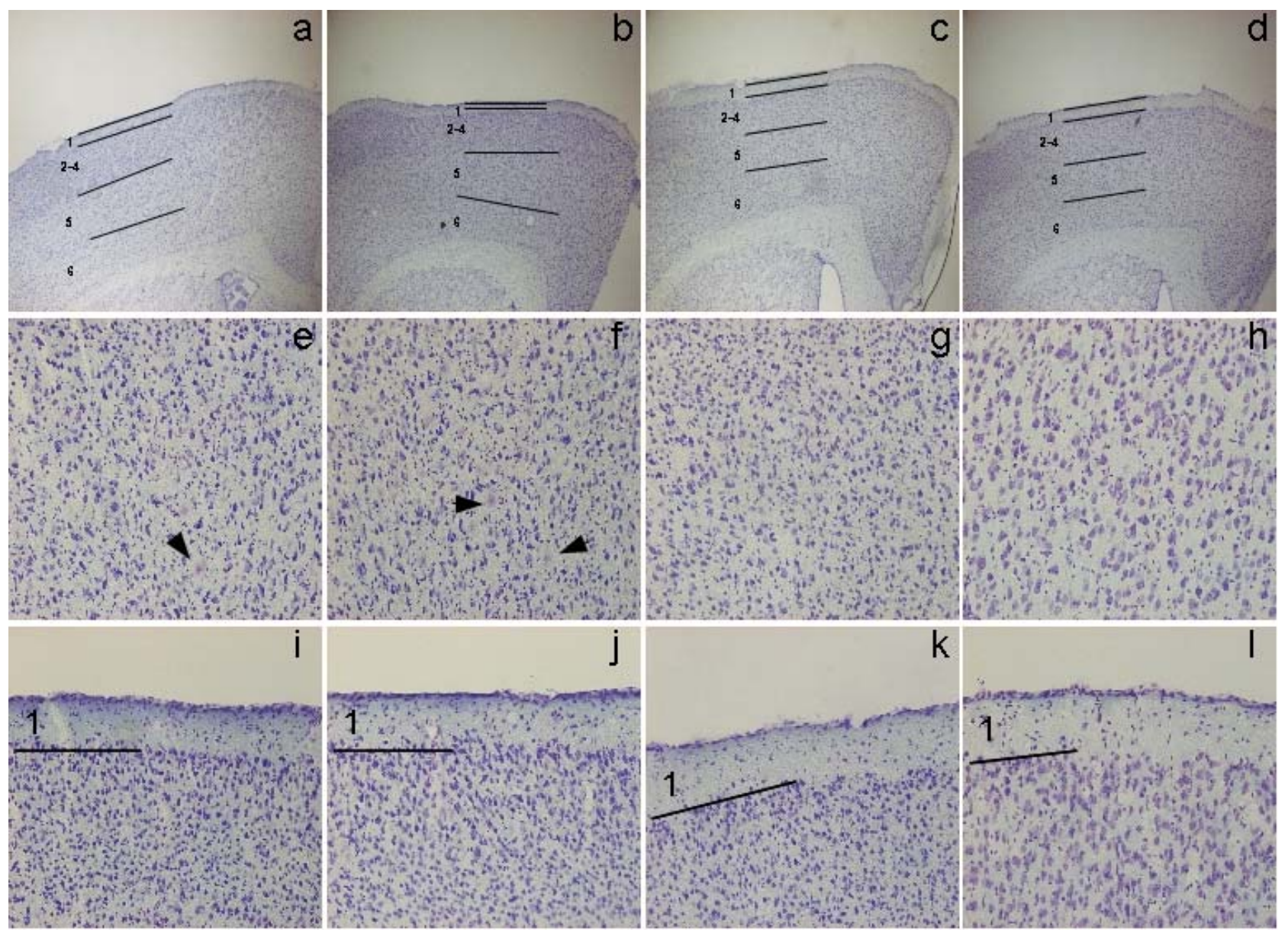

Abbildung 15: Mikroskopische Aufnahmen des Frontalkortex bei 5XFAD- und Wildtypmäusen, die Pfeile markieren neuronenarme Bereiche 
Exemplarische Aufnahmen in 20facher Vergrößerung sind von der fünften (e, f, g, h) bzw. der ersten Schicht (i-1) dargestellt. Auffällig ist, dass es Bereiche bei den 5XFAD-Mäusen gibt, in denen keine Neurone, sondern vermutlich nur Plaques zu finden sind (Pfeil $\rightarrow$; e, f), erkennbar an der leichten Verschattung bzw. Trübung. Dieses Phänomen fehlt völlig bei den vergleichenden Wildtyp-Aufnahmen (g, h). Bei Letzteren sind die Neurone einheitlicher in Morphe und Ausdehnung. Sie sind durchschnittlich größer, was besonders bei dem weiblichen Wildtyp auffällt. Die Kortexschicht eins scheint keine auffälligen Veränderungen in Dicke und Form zwischen den transgenen und nichttransgenen Mäusen zu haben (i, j, k, l).

\subsubsection{Gesamtneuronenzahl}

Für das Mausmodell 5XFAD, sechs Monate, B6/SJL, männlich ergaben sich für die Gesamtneuronenzahl im Frontalkortex folgende Werte (s. Tabelle 5):

\begin{tabular}{|l|l|}
\hline & 5XFAD, B6/SJL, männlich $(\mathrm{n}=4)$ \\
\hline Neuronenzahl & 1.814 .096 \\
& 1.184 .671 \\
& 1.458 .573 \\
& 1.539 .352 \\
\hline Mittelwert & $\mathbf{1 . 4 9 9 . 1 7 3}$ \\
\hline
\end{tabular}

Tabelle 5: Gesamtneuronenzahl des Frontalkortex der vier Mäuse 5XFAD, 6 Monate, B6/SJL, männlich

Bezüglich der Gesamtneuronenzahl für die Mausmodelle 5XFAD, sechs Monate, B6, je vier männlich und weiblich sind folgende Werte ermittelt worden (s. Tabelle 6):

\begin{tabular}{|l|l|l|}
\hline & 5XFAD, B6, männlich, $(\mathrm{n}=4)$ & 5XFAD, B6, weiblich, $(\mathrm{n}=4)$ \\
\hline Neuronenzahl & 1.516 .347 & 1.462 .294 \\
& 1.952 .446 & 1.441 .049 \\
& 1.737 .757 & 1.661 .020 \\
& 1.948 .565 & 1.256 .287 \\
\hline Mittelwert & $\mathbf{1 . 7 8 8 . 7 7 9}$ & $\mathbf{1 . 4 5 5 . 1 6 3}$ \\
\hline
\end{tabular}

Tabelle 6: Gesamtneuronenzahl des Frontalkortex der vier weiblichen und männlichen 5XFAD-Mäuse, 6 Monate, B6

Die durchschnittliche Gesamtneuronenzahl der 5XFAD-B6/SJL-Mäuse im Frontalkortex beträgt 1.499.173 (Standardabweichung $\sigma= \pm 259.069$ ). Im Vergleich zum männlichen Mausmodell 5XFAD-B6 mit einer durchschnittlichen Gesamtneuronenzahl von 1.788.779 ( $\sigma= \pm 207.478)$ zeigt 
sich eine deutliche, aber nicht signifikant geringere Neuronenzahl. Zwischen dem männlichen 5XFAD-B6-Mäusen und den äquivalenten weiblichen Mäusen mit einer durchschnittlichen Gesamtneuronenzahl von 1.455.163 ( $\sigma= \pm 165.508)$ zeigt sich eine signifikante Differenz.

Für die Kontrollgruppe der sechs männlichen und fünf weiblichen B6-Mäuse ergaben sich für die Gesamtneuronenzahl folgende Werte (s. Tabelle 7):

\begin{tabular}{|l|l|l|}
\hline & Wildtyp, B6, männlich, $(\mathrm{n}=6)$ & Wildtyp, B6, weiblich, $(\mathrm{n}=5)$ \\
\hline Neuronenzahl & 1.705 .390 & 1.414 .403 \\
& 1.508 .145 & 1.249 .566 \\
& 2.081 .676 & 1.098 .171 \\
& 1.802 .292 & 1.649 .577 \\
& 1.263 .889 & 1.761 .283 \\
\hline Mittelwert & 1.908 .516 & - \\
\hline
\end{tabular}

Tabelle 7: Gesamtneuronenzahl des Frontalkortex der fünf weiblichen und sechs männlichen Wildtyp-B6-Mäuse, 6 Monate

Die durchschnittliche Gesamtneuronenzahl der männlichen B6-Wildtypen beträgt 1.711.651 ( $\sigma= \pm$ 291.834). Dies demonstriert ein nicht signifikant höheres Ergebnis von 16 \% im Vergleich zum weiblichen Äquivalent mit einer durchschnittlichen Gesamtneuronenzahl von 1.434.600 ( $\sigma= \pm$ 274.211).

\subsubsection{Gesamtvolumina}

Für die Gesamtvolumina ergaben sich für das Mausmodell 5XFAD, sechs Monate, B6/SJL, männlich folgende Werte (s. Tabelle 8):

\begin{tabular}{|l|l|}
\hline & 5XFAD, B6/SJL, männlich $(\mathrm{n}=4)$ \\
\hline Volumen in $\mu \mathrm{m}^{3}$ & 11.681 .352 .963 \\
& 8.324 .538 .163 \\
& 8.961 .049 .579 \\
& 8.773 .765 .930 \\
\hline Mittelwert in $\boldsymbol{\mu m}^{\mathbf{3}}$ & $\mathbf{9 . 4 3 5 . 1 7 6 . 6 5 9}$ \\
\hline
\end{tabular}

Tabelle 8: Gesamtvolumen des Frontalkortex der vier Mäuse 5XFAD, 6 Monate, B6/SJL, männlich 
Bezüglich des Gesamtvolumens für die Mausmodelle 5XFAD, sechs Monate, B6, je vier männlich und weiblich sind folgende Werte ermittelt worden (s. Tabelle 9):

\begin{tabular}{|l|l|l|}
\hline & 5XFAD, B6, männlich, $(\mathrm{n}=4)$ & 5XFAD, B6, weiblich, $(\mathrm{n}=4)$ \\
\hline Volumen in $\mu \mathrm{m}^{3}$ & 9.745 .398 .045 & 10.617 .991 .763 \\
& 11.325 .261 .805 & 10.549 .129 .783 \\
& 9.696 .104 .244 & 9.457 .685 .791 \\
& 10.298 .427 .060 & 9.074 .459 .130 \\
\hline Mittelwert in $\boldsymbol{\mu m}^{\mathbf{3}}$ & $\mathbf{1 0 . 2 6 6 . 2 9 7 . 7 8 8}$ & $\mathbf{9 . 9 2 4 . 8 1 6 . 6 1 7}$ \\
\hline
\end{tabular}

Tabelle 9: Gesamtvolumen des Frontalkortex der vier weiblichen und männlichen 5XFAD-Mäuse, 6 Monate, B6

Das durchschnittliche Gesamtvolumen der 5XFAD-B6/SJL-Mäuse im Frontalkortex beträgt 9.435.176.659 $\mu^{3}{ }^{3}\left(\sigma= \pm 1.532 .000 .000 \mu \mathrm{m}^{3}\right)$. Das männliche 5XFAD-B6-Mausmodell mit einem durchschnittlichen Gesamtvolumen von 10.266.297.788 $\mu \mathrm{m}^{3}\left(\sigma= \pm 743.200 .000 \mu \mathrm{m}^{3}\right)$ bringt keine größeren Unterschiede hervor und zeigt auch zum weiblichen Äquivalent mit einem durchschnittlichen Gesamtvolumen von 9.924.816.617 $\mu \mathrm{m}^{3} \quad\left(\sigma= \pm 759.900 .000 \mu \mathrm{m}^{3}\right)$ kaum Differenz.

Für die Kontrollgruppe der sechs männlichen und fünf weiblichen B6-Mäuse ergaben sich für das Gesamtvolumen folgende Werte (s. Tabelle 10):

\begin{tabular}{|l|l|l|}
\hline & Wildtyp, B6, männlich, $(\mathrm{n}=6)$ & Wildtyp, B6, weiblich, $(\mathrm{n}=5)$ \\
\hline Volumen in $\mu \mathrm{m}^{3}$ & 8.781 .280 .264 & 15.171 .215 .787 \\
& 9.538 .946 .456 & 14.387 .705 .204 \\
& 10.794 .419 .202 & 11.684 .209 .533 \\
& 10.177 .953 .995 & 18.500 .158 .537 \\
& 6.986 .979 .168 & 20.729 .758 .760 \\
\hline Mittelwert in $\boldsymbol{\mu m}^{\mathbf{3}}$ & 10.144 .059 .171 & - \\
\hline
\end{tabular}

Tabelle 10: Gesamtvolumen des Frontalkortex der fünf weiblichen und sechs männlichen Wildtyp-B6-Mäuse, 6 Monate

Die männliche Wildtyp-B6-Maus mit einem durchschnittlichen Gesamtvolumen von 9.403.939.709 $\mu \mathrm{m}^{3}\left(\sigma= \pm 1.364 .000 .000 \mu \mathrm{m}^{3)}\right.$ liegt ungefähr im Bereich der transgenen B6- und B6/SJL-Mäuse. Dahingegen beträgt das durchschnittliche Gesamtvolumen der weiblichen B6-Wildtyp-Maus 16.094.609.564 $\mu^{3}\left(\sigma= \pm 3.535 .000 .000,00 \mu \mathrm{m}^{3}\right)$ und erbringt ein signifikant höheres Kortexvolumen als das männliche B6-Wildtyp-Modell und die weiblichen 5XFAD-B6-Mäuse. 


\subsubsection{Vergleich der stereologischen Daten der Mausmodelle}

Im Nachfolgenden sind die Ergebnisse aus dem Kapitel 3.2.1 und 3.2.2 graphisch vergleichend dargestellt. Die B6/SJL-Mäuse haben durchschnittlich $16 \%$ weniger Neurone und $8 \%$ weniger
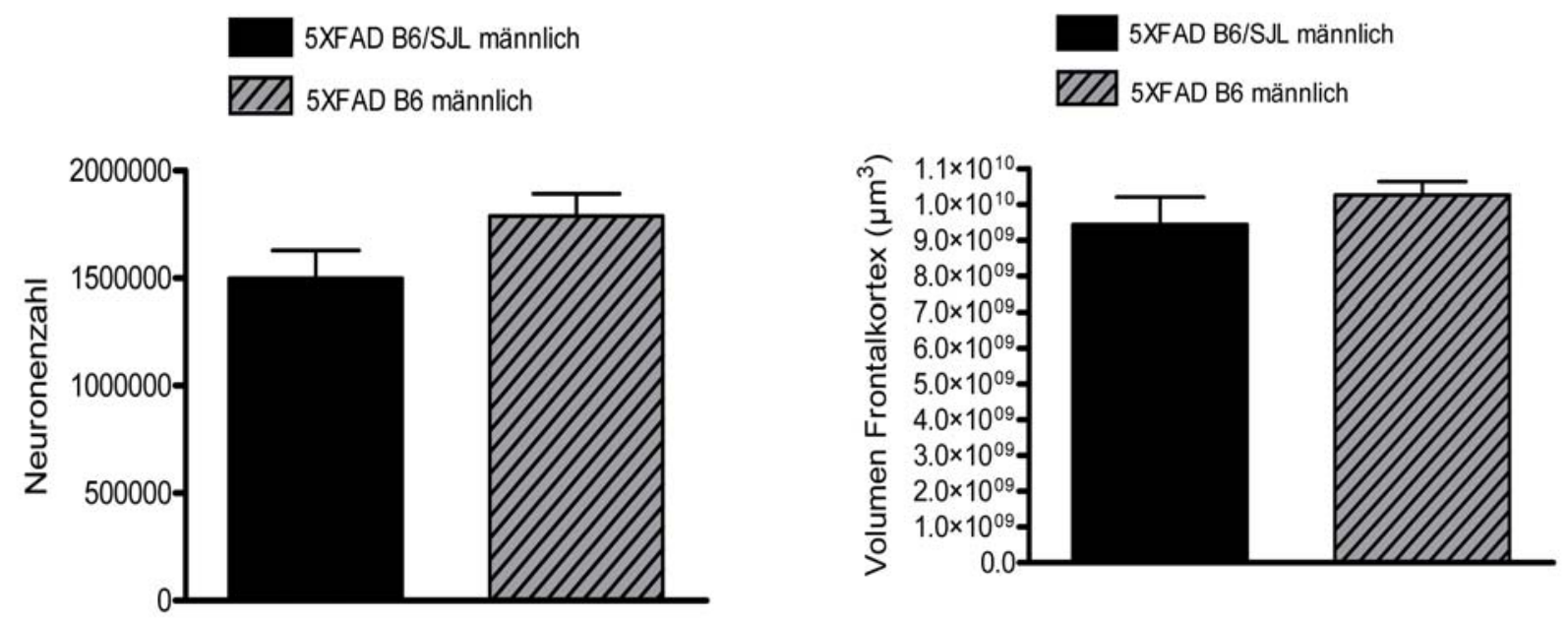

Abbildung 16: Vergleich der Gesamtneuronenzahl und des Volumens des Frontalkortex zwischen den Mausmodellen 5XFAD-B6/SJL, sechs Monate, männlich und 5XFAD-B6, sechs Monate, männlich

Volumen als die männlichen 5XFAD-B6-Mäuse. Zwischen den beiden 5XFAD-B6Mäusepopulationen offenbart sich eine deutlich niedrigere Neuronenzahl von $19 \%$ bei den Weibchen und zeigt bei einem durchgeführten t-Test ein $\mathrm{p}$ von $<0,05$. Das Volumen ist bei den Weibchen um $3 \%$ niedriger. Zwischen den Wildtypen zeigt das Männchen nur $58 \%$ des Kortexvolumens der Weibchen, hat aber $16 \%$ mehr Neurone. Die Varianzanalyse (ANOVA) für die Neuronenzahl erzielt ein $\mathrm{p}<0,001$ und der nachfolgende t-Test hat eine Signifikanz von $\mathrm{p}<$ 0,01 .

Die B6-Weibchen haben $1 \%$ mehr Neurone, aber $42 \%$ weniger Volumen als die weiblichen Wildtypen. Letzteres hat eine Signifikanz in der Varianzanalyse (ANOVA) von $p<0,001$ und einem t-Testergebnis von $\mathrm{p}<0,01$. Die B6-Männchen haben $4 \% \mathrm{mehr}$ Neurone und $8 \% \mathrm{mehr}$ Volumen als ihre Wildtypäquivalente (s. Abbildung 17). 

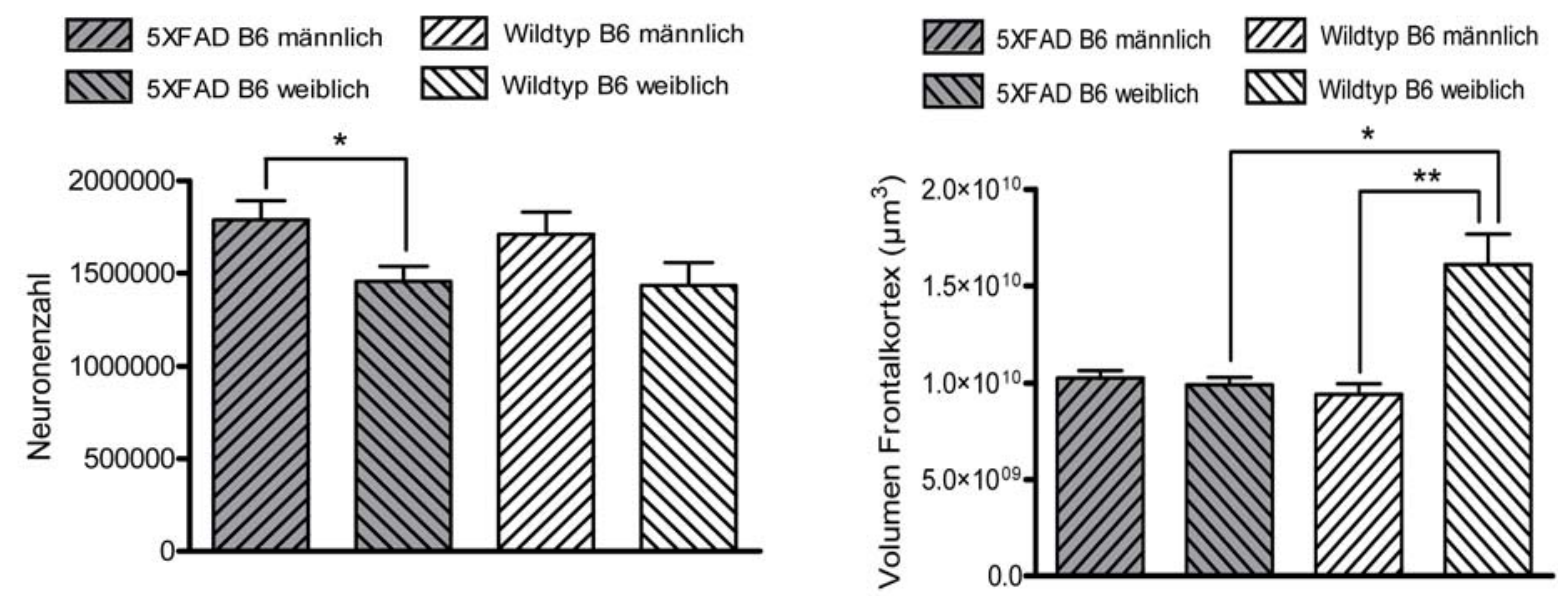

Abbildung 17: Vergleich der Gesamtneuronenzahl und des Volumens des Frontalkortex zwischen dem Mausmodell 5XFAD-B6, sechs Monate, männlich und weiblich und den Mausmodellen Wildtyp-B6, sechs Monate, männlich und weiblich

\subsection{Untersuchung der A $\beta$-Belastung}

Die Untersuchung erfolgte quantitativ und qualitativ wie in Kapitel 2.5.1 beschrieben. Der Antikörper APP diente dabei nur der qualitativen Untersuchung.

\subsubsection{Ergebnisse der qualitativen A $\beta$-Belastung}

Die Färbung gegen APP (a, b, c; s. Abbildung 18) zeigt die Verteilung des A $\beta$-Vorläuferproteins ausschließlich in der Zellmembran und nicht im Soma der Neuronen und in der Peripherie der Plaques. Im Kern dieser Plaques befindet sich das $A \beta$-Peptid (d, e, f; $A \beta[N]$-Antikörper), welches in Richtung Peripherie an Dichte deutlich abnimmt. Diese Verteilung der Proteine findet sich im Einklang mit der Beobachtung, dass sich innerhalb der Plaques Reste von Zellkernen finden lassen. Diese stammen wahrscheinlich aus lysierten Neuronen, die massiv mit intrazellulärem A $\beta-42$ beladen waren (D'Andrea et al. 2001). Peripher werden dystrophe aufgetriebene Neuriten durch den APP-Antikörper angezeigt (s. Kapitel 1.5.2.1).

Die intrazelluläre $A \beta$-Konzentration ist im gesamten Soma verteilt, konzentriert sich aber im Bereich des Axonhügels (g, h, i; 4G8-Antikörper und j, k, 1; mab2-48-Antikörper). Dies könnte im Zusammenhang mit einer einsetzenden Neurodegeneration im Sinne eines verminderten bzw. gestörten axonalen Transportes stehen. Stokin und Kollegen haben gezeigt, dass axonale Veränderungen schon sehr früh vor der Plaquebildung einsetzen (Stokin et al. 2005). Dadurch kann die präsynaptische trophische Versorgung reduziert sein und dies kann zur Neurodegeneration führen (Salehi et al. 2006). 
5XFAD B6/SJL männlich 5XFAD B6 männlich 5XFAD B6 weiblich

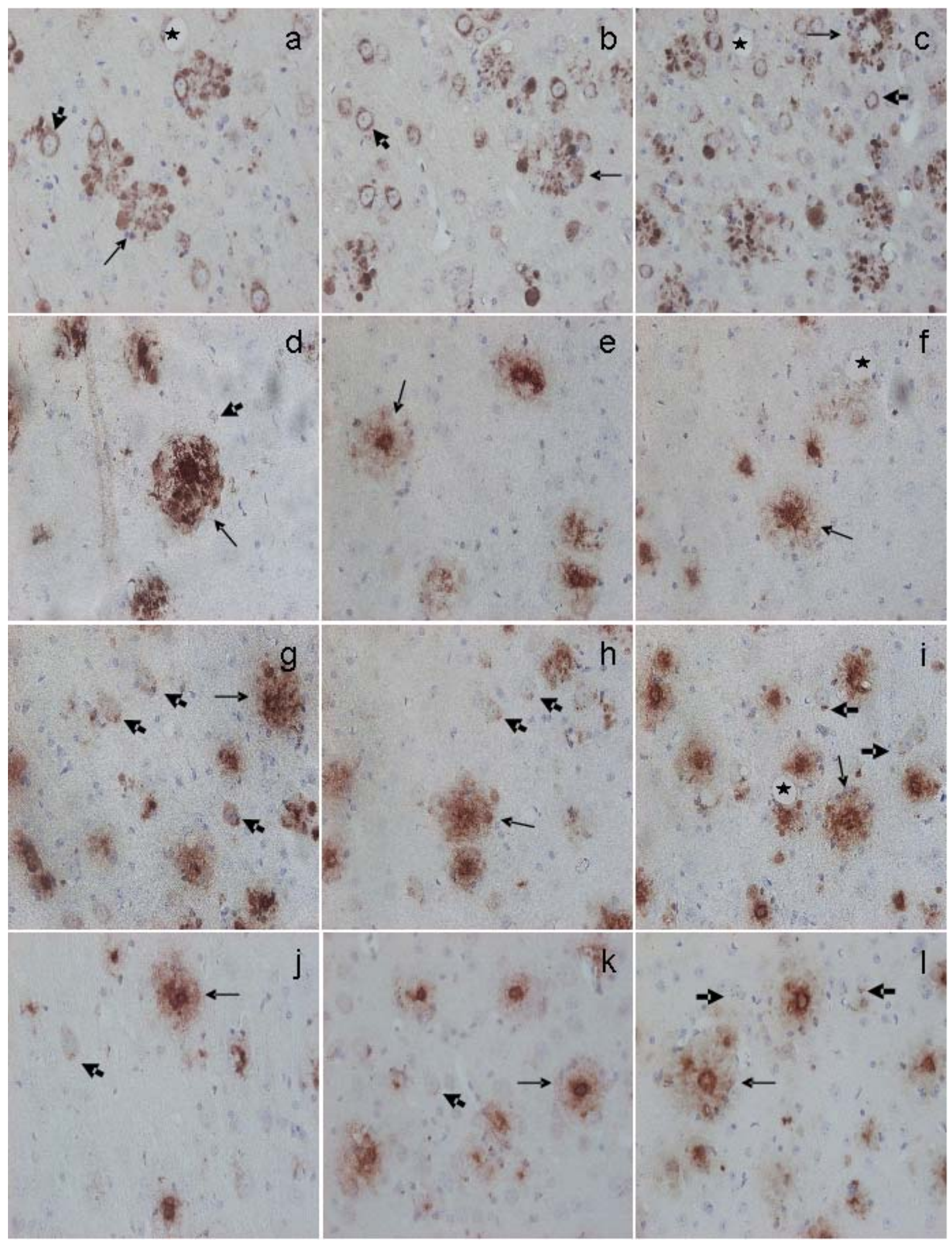

Abbildung 18: Übersicht über immunhistochemische Färbung des Frontalkortex mit intra- (dicker Pfeil) und extrazellulärer (dünner Pfeill) AB-Anfärbung bei $5 X F A D-B 6 / S J L$ und $5 X F A D-B 6(a, b, c=A P P ; d, e, f=A \beta[N] ; g, h, i$ $=4 G 8 ; j, k, l=$ mab2-48). Blutgefäße sind mit Stern markiert $(*)$. 


\subsubsection{Ergebnisse der quantitativen Bestimmung der A $\beta$-Belastung (Plaqueload)}

In Tabelle 11 sind die numerischen Ergebnisse der immunhistochemischen Färbung und Plaqueauswertung des Frontalkortex dargestellt. Es wurde die angefärbte Fläche des Frontalkortex in Prozent angegeben.

\begin{tabular}{|l|l|l|l|}
\hline \multicolumn{1}{|c|}{ Antikörper } & $\begin{array}{l}\mathrm{A} \beta[\mathrm{N}](1: 500) \\
\text { in \% }\end{array}$ & $\begin{array}{l}\text { 4G8 (1:10.000) } \\
\text { in \% }\end{array}$ & $\begin{array}{l}\text { mab2-48 (1:500) } \\
\text { in \% }\end{array}$ \\
\hline 5XFAD 6 Monate & 2,05 & 4,24 & 1,01 \\
B6/SJL männlich & 0,99 & 2,17 & 1,05 \\
& 3,47 & 3,03 & 1,08 \\
& 2,55 & 3,38 & 2,08 \\
& 1,31 & 2,79 & 1,21 \\
\hline Mittelwert & $\mathbf{2 , 0 8}$ & $\mathbf{3 , 1 2}$ & $\mathbf{1 , 2 9}$ \\
\hline 5XFAD 6 Monate B6 & 1,37 & 4,67 & 1,75 \\
männlich & 1,10 & 4,88 & 2,17 \\
& 0,77 & 4,30 & 0,93 \\
& 0,98 & 3,03 & 0,67 \\
\hline Mittelwert & $\mathbf{1 , 0 5}$ & $\mathbf{4 , 2 2}$ & $\mathbf{1 , 3 8}$ \\
\hline 5XFAD 6 Monate B6 & 2,48 & 8,50 & 2,00 \\
weiblich & 3,16 & 10,01 & 3,49 \\
& 1,88 & 5,80 & 2,59 \\
& 1,99 & 6,64 & 1,94 \\
\hline Mittelwert & $\mathbf{2 , 3 8}$ & $\mathbf{7 , 7 3}$ & $\mathbf{2 , 5 1}$ \\
\hline
\end{tabular}

Tabelle 11: Ergebnisse des Plaqueloads des Frontalkortex für die drei 5XFAD-Mauspopulationen

Die durchschnittliche Färbung der Fläche beim 5XFAD-B6/SJL-Mausmodell betrug mit dem $\mathrm{A} \beta[\mathrm{N}]$-Antikörper 2,08 \% $(\sigma= \pm 0,99 \%)$, mit dem 4G8-Antikörper 3,12 \% $(\sigma= \pm 0,76 \%)$ und das trunkierte A $\beta$ wurde zu 1,29 \% $(\sigma= \pm 0,45 \%)$ angefärbt. Das männliche 5XFAD-B6-Mausmodell hat nur die Hälfte der Anfärbung mit $A \beta[N]$ von durchschnittlich 1,05\% $(\sigma= \pm 0,25 \%)$ als sein männliches Äquivalent, aber eine deutlich höhere 4G8-Anfärbung mit durchschnittlich 4,22\% ( $\sigma=$ $\pm 0,83 \%)$ und eine ähnlich hohe Flächenanfärbung mit mab2-48 von durchschnittlich 1,38 \% $(\sigma= \pm$ 0,70 \%). Die höchsten Werte im Plaqueload hat bei allen Antikörpern das Weibchen. Mit dem Aâ[N]-Antikörper wurde eine Fläche von 2,38 \% $(\sigma= \pm 0,58 \%)$, mit dem 4G8-Antikörper von 7,73 $\%(\sigma= \pm 1,89 \%)$ und mit dem mab2-48 eine Fläche von 2,51\% $(\sigma= \pm 0,72 \%)$ angefärbt. 


\subsubsection{Vergleich der A $\beta$-Belastungen (Plaqueload)}

Im Nachfolgenden sind die Daten aus Kapitel 3.2.2 graphisch aufgearbeitet und auf statistische Signifikanz überprüft. Deutliche Unterschiede zeigen sich zwischen weiblichen und männlichen B6-Mäusen. In der 4G8-Färbung weisen die B6-Weibchen im Vergleich zu den B6-Männchen einen $46 \%$ höheren Gehalt an $\mathrm{A} \beta$ auf (s. Abbildung 19). Das Signifikanzniveau in der Varianzanalyse (ANOVA) betrug $\mathrm{p}<0,01$ und der t-Test erlangte ein $\mathrm{p}<0,05$. Einen noch größeren Geschlechtseffekt im Vergleich zur 4G8-Färbung zeigte sich bei den B6-Mäusen in der $\mathrm{A} \beta[\mathrm{N}]-$ Färbung, bei der die weiblichen B6-Mäuse mit 56 \% höher lagen als die männlichen B6Mäuse. Die Signifikanz lag beim t-Test bei $\mathrm{p}<0,01$. Auch bei der mab2-48-Färbung gegen trunkiertes $\mathrm{A} \beta$ haben die Weibchen eine 45 \%ig höhere Anfärbung. Es zeigte sich jedoch kein signifikanter Unterschied. Ein möglicher Einfluss des genetischen Hintergrundes zeigte beim B6/SJL-Genotyp im Vergleich zu den männlichen B6-Mäusen in der 4G8-Färbung eine um $26 \%$ und in der mab2-48-Färbung eine um $7 \%$ niedrigere $A \beta$-Anreicherung. Für nicht trunkiertes $A \beta$ wurde aber eine 50 \%ig höhere Flächenanfärbung für den B6/SJL-Genotyp gefunden. Die Ergebnisse für die Untersuchung des genetischen Hintergrundes lieferten keine Signifikanz.
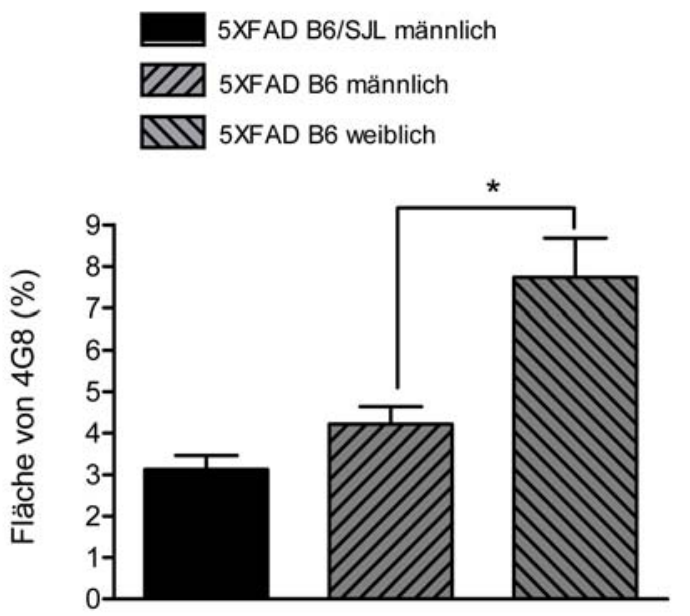

5XFAD B6/SJL männlich

27 5XFAD B6 männlich

DIFAD B6 weiblich

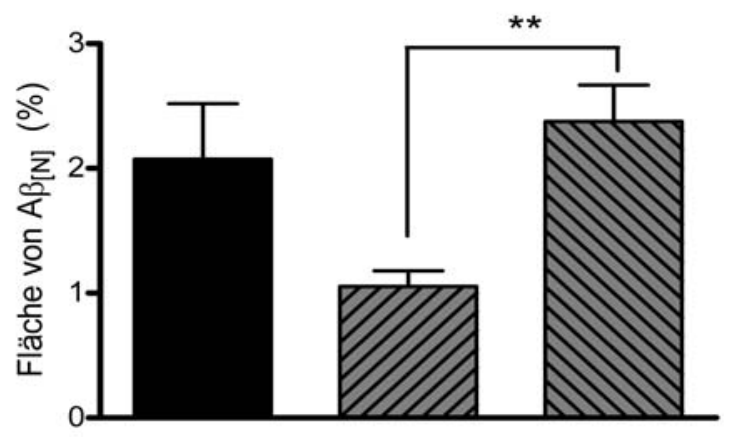

5XFAD B6/SJL männlich

PA 5XFAD B6 männlich

ND 5XFAD B6 weiblich

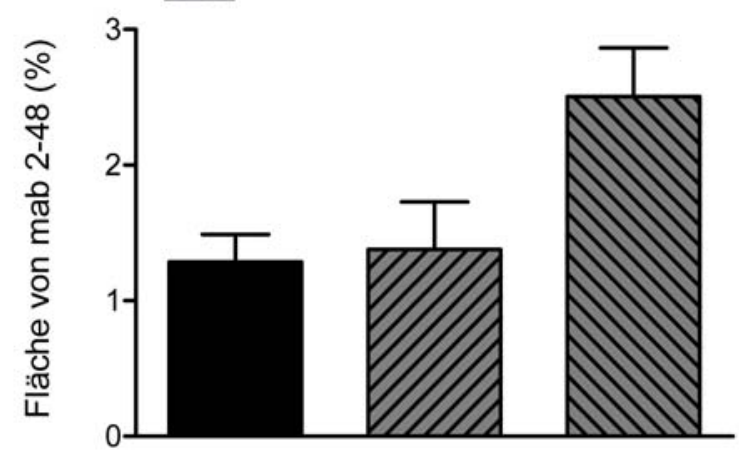

Abbildung 19: Vergleich der AB-Belastung beim männlichen, sechs Monate alten 5XFAD-B6/SJLMausmodell und den weiblichen und männlichen, sechs Monate alten 5XFAD-B6-Mäusen 
Das Verhältnis immunreaktiver extrazellulärer Plaques gegen trunkiertes Pyroglutamat-A $\beta$ (mab248), gegen nicht trunkiertes $A \beta(A \beta[N])$ und deren Vergleich zum Gesamt-A $\beta$ (4G8) werden in Abbildung 20 dargestellt.
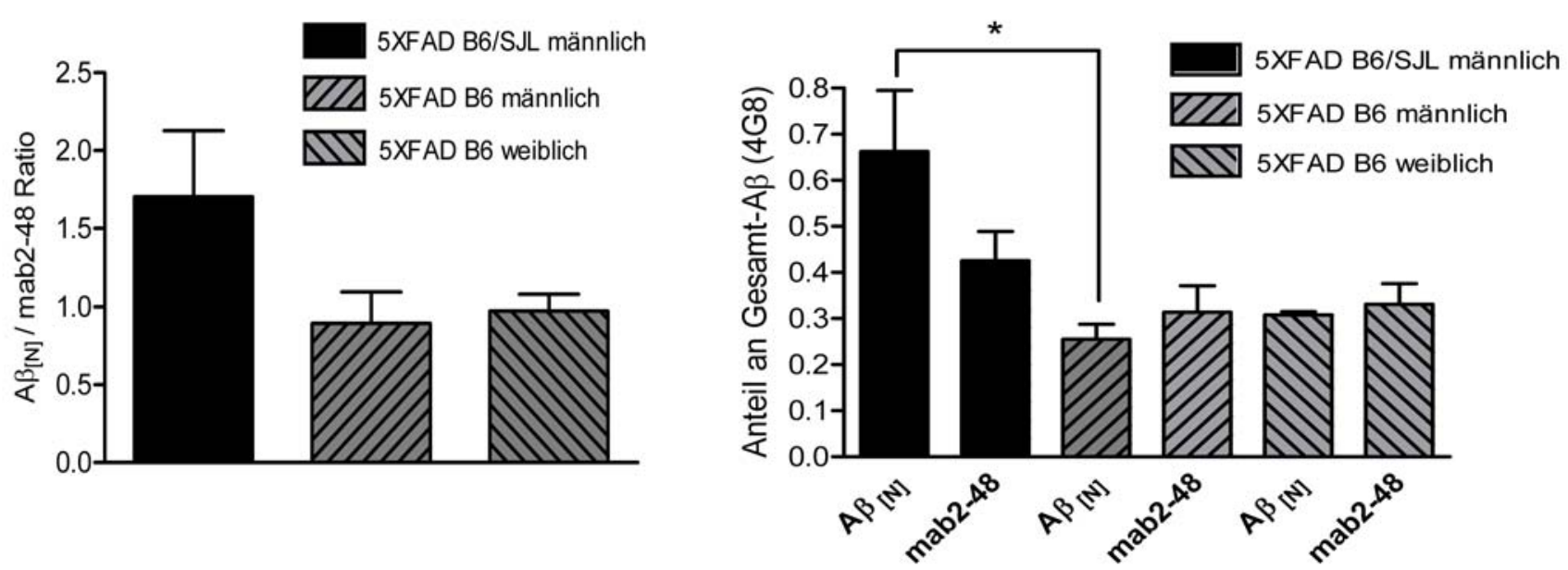

Abbildung 20: Verhältnis der AB[N]- und mab2-48-Antikörperfärbung und deren Darstellung im Vergleich zum Gesamt-A (4G8-Färbung) 


\section{Diskussion}

In der Pathologie der Alzheimererkrankung interferieren viele Faktoren, wie beispielsweise das Alter, das Geschlecht, genetische Alterationen, Umwelteinflüsse und weitere teilweise noch unbekannte Variablen. Um ein besseres Verständnis für die Zusammenhänge dieser Demenz zu entwickeln, werden Mausmodelle untersucht, die verschiedene Merkmale besitzen, die eine Akzeleration der Krankheit bewirken. Dieser Arbeit liegt das doppelt transgene Mausmodell 5XFAD zu Grunde, welches drei Mutationen im APP- und zwei im PS1-Gen vereinigt (s. Kapitel 2.1). Dies führt $\mathrm{zu}$ einer Überexprimierung von Gesamt-A $\beta$ und speziell von $\mathrm{A} \beta-42$. Vorausgegangene Studien hatten vermuten lassen, dass sich diese Mutationen additiv in ihrer Auswirkung zueinander verhalten und gerade das hochtoxische A $\beta-42$ stark ansteigen lassen (Citron et al. 1998; Eckman et al. 1997). Oakley et al. (2006) hatten bei diesem Mausmodell bei neun Monate alten transgenen Mäusen im Vergleich zu einer nichttransgenen Kontrollgruppe in der Kortexschicht fünf einen Neuronenverlust und in Schicht eins eine Ausdünnung festgestellt. Es wurde jedoch keine vergleichende Neuronenzählung durchgeführt.

Die stereologischen Ergebnisse in dieser Arbeit zeigen zwischen den beiden transgenen Mäusepopulationen im Vergleich zur Wildtyppopulation im Alter von sechs Monaten keinen signifikanten Unterschied in der Neuronenzahl im Frontalkortex (s. Kapitel 3.1.3) und konnten damit den von Oakley und Kollegen beschriebenen Neuronenverlust quantitativ nicht untermauern. Eventuell spielt das jüngere Alter der in dieser Arbeit untersuchten Mäuse eine größere Rolle als vorher anzunehmen war, denn Gedächtnisdefizite konnten Oakley und Kollegen schon mit vier bis fünf Monaten und erstes intraneuronales A $\beta$-Peptid schon mit anderthalb Monaten feststellen. Andererseits wurden in Bezug auf Marker für Neurodegeneration wie Synaptophysin, signifikante Unterschiede erst im Alter von neun Monaten zwischen Wildtypmäusen und den transgenen 5XFAD-Mäusen bewiesen. Es ist nicht auszuschließen, dass sich die in dieser Arbeit untersuchte Mäusepopulation mit ihren sechs Monaten genau in einem Zeitfenster der Erkrankung befindet, in dem durch Synapsendegeneration schon deutliche Einschränkungen der Gedächtnisleistung zu finden sind, es aber noch keinen signifikanten Neuronenverlust gibt.

Das parallel dazu untersuchte Gehirnvolumen zeigte zwischen den 5XFAD-Männchen keinen signifikanten Unterschied, wohingegen das weibliche 5XFAD-Mausmodell nur noch $58 \%$ des Volumens der weiblichen Wildtypen hat. Als Ursache kann ein Verlust an Neuronen anhand der unwesentlichen Neuronendifferenz von $1 \%$ zwischen diesen beiden Populationen als unwahrscheinlich angesehen werden. Es könnte vermutet werden, dass der von Oakley und 
Kollegen beschriebene Synapsenverlust und damit einhergehend die von ihm beobachtete Ausdünnung der ersten Kortexschicht bei Weibchen deutlich ausgeprägter ist als bei Männchen. Das würde bedeuten, dass obwohl die Weibchen in beiden Populationen absolut weniger Neurone haben, ihr Synapsenverlust überproportional im Vergleich zu dem jeweiligen männlichen Äquivalent ist. Zu diesem Ergebnis passen aber nicht die in dieser Arbeit angefertigten Aufnahmen des Frontalkortex, wo keine Abnahme der ersten Schicht des Kortex bei transgenen Weibchen und Männchen im Vergleich zur Kontrollgruppe zu sehen ist. Die genaue Ursache für das deutlich höhere Volumen des weiblichen Wildtypen und den starken Volumenverlust der transgenen weiblichen Mäuse kann abschließend nicht geklärt werden. Als Ausblick wäre eine Messung von Synaptophysin zwischen männlichen und weiblichen transgenen und nichttransgenen Mäusen hilfreich, um numerische Daten zu erhalten, die eine genauere Aussage über die Ursache des Hirnvolumenverlustes erlauben.

In diesem Zusammenhang ist es auch Interessant, dass die weiblichen 5XFAD-B6-Mäuse 19 \% weniger Neurone als die Männchen bei annähernd gleichem Volumen haben. Eine Ursache für die nicht vorhandene Volumendifferenz könnte die ca. $50 \%$ höhere $A \beta$-Belastung sein, die sich zum größten Teil in einer Anfärbung der extrazellulären Plaques darstellt (s. Kapitel 3.2.3). Plaques sind in ihrem Durchmesser deutlich größer als Neurone (s. Kapitel 3.2.1) und könnten einen gewissen Verdrängungseffekt haben, der dazu führt, dass eine zu erwartende Volumenabnahme zunächst nicht so deutlich ausfällt. Bei Fortschreiten der Erkrankung kann man aber annehmen, dass sich dennoch ein deutlicher Volumenrückgang einstellt, wie es typischerweise zu erwarten wäre.

Die Tatsache, dass Oakley und Kollegen einen Neuronenverlust annahmen, beruht darauf, dass die Aufnahmen des Kortex der transgenen Mäuse (s. Kapitel 1.6) Bereiche aufweisen, die weniger oder keine Neurone haben. Dies hat dazu ermuntert anzunehmen, dass es generell eine Abnahme der Neuronenzahl geben muss. Aufnahmen, die in dieser Arbeit gemacht wurden (s. Kapitel 3.1), weisen ebenso Bereiche bei den 5XFAD-Mäusen auf, in denen relativ weniger Neurone angesiedelt sind. Die Neurone sind ebenso sichtbar in ihrer Größe reduziert. Wie bei Oakley und Kollegen wurden die Aufnahmen an Schnitten gemacht, die mit Cresylviolett angefärbt wurden, das aber keine Plaques anfärbt. Die beschriebenen Bereiche sind vermutlich von Plaques ausgefüllt, die zu einer räumlichen Verdrängung führen und dadurch den Eindruck vermitteln, die Dichte der Neurone sei geringer. Wenn man dies und die stereologischen Ergebnisse, die sich durch punktuelle Dichteabnahmen nicht beeinflussen lassen, berücksichtigt, kann man die widersprüchlichen qualitativen und quantitativen Ergebnisse erklären. Es ist anzunehmen, dass Übersichtsaufnahmen nicht geeignet sind, um ein eindeutiges Urteil über quantitative Unterschiede in der Neuronenzahl 
zu treffen.

Der Einfluss des genetischen Hintergrundes als möglicher Faktor in der Beeinflussung der Pathogenese zwischen den männlichen B6/SJL- und B6-Mäusen zeigte bezüglich Neuronenzahl und Volumen niedrigere Werte von $16 \%$ und $8 \%$ für den B6/SJL-Genotyp (s. Kapitel 3.2.3).

Gemäß den niedrigeren Werten in der stereologischen Untersuchung für den B6/SJL-Genotyp wären höhere Werte für die quantitative $A \beta$-Auswertung zu erwarten gewesen. Dies hat sich nur teilweise bestätigt, denn die Auswertung mittels 4G8-Antikörper ergab sogar nur 74 \% (s. Kapitel 3.2.3) des Gesamt-A $\beta$ im Vergleich zum männlichen B6-Modell. Anders hat es sich mit dem $\mathrm{A} \beta[\mathrm{N}]$-Antikörper gegen nicht trunkiertes $\mathrm{A} \beta$ verhalten, bei dem der B6-Genotyp $50 \%$ mehr Anfärbung hatte. Um der Frage nachzugehen, ob trunkiertes $A \beta$ eine Rolle in der Ursache der niedrigeren Neuronenzahl und des geringeren Volumens spielen könnte, wurde mittel mab2-48 gegen trunkiertes $A \beta_{\mathrm{pE3}-\mathrm{x}}$ gefärbt (s. Kapitel 1.5.4.3). Zwischen den beiden männlichen Genotypen konnte nur eine leichte Differenz von 7 \% weniger trunkiertem A $\beta$ für die B6/SJL-Mäuse gefunden werden. Letztere haben insgesamt deutlich höhere Anteile von $A \beta_{\mathrm{pE} 3-\mathrm{x}}$ am gesamten $\mathrm{A} \beta$ von $41 \%$ im Vergleich zu 25 \% beim B6-Genotyp. Dies findet sich im Einklang mit Beobachtungen, die eine erhöhte Toxizität für das $A \beta_{\mathrm{pE} 3-\mathrm{x}}$ beschreiben (Wirths et al. 2010). Interessanterweise ergeben die Anteile von trunkiertem $A \beta_{\mathrm{pE3}-\mathrm{x}}$ und untrunkiertem $\mathrm{A} \beta$ bei den B6-SJL-Mäusen ziemlich genau das gemessene Gesamt-Aß. Dies ist nicht bei den B6-Mäusen der Fall. Hier erreichen die Männchen nur $58 \%$ und die Weibchen nur $63 \%$ des gesamten $A \beta$. Es ist daher davon auszugehen, dass noch andere trunkierte $A \beta$-Spezies (z.B. A $\beta 2-42, A \beta 4-42$ ), wie sie beispielsweise von Casas und Kollegen für ein anderes Mausmodell beschrieben wurden, zu finden sind (Casas et al. 2004).

Oakley et al. (2006) haben einen geschlechtsbezogenen Unterschied in der A $\beta$-Belastung der 5XFAD-Mäuse besonders im Alter von neun Monaten festgestellt. Mittels ELISA haben sie die A $\beta$ 40- und A $\beta-42-M e n g e$ in Relation zum Gesamtprotein gesetzt. In fast jedem Alter zeigen die weiblichen Mäuse eine leicht höhere Belastung mit toxischem A $\beta$-Peptid als die Männchen (s. Kapitel 1.6) und die Differenz steigt mit zunehmendem Alter deutlich beim A $\beta-40$. Im vergleichenden Plaqueload dieser Arbeit wurde auf eine Differenzierung zwischen A $\beta-40$ und A $\beta$ 42 verzichtet. Im Vergleich konnten die Beobachtungen von Oakley und Kollegen bestätigt werden. Sie haben durchschnittlich $46 \%$ mehr Gesamt-A $\beta, 56 \%$ mehr nicht trunkiertes und $45 \%$ mehr trunkiertes $A \beta$ bei den Weibchen als bei den Männchen in der 5XFAD-Reihe ergeben. Die Beobachtungen haben damit einen noch deutlicheren Unterschied schon bei den sechs Monate alten 
Mäusen hervorgebracht. Wenn man noch die niedrigere Neuronenzahl der 5XFAD-Weibchen von 19 \% hinzuzieht, kann man insgesamt von einer stärkeren Ausprägung der alzheimertypischen Pathologie bei 5XFAD-Weibchen sprechen. Dieses Ergebnis kann in Bezug zu bisherigen Erkenntnissen von anderen Gruppen gesehen werden. Bei verschiedenen Mausmodellen wurden ebenso Geschlechtseffekte festgestellt, die sich in einer höheren Belastung mit $\beta$-Amyloid bei Weibchen als bei Männchen äußerten. Bei der Maus Tg2576 wurde im Neokortex und Hippokampus (Callahan et al. 2001) und nur im Hippokampus bei dem Mausmodell APP/PS1 (Wang et al. 2003) ein solcher Geschlechtseffekt demonstriert. In einer weiteren APP-transgenen Linie konnte bereits im Alter von 14 Wochen in weiblichen Mäusen eine signifikant höhere Menge an Aß40-Peptiden im Vergleich zu männlichen Tieren nachgewiesen werden (Schafer et al. 2007). Ähnliche Ergebnisse wurden auch schon beim Menschen veröffentlicht (Barnes et al. 2005; Kraszpulski et al. 2001). Demnach würde sich auch das Mausmodell 5XFAD zur Ursachenforschung für geschlechtliche Einflüsse in der Alzheimerpathogenese eignen.

Neueren Erkenntnissen entsprechend kommt gerade dem $A \beta-42$ und seiner intraneuronalen Akkumulation besondere Bedeutung zu. Vermutlich bewirkt gerade die intraneuronale Akkumulation a priori eine Neurodegeneration und erst nachfolgend formieren sich in einem zweiten Schritt, nachdem das Neuron untergegangen ist, die schon von Alois Alzheimer beschriebenen extrazellulären Plaques. Dabei wird vermutet, dass das abgestorbene Neuron Mittelpunkt der Bildung der Plaques ist, da Kernreste innerhalb dieser Plaques Neuronen zugeordnet werden konnten (D'Andrea et al. 2001; Wirths et al. 2004). Lange konnte bisher keine Korrelation zwischen der Bildung von Plaques und einem Neuronenverlust hergestellt werden, bis in neueren Arbeiten am Frontalkortex und Thalamus eine vorrangige Bedeutung der transienten intrazellulären Anhäufung in Bezug auf einen Neuronenverlust in einem anderen doppelt transgenen Mausmodell APP/PS1KI demonstriert werden konnte (Christensen et al. 2008). Diese Ergebnisse werden von Veröffentlichungen über Downsyndrom-Patienten unterstützt, bei denen sich eine intraneuronale $A \beta-42-A k k u m u l a t i o n$ nur im jungen Alter findet und invers mit der Zunahme von Plaques korreliert (Gyure et al. 2001; Mori et al. 2002). Auch Oakley und Kollegen haben bei der 5XFAD-Maus bereits im Alter von anderthalb Monaten erste intraneuronale Anfärbungen von $\mathrm{A} \beta$ gefunden, welches mit dem ersten Anstieg an A $\beta-42$ zusammenfiel und noch vor der ersten Plaquebildung mit zwei Monaten auftrat. Diesen Beobachtungen folgend, wurden in dieser Arbeit besonders mit dem 4G8-Antikörper, aber auch mit der Färbung gegen trunkiertes und untrunkiertes $A \beta$ deutliche intrazelluläre $A \beta$-Ansammlungen gefunden, die sich über das gesamte 
Soma der Neuronen verteilen und besonders hohe Dichte am Axonhügel aufweisen. Es ist nicht sicher beurteilbar, ob Letzteres als erster bildgebender Hinweis für neurotrophe Störungen des Axons interpretiert werden kann.

$\mathrm{Da}$ sich in dieser Arbeit mit den sechs Monate alten Mäusen kein signifikanter Neuronenverlust zwischen Wildtyp- und 5XFAD-Mäusen einstellte und es keinen Altersvergleich gibt, aber dennoch eine deutliche intra- und extrazelluläre $A \beta$-Anfärbung besteht, kann keine eindeutige Aussage zum neurotoxischen Effekt des transienten intrazellulären $\beta$-Amyloids, wie er im APP/PS1KIMausmodell im Alter zwischen zwei und sechs Monaten gefunden wurde, gemacht werden. Entweder erfährt die transiente intrazelluläre $A \beta$-Anreicherung in diesem Mausmodell keine so starke Gewichtung oder hat zu einem späteren Zeitpunkt seine größte Auswirkung. Obwohl Oakley und Kollegen diesbezüglich keine Untersuchungen bei ihren neun und zwölf Monate alten Mäusen gemacht haben und keine ergänzenden Hinweise für die Bedeutung der intraneuronalen Akkumulation gefunden wurden, darf ihr zumindest nicht nach den Beobachtungen in dieser Arbeit widersprochen werden. Vergleichende Untersuchungen verschiedener Altersgruppen unter Berücksichtigung einer eventuellen Abnahme von Neuronenzahl und Beobachtung des intraneuronalen A $\beta$-Gehaltes könnte näheren Aufschluss zu dieser Frage geben.

Generell müssen alle Ergebnisse in der Alzheimerforschung, die durch Maustiermodelle gewonnen werden, kritisch betrachtet werden, denn die den Modellen zugrunde liegenden transgenen DNAKonstrukte sind auf der Basis von humanen Mutationen entwickelt, die sich für die Entstehung der EOAD verantwortlich zeigen. Diese Form der AD entwickeln aber nur circa $2 \%$ der betroffenen Menschen. Das Fortschreiten der Erkrankung verläuft beim Menschen über Jahre und wird bei der Maus auf wenige Monate verkürzt. Es bleibt offen, ob das Verständnis der AD, gewonnen aus Daten der Mausmodelle, und daraus entwickelte Therapieformen problemlos auf den Menschen übertragen werden können.

Speziell muss in dieser Arbeit berücksichtigt werden, dass für den B6/SJL-Genotyp keine WildtypKontrollgruppe zur Verfügung stand. Es kann nicht ausgeschlossen werden, dass die 5XFADB6/SJL-Mäuse per se eine erniedrigte Neuronenzahl und ein geringeres Hirnvolumen haben und genetische Effekte als Einfluss auf die Alzheimerpathogenese überbewertet werden.

Zusammenfassend sollte erwähnt werden, dass das Maustiermodell 5XFAD, das von Oakley und Kollegen mit fünf Mutationen im APP- und PS1-Gen generiert wurde, nach den stereologischen Ergebnissen in dieser Arbeit nicht den vermuteten Neuronenverlust aufweist. Dies wäre durch den 
kumulativen Effekt der Mutationen und dem angedeuteten Neuronenverlust in der Bildgebung bei den neun Monate alten 5XFAD-Mäusen durchaus zu erwarten gewesen.

Vielmehr konnte ein Geschlechtseffekt bei dem Plaqueload und der Neuronenzahl zu Ungunsten der weiblichen 5XFAD-Mäuse gezeigt werden, wie er durch Ergebnisse in anderen Mäusepopulationen und entsprechend der Verteilung der A $\beta$-Belastungen bei Oakley und Kollegen zu erwarten war.

Ein Einfluss des genetischen Hintergrundes konnte nur teilweise gefunden werden. Der B6/SJLHintergund scheint eine erhöhte Neigung zu dem toxischeren trunkierten $A \beta_{\mathrm{pE} 3-\mathrm{x}}$ zu haben.

Wie bei Oakley und Kollegen konnten intrazelluläre Akkumulationen von A $\beta$-Peptid gefunden werden. Eine vorwiegende Bedeutung der intrazellulären Akkumulation in der Alzheimerpathogenese kann aber in dieser Arbeit nicht sicher beurteilt werden. 


\section{Zusammenfassung}

Die Alzheimerdemenz ist die häufigste Demenzform und betrifft in Deutschland zur Zeit ca. 900.000 Erkrankte. Obwohl seit Alois Alzheimer intensiv an dem Verständnis der Pathogenese geforscht wird, gibt es bis heute keine etablierte kausale Therapie.

Neuropathologisch ist die Erkrankung durch intra- und extrazelluläre $\beta$-Amyloid-Ablagerungen, intrazelluläre Neurofibrillen, Synapsen- und Neuronenverluste charakterisiert. Der typischerweise auftretende Gedächtnisverlust wird durch den Neuronenverlust, die Synapsendegeneration und inflammatorische Prozesse vermittelt. Der zugrunde liegende Mechanismus ist weiterhin umstritten und Gegenstand intensiver Forschung. Um einen fokussierten Blick auf bestimmte Merkmale der Erkrankung zu werfen, werden transgene Mausmodelle benutzt, die unterschiedliche humane Mutationen exprimieren oder als Knockout-Mäuse Schlüsselproteine aufzeigen. In dieser Arbeit wurde das doppelt transgene Mausmodell 5XFAD von Oakley und Kollegen mit fünf humanen EOAD-Mutationen (early-onset Alzheimer's disease), welches drei APP-Mutationen (Amyloid Precursor Protein) und zwei PS1-Mutationen (Presenilin-1) beinhaltet, erstmals quantitativ mittels stereologischer Untersuchungstechniken auf Neuronenverlust und Hirnvolumenminderung im Frontalkortex im Alter von sechs Monaten, sowie auf geschlechtliche Unterschiede und genetische Einflüsse zwischen dem B6- und B6/SJL-Hintergrund untersucht. Zusätzlich wurde noch eine vergleichende Untersuchung zur A $\beta$-Amyloid-Belastung (Plaqueload) durchgeführt. Als Kontrollgruppe dienten B6-Wildtypmäuse. Die von Oakley und Kollegen beschriebenen Verhaltensauffälligkeiten im Alter von vier Monaten und der vermutete Neuronenverlust konnten in dieser Arbeit stereologisch nicht untermauert werden. Es fand sich aber bei den Weibchen eine deutlich niedrigere Neuronenzahl, ein massiver Volumenverlust und eine höhere Belastung mit toxischem A $\beta$-Peptid als bei den Männchen. In diesem Zusammenhang könnte das 5XFADMausmodell zur weiteren Forschung geschlechtlicher Einflüsse durchaus interessant sein.

Der genetische Hintergrund der Mäuse scheint vergleichsweise nur eine untergeordnete Rolle zu spielen, es konnte aber für den B6/SJL-Genotyp eine erhöhte Bildung von toxischem $\mathrm{A} \beta_{\mathrm{pE} 3-\mathrm{x}}$ gezeigt werden. Der B6-Hintergrund bildet neben dem $\mathrm{A} \beta_{\mathrm{pE} 3-\mathrm{x}}$ noch weitere unbekannte $\mathrm{A} \beta$ Isovarianten, die aber insgesamt eine geringere Neurotoxizität haben.

Als Ausblick wirft dieses Mausmodell viele Fragen auf, denn es bleibt unklar, warum das Mausmodell mit fünf EOAD-Mutationen keinen signifikanten Neuronenverlust zeigt, obwohl andere Mausmodelle mit ähnlichen, aber insgesamt weniger Mutationen (z.B. APP/PS1KI Mäuse) schon zwischen zwei und sechs Monaten einen massiven Neuronenverlust haben. 


\section{Abbildungsverzeichnis}

Abbildung 1: Auguste D. (www.hirnliga.de/images/augusteD.jpg) 12

Abbildung 2:

Alois

Alzheimer

(www.deutsche-

alzheimer.de/fileadmin/alz/templates/template_images/Alois_Alzheimer.jpg) 12

Abbildung 3: Hirnatrophie eines Alzheimerkranken (Tang-Wai et al. 2005, S. 422). 13

Abbildung 4: Neuritische Plaque mit Amyloid-Kern, umrandet von dystrophen Neuriten und Neurofibrillen (Tang-Wai et al. 2005, S. 422)

Abbildung 5:a) Lichtmikroskopische Aufnahme von intrazellulären Neurofibrillen (dicker Pfeil) und dystrophen Neuriten in einer neuritischen Plaque (kleine Pfeile); b) Elektronenmikroskopische Aufnahme von PHF (Arendt 2002, S. 114)

Abbildung 6: Schematische Darstellung der APP-Prozessierung, verändert nach Selkoe (Selkoe 2001, S. 746)

Abbildung 7: Schematische Darstellung der APP-Prozessierung, verändert nach Selkoe (Selkoe 2001, S. 749)

Abbildung 8: Die Amyloid-Kaskaden-Hypothese, verändert nach Hardy und Allsop (Hardy und Allsop 1991, S. 387) 25

Abbildung 9: Die modifizierte Amyloid-Kaskaden-Hypothese nach Wirths und Kollegen (Wirths et al. 2004, S. 515) 26

Abbildung 10: Neokortex-Kontrollgruppe (A, C) und 5XFAD (Tg6799 = APP hoch exprimierend; $\mathrm{B}, \mathrm{D})$

Abbildung 11: Aß-Level in 5XFAD-Mäusegehirnen (Tg6799 = APP hochexprimierend) (Oakley et al. 2006, S. 10132)

Abbildung 12: Schematische Darstellung der APP- und PS1-Transgene $(\mathrm{Sw}=$ swedish, F1 $=$ Florida, Lon = London) (Oakley et al. 2006, S. 10131)

Abbildung 13: Immunoblot-Analyse der Expression von APP und PS1 der transgenen Mauslinien Tg6799, Tg7092, Tg7031 und zum Vergleich Tg2576, sowie einer nicht transgenen Vergleichsgruppe (Non-Tg). Actin-Bestimmung zur Funktionskontrolle (Oakley et al. 2006, S. 10131).

Abbildung 14: Darstellung des Frontalkortex der linken Hemisphären, grau unterlegt ist der untersuchte Bereich, Zwischenstufen sind nicht dargestellt. Verändert nach dem Mäusebildatlas von Paxinos und Franklin (Paxinos und Franklin 2001) .33 Abbildung 15: Mikroskopische Aufnahmen des Frontalkortex bei 5XFAD- und Wildtypmäusen, die 
Pfeile markieren neuronenarme Bereiche 38

Abbildung 16: Vergleich der Gesamtneuronenzahl und des Volumens des Frontalkortex zwischen den Mausmodellen 5XFAD-B6/SJL, sechs Monate, männlich und 5XFAD-B6, sechs Monate, männlich.

Abbildung 17: Vergleich der Gesamtneuronenzahl und des Volumens des Frontalkortex zwischen dem Mausmodell 5XFAD-B6, sechs Monate, männlich und weiblich und den Mausmodellen Wildtyp-B6, sechs Monate, männlich und weiblich .

Abbildung 18: Übersicht über immunhistochemische Färbung des Frontalkortex mit intra- (dicker Pfeil) und extrazellulärer (dünner Pfeịl) AB-Anfärbung bei 5XFAD-B6/SJL und 5XFAD-B6 (a, b, c $=A P P ; d, e, f=A \beta[N] ; g, h, i=4 G 8 ; j, k, l=$ mab2-48). Blutgefäße sind mit Stern markiert (*). .44 Abbildung 19: Vergleich der AB-Belastung beim männlichen, sechs Monate alten 5XFAD-B6/SJLMausmodell und den weiblichen und männlichen, sechs Monate alten 5XFAD-B6-Mäusen 46 Abbildung 20: Verhältnis der Aß[N]- und mab2-48-Antikörperfärbung und deren Darstellung im Vergleich zum Gesamt-Aß (4G8-Färbung)..... 


\section{Tabellenverzeichnis}

Tabelle 1: ICD-10 Kriterien der Demenz (Ihl 2002) …............................................................ 8

Tabelle 2: Einteilung der Demenzen (Zeyfang et al. 2008, S. 143) ............................................... 10

Tabelle 3: Übersicht über die verwendeten Mäuse; *=hier eine Maus mehr untersucht für Plaqueload, ** da Wildtyp, hier keine Plaques

Tabelle 4: Übersicht über verwendete Mäuse und Antikörper für den Plaqueload.

Tabelle 5: Gesamtneuronenzahl des Frontalkortex der vier Mäuse 5XFAD, 6 Monate, B6/SJL, männlich.

Tabelle 6: Gesamtneuronenzahl des Frontalkortex der vier weiblichen und männlichen 5XFAD-

Mäuse, 6 Monate, B6 .....

Tabelle 7: Gesamtneuronenzahl des Frontalkortex der fünf weiblichen und sechs männlichen Wildtyp-B6-Mäuse, 6 Monate .

Tabelle 8: Gesamtvolumen des Frontalkortex der vier Mäuse 5XFAD, 6 Monate, B6/SJL, männlich

Tabelle 9: Gesamtvolumen des Frontalkortex der vier weiblichen und männlichen 5XFAD-Mäuse, 6 Monate, B6.

Tabelle 10: Gesamtvolumen des Frontalkortex der fünf weiblichen und sechs männlichen WildtypB6-Mäuse, 6 Monate

Tabelle 11: Ergebnisse des Plaqueloads des Frontalkortex für die drei 5XFAD-Mauspopulationen

Tabelle 12: Altersspezifische Prävalenz (in Prozent) von Demenzerkrankungen auf der Grundlage von Metaanalysen *Gesamtrate für die über 65-Jährigen bei Standardisierung auf die Altersstruktur der deutschen Altenbevölkerung zum Ende des Jahres 2002 (Bickel 2004) 58

Tabelle 13: Altersspezifische Prävalenz (in Prozent) von Demenzerkrankungen auf der Grundlage von Metaanalysen, *Gesamtrate für die über 65-Jährigen bei Standardisierung auf die Altersstruktur der deutschen Altenbevölkerung zum Ende des Jahres 2002 (Bickel 2004).............58

Tabelle 14: Stadieneinteilung nach DEGAM (2008)...

Tabelle 15: Klinische Diagnosekriterien für die Alzheimerdemenz nach NINCDSADRDA (McKhann et al. 1984) . .60

Tabelle 16: Färbeprotokoll für Paraffinschnitte. 62 


\section{Anhang}

8.1 Altersspezifische Prävalenz (in Prozent) von Demenzerkrankungen

\begin{tabular}{|c|c|c|c|c|c|}
\hline \multirow[t]{2}{*}{ Altersgruppe } & \multirow{2}{*}{$\begin{array}{l}\text { Jorm et al. } \\
(1987)\end{array}$} & \multirow{2}{*}{$\begin{array}{l}\text { Hofman et al. } \\
(1991)\end{array}$} & \multirow{2}{*}{$\begin{array}{l}\text { Ritchie \& } \\
\text { Kildea (1995) }\end{array}$} & \multicolumn{2}{|c|}{ Lobo et. Al. (2000) } \\
\hline & & & & Männer & Frauen \\
\hline Gesamtrate* & 6,5 & 6,9 & 7,3 & 4,5 & 7,3 \\
\hline 65-69 Jahre & 1,4 & 1,4 & 1,5 & 1,6 & 1,0 \\
\hline 70-74 Jahre & 2,8 & 4,1 & 3,5 & 2,9 & 3,1 \\
\hline 75-79 Jahre & 5,6 & 5,7 & 7,3 & 5,6 & 6,0 \\
\hline 80-84 Jahre & 10,5 & 13,0 & 13,4 & 11,0 & 12,6 \\
\hline 85-89 Jahre & 20,8 & 21,6 & 22,2 & 12,8 & 20,2 \\
\hline 90-94 Jahre & 38,6 & 32,2 & 33,0 & 22,1 & 30,8 \\
\hline 95+ Jahre & 34,7 & 34,7 & 44,8 & - & - \\
\hline
\end{tabular}

Tabelle 12: Altersspezifische Prävalenz (in Prozent) von Demenzerkrankungen auf der Grundlage von Metaanalysen *Gesamtrate für die über 65-Jährigen bei Standardisierung auf die Altersstruktur der deutschen Altenbevölkerung zum Ende des Jahres 2002 (Bickel 2004)

\subsection{Altersspezifische Inzidenz (in Prozent) von Demenzerkrankungen}

\begin{tabular}{|l|l|l|l|}
\hline Altersgruppe & Jorm und Jolley (1998) & Gao et al. (1998) & Fratiglioni et al. (2000) \\
\hline Gesamtrate* & $\mathbf{3 , 2}$ & $\mathbf{1 , 6}$ & $\mathbf{1 , 4}$ \\
\hline 65-69 Jahre & 0,91 & 0,33 & 0,24 \\
\hline 70-74 Jahre & 1,76 & 0,84 & 0,55 \\
\hline 75-79 Jahre & 3,33 & 1,82 & 1,60 \\
\hline 80-84 Jahre & 5,99 & 3,36 & 3,05 \\
\hline 85-89 Jahre & 10,41 & 5,33 & 4,86 \\
\hline 90-94 Jahre & 17,98 & 7,29 & 7,02 \\
\hline 95+ Jahre & - & 8,68 & - \\
\hline
\end{tabular}

Tabelle 13: Altersspezifische Prävalenz (in Prozent) von Demenzerkrankungen auf der Grundlage von Metaanalysen, *Gesamtrate für die über 65-Jährigen bei Standardisierung auf die Altersstruktur der deutschen Altenbevölkerung zum Ende des Jahres 2002 (Bickel 2004) 


\subsection{Stadieneinteilung der Demenzen}

\begin{tabular}{|c|c|c|c|c|}
\hline $\begin{array}{l}\text { Schwere- } \\
\text { grad }\end{array}$ & $\begin{array}{l}\text { Kognition/ } \\
\text { Tätigkeiten }\end{array}$ & Lebensführung & $\begin{array}{l}\text { Störungen von } \\
\text { Antrieb und Affekt }\end{array}$ & Mini-Mental-Test \\
\hline leicht & $\begin{array}{l}\text { Komplizierte } \\
\text { tägliche Arbeiten } \\
\text { oder Freizeit- } \\
\text { beschäftigungen } \\
\text { können nicht (mehr) } \\
\text { ausgeführt werden }\end{array}$ & $\begin{array}{l}\text { Die selbstständige } \\
\text { Lebensführung ist } \\
\text { zwar eingeschränkt, } \\
\text { ein unabhängiges } \\
\text { Leben ist aber noch } \\
\text { möglich }\end{array}$ & $\begin{array}{l}\text { Fehlende } \\
\text { Spontaneität, } \\
\text { Depression, } \\
\text { Antriebsmangel, } \\
\text { Reizbarkeit, } \\
\text { Stimmungslabilität }\end{array}$ & Unter 23-24 Punkten \\
\hline mittel & $\begin{array}{l}\text { Nur einfache } \\
\text { Tätigkeiten werden } \\
\text { beibehalten, andere } \\
\text { werden nicht mehr } \\
\text { vollständig oder } \\
\text { unangemessen } \\
\text { ausgeführt }\end{array}$ & $\begin{array}{l}\text { Ein unabhängiges } \\
\text { Leben ist nicht mehr } \\
\text { möglich. Patienten } \\
\text { sind auf fremde } \\
\text { Hilfe angewiesen, } \\
\text { eine selbstständige } \\
\text { Lebensführung ist } \\
\text { aber noch teilweise } \\
\text { möglich }\end{array}$ & $\begin{array}{l}\text { Unruhe, } \\
\text { Wutausbrüche, } \\
\text { aggressive } \\
\text { Verhaltensweise }\end{array}$ & Unter 20 Punkten \\
\hline schwer & $\begin{array}{l}\text { Es können keine } \\
\text { Gedankengänge } \\
\text { mehr } \\
\text { nachvollziehbar } \\
\text { kommuniziert } \\
\text { werden }\end{array}$ & $\begin{array}{l}\text { Die selbstständige } \\
\text { Lebensführung ist } \\
\text { gänzlich } \\
\text { aufgehoben }\end{array}$ & $\begin{array}{l}\text { Unruhe, } \\
\text { Nesteln, } \\
\text { Schreien, } \\
\text { Störungen des Tag- } \\
\text { Nacht-Rhythmus }\end{array}$ & Unter 10 Punkten \\
\hline
\end{tabular}

Tabelle 14: Stadieneinteilung nach DEGAM (2008) 


\subsection{Klinische Diagnosekriterien für die Alzheimerdemenz nach NINCDSADRDA}

1.Klinische Diagnosekriterien für eine wahrscheinliche Alzheimererkrankung:

- durch klinische Untersuchung diagnostizierte Demenz, dokumentiert durch den MiniMental-Status-Test, die Blessed Demenzskala oder ähnliche Untersuchungen und durch neuropsychologische Tests bestätigt.

- Defizit in mindestens 2 kognitiven Funktionen

- progressive Verschlechterung von Gedächtnis und anderer kognitiver Funktionen

- keine Bewusstseinseintrübung

- Auftreten zwischen dem 40. und 90. Lebensjahr, meistens nach dem 65. Lebensjahr

- Ausschluss allgemeiner oder zerebraler Erkrankungen, die direkt oder indirekt für die fortschreitenden Ausfälle von Gedächtnis und kognitiven Funktionen verantwortlich sein könnten.

2. Die wahrscheinliche Alzheimerdiagnose wird unterstützt durch:

- die zunehmende Verschlechterung von spezifischen kognitiven Funktionen, wie Sprache (Aphasie), motorische Fertigkeiten (Apraxie) und Wahrnehmung (Agnosie)

- Beeinträchtigung der alltäglichen Aktivitäten und Verhaltensänderungen

- gleiche Störung in der Familie, besonders wenn diese neuropathologisch bestätigt ist

- Laboruntersuchungen mit einem unauffälligen Liquor, normalen EEG, progressive zerebrale Atrophie im CT in aufeinanderfolgenden Untersuchungen

3. Andere klinische Befunde passend $\mathrm{zu}$ einer wahrscheinlichen Alzheimerdemenz, nach Ausschluss anderer Ursachen einer Demenz sind:

- Plateaus im fortschreitendem Verlauf der Erkrankung

- assoziierte Symptome wie Depression, Schlaflosigkeit, Inkontinenz, Wahnvorstellungen, Halluzinationen, plötzliche verbale, emotionale oder physische Ausbrüche, sexuelle Störungen und Gewichtsverlust

- motorische Störungen wie erhöhter Muskeltonus, Myoklonus, Gangstörungen

- Krampfanfälle im fortgeschrittenem Krankheitsstadium

- normales altersentsprechendes CT

4. Befunde, die an einer wahrscheinlichen Alzheimerdiagnose zweifeln lassen müssen:

- plötzlicher Apoplex

- fokal-neurologische Befunde wie Hemiparese, Sinnesverlust, Gesichtsfeldausfälle, Koordinationsstörungen im frühen Stadium der Krankheit

- Krampfanfälle oder Gangstörungen in der Anfangsphase der Erkrankung

5. Kriterien für eine definitive Diagnose sind:

- klinische Kriterien für eine wahrscheinliche Alzheimerdemenz

- typische Histopathologie des Gehirns

Tabelle 15: Klinische Diagnosekriterien für die Alzheimerdemenz nach NINCDSADRDA (McKhann et al. 1984) 


\subsection{Färbeprotokoll für Paraffinschnitte}

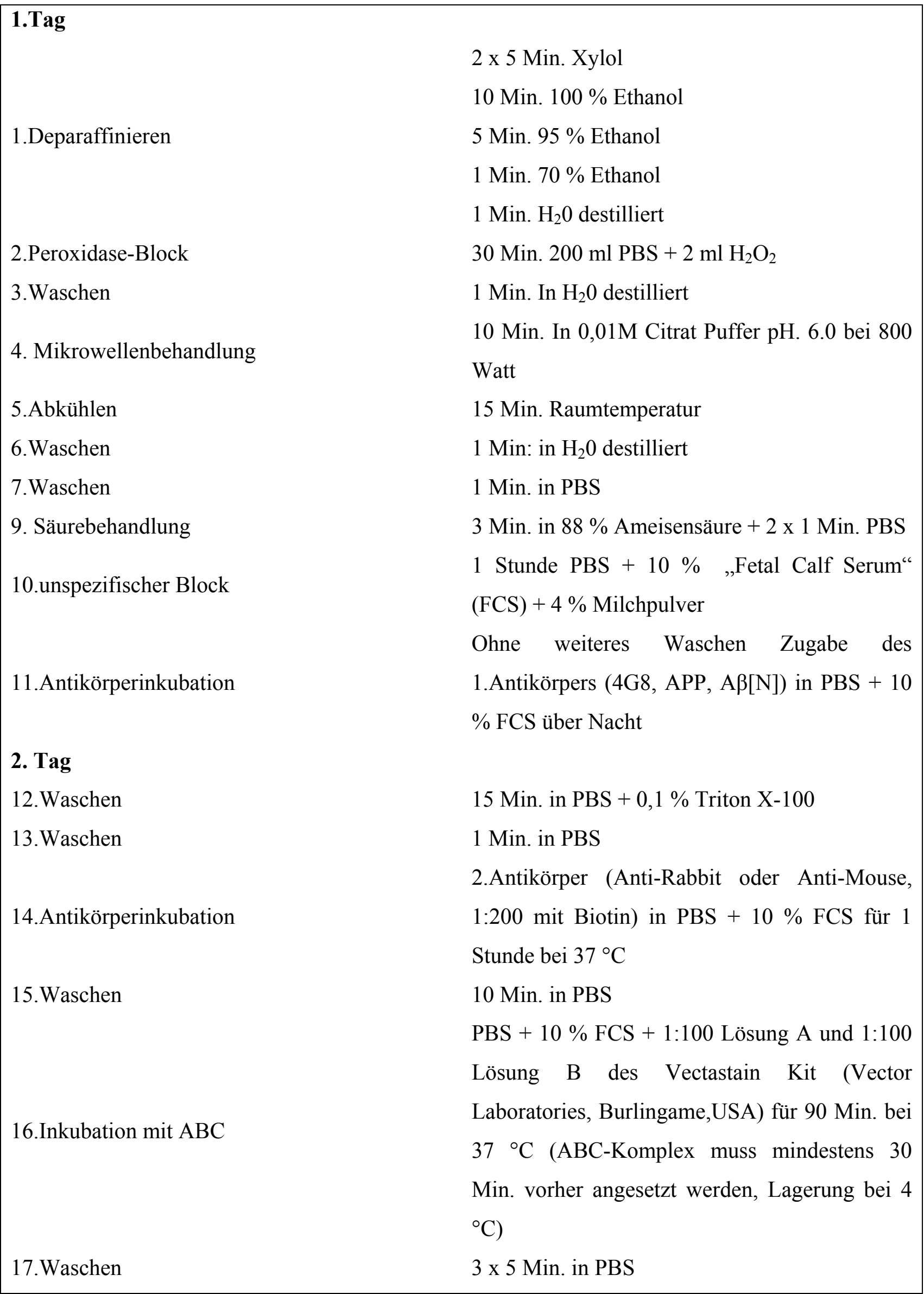


62| A in ha $\mathrm{ng}$

$5 \mathrm{ml} 0,05 \mathrm{M}$ Tris-HCl pH7,5 + $100 \mu \mathrm{l}$ DAB

18.Färbung mit Substrat

(3,3-Diaminobenzidin) Stocklösung $+2,5 \mu 1$ $\mathrm{H}_{2} \mathrm{O}_{2}$

19. Waschen

10 Min. PBS

20. Gegenfärbung

40 Sekunden mit Hämatoxylin

1 Min. $70 \%$ Ethanol

21.Aufsteigende Alkoholreihe

5 Min. $95 \%$ Ethanol

10 Min. 100 \% Ethanol

2 x 10 Min. Xylol

Tabelle 16: Färbeprotokoll für Paraffinschnitte 


\section{Literaturverzeichnis}

Andersen K, Launer LJ, Dewey ME, Letenneur L, Ott A, Copeland JR, Dartigues JF, KraghSorensen P, Baldereschi M, Brayne C et al (1999): Gender differences in the incidence of $\mathrm{AD}$ and vascular dementia: The EURODEM Studies. EURODEM Incidence Research Group. Neurology $\underline{53}$, 1992-1997

Araujo DM, Cotman CW (1992): Beta-amyloid stimulates glial cells in vitro to produce growth factors that accumulate in senile plaques in Alzheimer's disease. Brain Res $\underline{569}, 141-145$

Arendt T: Neuronale Pathologie; in: Demenzen - Grundlagen und Klinik; hrsg v. Beyreuther K, Einhäupl KM, Förstl H and Kurz A; Thieme Stuttgart, New York 2002, 106-117

Baker FM, Jordan B, Barclay L, Schoenberg BS (1993): Risk factors for clinically diagnosed alzheimer's disease. Int J Geriatr Psychiatry $\underline{8}, 379-385$

Ball MJ (1977): Neuronal loss, neurofibrillary tangles and granulovacuolar degeneration in the hippocampus with ageing and dementia. A quantitative study. Acta Neuropathol 37, 111118

Bancher C, Brunner C, Lassmann H, Budka H, Jellinger K, Wiche G, Seitelberger F, GrundkeIqbal I, Iqbal K, Wisniewski HM (1989): Accumulation of abnormally phosphorylated tau precedes the formation of neurofibrillary tangles in Alzheimer's disease. Brain Res $\underline{477}, 90$ 99

Barnes LL, Wilson RS, Bienias JL, Schneider JA, Evans DA, Bennett DA (2005): Sex differences in the clinical manifestations of Alzheimer disease pathology. Arch Gen Psychiatry $\underline{62}, 685-691$

Bentahir M, Nyabi O, Verhamme J, Tolia A, Horre K, Wiltfang J, Esselmann H, De Strooper B (2006): Presenilin clinical mutations can affect gamma-secretase activity by different mechanisms. J Neurochem $\underline{96}, 732-742$

Bickel H: Grundlagen des normalen und pathologischen Alterns; in: Lehrbuch der Gerontopsychiatrie, Band 63; hrsg v. Förstl H; Enke, Stuttgart 1997, 1-15

Bickel H: Epidemiologie und Gesundheitsökonomie; in: Demenzen Thieme-Referenzreihe; hrsg v. Wallesch C and Förstl H; Thieme, Stuttgart-NewYork 2004, 1-13

Blennow K, de Leon MJ, Zetterberg H (2006): Alzheimer's disease. Lancet 368, 387-403

Bondareff W, Mountjoy CQ, Roth M (1982): Loss of neurons of origin of the adrenergic projection to cerebral cortex (nucleus locus ceruleus) in senile dementia. Neurology $\underline{32}, 164-168$

Bowen RL, Isley JP, Atkinson RL (2000): An association of elevated serum gonadotropin concentrations and Alzheimer disease? J Neuroendocrinol 12, 351-354

Bowen RL, Smith MA, Harris PL, Kubat Z, Martins RN, Castellani RJ, Perry G, Atwood CS 
(2002): Elevated luteinizing hormone expression colocalizes with neurons vulnerable to Alzheimer's disease pathology. J Neurosci Res $\underline{70}$, 514-518

Braak H, Braak E (1991): Neuropathological stageing of Alzheimer-related changes. Acta Neuropathol $\underline{82}, 239-259$

Braak H, Braak E, Grundke-Iqbal I, Iqbal K (1986): Occurrence of neuropil threads in the senile human brain and in Alzheimer's disease: a third location of paired helical filaments outside of neurofibrillary tangles and neuritic plaques. Neurosci Lett $\underline{65}, 351-355$

Brion JP, Couck AM, Bruce M, Anderton B, Flament-Durand J (1991): Synaptophysin and chromogranin A immunoreactivities in senile plaques of Alzheimer's disease. Brain Res $\underline{539}, 143-150$

Brun A, Englund E (1981): Regional pattern of degeneration in Alzheimer's disease: neuronal loss and histopathological grading. Histopathology $\underline{5}, 549-564$

Buxbaum JD, Liu KN, Luo Y, Slack JL, Stocking KL, Peschon JJ, Johnson RS, Castner BJ, Cerretti DP, Black RA (1998): Evidence that tumor necrosis factor alpha converting enzyme is involved in regulated alpha-secretase cleavage of the Alzheimer amyloid protein precursor. J Biol Chem $\underline{273}$, 27765-27767

Cai XD, Golde TE, Younkin SG (1993): Release of excess amyloid beta protein from a mutant amyloid beta protein precursor. Science $\underline{259}, 514-516$

Callahan MJ, Lipinski WJ, Bian F, Durham RA, Pack A, Walker LC (2001): Augmented senile plaque load in aged female beta-amyloid precursor protein-transgenic mice. Am J Pathol $\underline{158}, 1173-1177$

Casadesus G, Milliken EL, Webber KM, Bowen RL, Lei Z, Rao CV, Perry G, Keri RA, Smith MA (2007): Increases in luteinizing hormone are associated with declines in cognitive performance. Mol Cell Endocrinol 269, 107-111

Casas C, Sergeant N, Itier JM, Blanchard V, Wirths O, van der Kolk N, Vingtdeux V, van de Steeg E, Ret G, Canton T et al (2004): Massive CA1/2 neuronal loss with intraneuronal and N-terminal truncated Abeta42 accumulation in a novel Alzheimer transgenic model. Am J Pathol $\underline{165}, 1289-1300$

Cataldo AM, Hamilton DJ, Nixon RA (1994): Lysosomal abnormalities in degenerating neurons link neuronal compromise to senile plaque development in Alzheimer disease. Brain Res $\underline{640}, 68-80$

Christensen DZ, Kraus SL, Flohr A, Cotel MC, Wirths O, Bayer TA (2008): Transient intraneuronal A beta rather than extracellular plaque pathology correlates with neuron loss in the frontal cortex of APP/PS1KI mice. Acta Neuropathol 116, 647-655

Citron M, Eckman CB, Diehl TS, Corcoran C, Ostaszewski BL, Xia W, Levesque G, St George Hyslop P, Younkin SG, Selkoe DJ (1998): Additive effects of PS1 and APP mutations on secretion of the 42-residue amyloid beta-protein. Neurobiol Dis $\underline{5}, 107-116$ 
Coleman PD, Yao PJ (2003): Synaptic slaughter in Alzheimer's disease. Neurobiol Aging 24, 10231027

Corder EH, Saunders AM, Strittmatter WJ, Schmechel DE, Gaskell PC, Small GW, Roses AD, Haines JL, Pericak-Vance MA (1993): Gene dose of apolipoprotein E type 4 allele and the risk of Alzheimer's disease in late onset families. Science 261, 921-923

Corder EH, Saunders AM, Risch NJ, Strittmatter WJ, Schmechel DE, Gaskell PC, Jr., Rimmler JB, Locke PA, Conneally PM, Schmader KE et al (1994): Protective effect of apolipoprotein E type 2 allele for late onset Alzheimer disease. Nat Genet $\underline{7}, 180-184$

Cynis H, Schilling S, Bodnar M, Hoffmann T, Heiser U, Saido TC, Demuth HU (2006): Inhibition of glutaminyl cyclase alters pyroglutamate formation in mammalian cells. Biochim Biophys Acta 1764, 1618-1625

D'Andrea MR, Nagele RG, Wang HY, Peterson PA, Lee DH (2001): Evidence that neurones accumulating amyloid can undergo lysis to form amyloid plaques in Alzheimer's disease. Histopathology $\underline{38}, 120-134$

Davies CA, Mann DM, Sumpter PQ, Yates PO (1987): A quantitative morphometric analysis of the neuronal and synaptic content of the frontal and temporal cortex in patients with Alzheimer's disease. J Neurol Sci $\underline{78}, 151-164$

Deane R, Sagare A, Hamm K, Parisi M, Lane S, Finn MB, Holtzman DM, Zlokovic BV (2008): apoE isoform-specific disruption of amyloid beta peptide clearance from mouse brain. J Clin Invest $\underline{118}, 4002-4013$

DEGAM - Deutsche Gesellschaft für Allgemeinmedizin und Familienmedizin: Demenz DEGAM Leitlinie Nr.12; omikron publishing, Düsseldorf 2008; http://www.degam.de/typo/uploads/media/LL-12_Langfassung_gekuerzt.pdf

De Strooper B, Saftig P, Craessaerts K, Vanderstichele H, Guhde G, Annaert W, Von Figura K, Van Leuven F (1998): Deficiency of presenilin-1 inhibits the normal cleavage of amyloid precursor protein. Nature $\underline{391}, 387-390$

Dickson DW (1997): The pathogenesis of senile plaques. J Neuropathol Exp Neurol $\underline{56}, 321-339$

Dickson DW, Farlo J, Davies P, Crystal H, Fuld P, Yen SH (1988): Alzheimer's disease. A double-labeling immunohistochemical study of senile plaques. Am J Pathol 132, 86-101

Eckert A (2002): [From the Frankfurter Institute for the Insane and Epileptics. Alois Alzheimer and Alzheimer disease]. Pharm Unserer Zeit 31, 356-360

Eckman CB, Mehta ND, Crook R, Perez-tur J, Prihar G, Pfeiffer E, Graff-Radford N, Hinder P, Yager D, Zenk B et al (1997): A new pathogenic mutation in the APP gene (I716V) increases the relative proportion of A beta 42(43). Hum Mol Genet $\underline{6}, 2087-2089$ 
Eikelenboom P, Stam FC (1982): Immunoglobulins and complement factors in senile plaques. An immunoperoxidase study. Acta Neuropathol 57, 239-242

Ellis RJ, Olichney JM, Thal LJ, Mirra SS, Morris JC, Beekly D, Heyman A (1996): Cerebral amyloid angiopathy in the brains of patients with Alzheimer's disease: the CERAD experience, Part XV. Neurology $\underline{46}$, 1592-1596

Esch FS, Keim PS, Beattie EC, Blacher RW, Culwell AR, Oltersdorf T, McClure D, Ward PJ (1990): Cleavage of amyloid beta peptide during constitutive processing of its precursor. Science $\underline{248}, 1122-1124$

Fernandez-Vizarra P, Fernandez AP, Castro-Blanco S, Serrano J, Bentura ML, Martinez-Murillo R, Martinez A, Rodrigo J (2004): Intra- and extracellular Abeta and PHF in clinically evaluated cases of Alzheimer's disease. Histol Histopathol 19, 823-844

Fratiglioni L, Launer LJ, Andersen K, Breteler MM, Copeland JR, Dartigues JF, Lobo A, Martinez-Lage J, Soininen H, Hofman A (2000): Incidence of dementia and major subtypes in Europe: A collaborative study of population-based cohorts. Neurologic Diseases in the Elderly Research Group. Neurology $\underline{54}$, S10-15

Furukawa K, Sopher BL, Rydel RE, Begley JG, Pham DG, Martin GM, Fox M, Mattson MP (1996): Increased activity-regulating and neuroprotective efficacy of alpha-secretase-derived secreted amyloid precursor protein conferred by a C-terminal heparin-binding domain. $\mathrm{J}$ Neurochem $\underline{67}, 1882-1896$

Gearing M, Mori H, Mirra SS (1996): Abeta-peptide length and apolipoprotein E genotype in Alzheimer's disease. Ann Neurol 39, 395-399

Gitter BD, Cox LM, Rydel RE, May PC (1995): Amyloid beta peptide potentiates cytokine secretion by interleukin-1 beta-activated human astrocytoma cells. Proc Natl Acad Sci U S A $\underline{92}, 10738-10741$

Glenner GG, Wong CW (1984a): Alzheimer's disease and Down's syndrome: sharing of a unique cerebrovascular amyloid fibril protein. Biochem Biophys Res Commun $\underline{122}, 1131-1135$

Glenner GG, Wong CW (1984b): Alzheimer's disease: initial report of the purification and characterization of a novel cerebrovascular amyloid protein. Biochem Biophys Res Commun $\underline{120}, 885-890$

Goate A, Chartier-Harlin MC, Mullan M, Brown J, Crawford F, Fidani L, Giuffra L, Haynes A, Irving N, James L et al (1991): Segregation of a missense mutation in the amyloid precursor protein gene with familial Alzheimer's disease. Nature $\underline{349}, 704-706$

Gomez-Isla T, Price JL, McKeel DW, Jr., Morris JC, Growdon JH, Hyman BT (1996): Profound loss of layer II entorhinal cortex neurons occurs in very mild Alzheimer's disease. J Neurosci $\underline{16}, 4491-4500$

Greenberg SM, Vonsattel JP, Segal AZ, Chiu RI, Clatworthy AE, Liao A, Hyman BT, Rebeck GW (1998): Association of apolipoprotein E epsilon2 and vasculopathy in cerebral amyloid 
angiopathy. Neurology $\underline{50}, 961-965$

Greenfield JG, Bosanquet FD (1953): The brain-stem lesions in Parkinsonism. J Neurol Neurosurg Psychiatry $\underline{16}, 213-226$

Grundke-Iqbal I, Iqbal K, Quinlan M, Tung YC, Zaidi MS, Wisniewski HM (1986): Microtubule-associated protein tau. A component of Alzheimer paired helical filaments. J Biol Chem 261, 6084-6089

Gyure KA, Durham R, Stewart WF, Smialek JE, Troncoso JC (2001): Intraneuronal abetaamyloid precedes development of amyloid plaques in Down syndrome. Arch Pathol Lab Med 125, 489-492

Haass C, Hung AY, Selkoe DJ, Teplow DB (1994): Mutations associated with a locus for familial Alzheimer's disease result in alternative processing of amyloid beta-protein precursor. J Biol Chem 269, 17741-17748

Hardy J, Allsop D (1991): Amyloid deposition as the central event in the aetiology of Alzheimer's disease. Trends Pharmacol Sci $\underline{12}, 383-388$

Hasegawa M, Morishima-Kawashima M, Takio K, Suzuki M, Titani K, Ihara Y (1992): Protein sequence and mass spectrometric analyses of tau in the Alzheimer's disease brain. J Biol Chem 267, 17047-17054

Haupt M, Kurz A, Pollmann S, Romero B (1992): [Psychopathologic disorders at the onset of Alzheimer's disease]. Fortschr Neurol Psychiatr $\underline{60}$, 3-7

He W, Barrow CJ (1999): The A beta 3-pyroglutamyl and 11-pyroglutamyl peptides found in senile plaque have greater beta-sheet forming and aggregation propensities in vitro than full-length A beta. Biochemistry $\underline{38}, 10871-10877$

Heun R, Kolsch H, Jessen F (2006): Risk factors and early signs of Alzheimer's disease in a family study sample. Risk of AD. Eur Arch Psychiatry Clin Neurosci 256, 28-36

Hof PR, Glannakopoulos P, Bouras C (1996): The neuropathological changes associated with normal brain aging. Histol Histopathol 11, 1075-1088

Holcomb L, Gordon MN, McGowan E, Yu X, Benkovic S, Jantzen P, Wright K, Saad I, Mueller R, Morgan D et al (1998): Accelerated Alzheimer-type phenotype in transgenic mice carrying both mutant amyloid precursor protein and presenilin 1 transgenes. Nat Med $\underline{4}, 97-100$

Honer WG, Dickson DW, Gleeson J, Davies P (1992): Regional synaptic pathology in Alzheimer's disease. Neurobiol Aging $\underline{13}, 375-382$

Ihl R: Demenzen; in: Diagnostik und Therapie psychischer Störungen; hrsg v. Gaebel W and Müller-Spahn F; W. Kohlhammer GmbH, Stuttgart 2002, 83-110

Ishii T, Haga S (1976): Immuno-electron microscopic localization of immunoglobulins in amyloid 
fibrils of senile plaques. Acta Neuropathol $\underline{36}, 243-249$

Ishii T, Haga S (1984): Immuno-electron-microscopic localization of complements in amyloid fibrils of senile plaques. Acta Neuropathol $\underline{63}, 296-300$

Jarrett JT, Berger EP, Lansbury PT, Jr. (1993): The carboxy terminus of the beta amyloid protein is critical for the seeding of amyloid formation: implications for the pathogenesis of Alzheimer's disease. Biochemistry $\underline{32}$, 4693-4697

Jorm AF, Jolley D (1998): The incidence of dementia: a meta-analysis. Neurology $\underline{51}, 728-733$

Kamal A, Almenar-Queralt A, LeBlanc JF, Roberts EA, Goldstein LS (2001): Kinesin-mediated axonal transport of a membrane compartment containing beta-secretase and presenilin-1 requires APP. Nature $\underline{414}, 643-648$

Kang J, Lemaire HG, Unterbeck A, Salbaum JM, Masters CL, Grzeschik KH, Multhaup G, Beyreuther K, Muller-Hill B (1987): The precursor of Alzheimer's disease amyloid A4 protein resembles a cell-surface receptor. Nature $\underline{325}, 733-736$

Kidd M (1964): Alzheimer's Disease--an Electron Microscopical Study. Brain 87, 307-320

Kraszpulski M, Soininen H, Helisalmi S, Alafuzoff I (2001): The load and distribution of betaamyloid in brain tissue of patients with Alzheimer's disease. Acta Neurol Scand $\underline{103}, 88-92$

Ksiezak-Reding H, Binder LI, Yen SH (1990): Alzheimer disease proteins (A68) share epitopes with tau but show distinct biochemical properties. J Neurosci Res $\underline{25}$, 420-430

Kuo YM, Webster S, Emmerling MR, De Lima N, Roher AE (1998): Irreversible dimerization/tetramerization and post-translational modifications inhibit proteolytic degradation of A beta peptides of Alzheimer's disease. Biochim Biophys Acta 1406, 291298

Lammich S, Kojro E, Postina R, Gilbert S, Pfeiffer R, Jasionowski M, Haass C, Fahrenholz F (1999): Constitutive and regulated alpha-secretase cleavage of Alzheimer's amyloid precursor protein by a disintegrin metalloprotease. Proc Natl Acad Sci U S A 966, 3922-3927

Lemere CA, Blusztajn JK, Yamaguchi H, Wisniewski T, Saido TC, Selkoe DJ (1996): Sequence of deposition of heterogeneous amyloid beta-peptides and APO E in Down syndrome: implications for initial events in amyloid plaque formation. Neurobiol Dis $\underline{3}, 16-32$

Levy-Lahad E, Wijsman EM, Nemens E, Anderson L, Goddard KA, Weber JL, Bird TD, Schellenberg GD (1995): A familial Alzheimer's disease locus on chromosome 1. Science $\underline{269}, 970-973$

Liu WK, Ksiezak-Reding H, Yen SH (1991): Abnormal tau proteins from Alzheimer's disease brains. Purification and amino acid analysis. J Biol Chem 266, 21723-21727

Lorenzo A, Yankner BA (1994): Beta-amyloid neurotoxicity requires fibril formation and is inhibited by congo red. Proc Natl Acad Sci U S A 91, 12243-12247 
Lowes-Hummel P, Gertz HJ, Ferszt R, Cervos-Navarro J (1989): The basal nucleus of Meynert revised: the nerve cell number decreases with age. Arch Gerontol Geriatr $\underline{8}, 21-27$

Mandybur TI, Nagpaul AS, Pappas Z, Niklowitz WJ (1977): Alzheimer neurofibrillary change in subacute sclerosing panencephalitis. Ann Neurol $\underline{1}, 103-107$

Mann DM, Brown AM, Prinja D, Jones D, Davies CA (1990): A morphological analysis of senile plaques in the brains of non-demented persons of different ages using silver, immunocytochemical and lectin histochemical staining techniques. Neuropathol Appl Neurobiol $\underline{16}, 17-25$

Marder K, Sano M (2000): Estrogen to treat Alzheimer's disease: too little, too late? So what's a woman to do? Neurology $\underline{54}, 2035-2037$

Masters CL, Simms G, Weinman NA, Multhaup G, McDonald BL, Beyreuther K (1985a): Amyloid plaque core protein in Alzheimer disease and Down syndrome. Proc Natl Acad Sci U S A $\underline{82}, 4245-4249$

Masters CL, Multhaup G, Simms G, Pottgiesser J, Martins RN, Beyreuther K (1985b): Neuronal origin of a cerebral amyloid: neurofibrillary tangles of Alzheimer's disease contain the same protein as the amyloid of plaque cores and blood vessels. EMBO J $\underline{4}, 2757-2763$

McEwen BS, Alves SE, Bulloch K, Weiland NG (1997): Ovarian steroids and the brain: implications for cognition and aging. Neurology $\underline{48}, \mathrm{~S} 8-15$

McKhann G, Drachman D, Folstein M, Katzman R, Price D, Stadlan EM (1984): Clinical diagnosis of Alzheimer's disease: report of the NINCDS-ADRDA Work Group under the auspices of Department of Health and Human Services Task Force on Alzheimer's Disease. Neurology $\underline{34}, 939-944$

Miller DL, Currie JR, Iqbal K, Potempska A, Styles J (1989): Relationships among the cerebral amyloid peptides and their precursors. Ann Med 21, 83-87

Miller DL, Papayannopoulos IA, Styles J, Bobin SA, Lin YY, Biemann K, Iqbal K (1993): Peptide compositions of the cerebrovascular and senile plaque core amyloid deposits of Alzheimer's disease. Arch Biochem Biophys $\underline{301}$, 41-52

Moechars D, Lorent K, De Strooper B, Dewachter I, Van Leuven F (1996): Expression in brain of amyloid precursor protein mutated in the alpha-secretase site causes disturbed behavior, neuronal degeneration and premature death in transgenic mice. EMBO J $\underline{15}, 1265-1274$

Mooradian AD (1993): Antioxidant properties of steroids. J Steroid Biochem Mol Biol 45, 509-511

Mori C, Spooner ET, Wisniewsk KE, Wisniewski TM, Yamaguch H, Saido TC, Tolan DR, Selkoe DJ, Lemere CA (2002): Intraneuronal Abeta42 accumulation in Down syndrome brain. Amyloid $\underline{9}, 88-102$

Morrison JH, Hof PR (1997): Life and death of neurons in the aging brain. Science 278, 412-419 
Mulnard RA, Cotman CW, Kawas C, van Dyck CH, Sano M, Doody R, Koss E, Pfeiffer E, Jin S, Gamst A et al (2000): Estrogen replacement therapy for treatment of mild to moderate Alzheimer disease: a randomized controlled trial. Alzheimer's Disease Cooperative Study. JAMA $\underline{283}, 1007-1015$

Munoz DG (1991): Chromogranin A-like immunoreactive neurites are major constituents of senile plaques. Lab Invest $\underline{64}, 826-832$

Namba Y, Tomonaga M, Kawasaki H, Otomo E, Ikeda K (1991): Apolipoprotein E immunoreactivity in cerebral amyloid deposits and neurofibrillary tangles in Alzheimer's disease and kuru plaque amyloid in Creutzfeldt-Jakob disease. Brain Res $\underline{541}$, 163-166

Oakley H, Cole SL, Logan S, Maus E, Shao P, Craft J, Guillozet-Bongaarts A, Ohno M, Disterhoft J, Van Eldik L et al (2006): Intraneuronal beta-amyloid aggregates, neurodegeneration, and neuron loss in transgenic mice with five familial Alzheimer's disease mutations: potential factors in amyloid plaque formation. J Neurosci 26, 1012910140

Ott A, Breteler MM, van Harskamp F, Claus JJ, van der Cammen TJ, Grobbee DE, Hofman A (1995): Prevalence of Alzheimer's disease and vascular dementia: association with education. The Rotterdam study. BMJ $\underline{310}$, 970-973

Pakkenberg B, Gundersen HJ (1997): Neocortical neuron number in humans: effect of sex and age. J Comp Neurol 384, 312-320

Pakkenberg B, Pelvig D, Marner L, Bundgaard MJ, Gundersen HJ, Nyengaard JR, Regeur L (2003): Aging and the human neocortex. Exp Gerontol 38, 95-99

Paris D, Town T, Parker T, Humphrey J, Mullan M (2000): A beta vasoactivity: an inflammatory reaction. Ann N Y Acad Sci $\underline{903}$, 97-109

Paxinos G, Franklin K: The mouse brain in stereotaxic coordinates. 2. Auflage; Academic Press, New York 2001

Perry G, Friedman R, Shaw G, Chau V (1987): Ubiquitin is detected in neurofibrillary tangles and senile plaque neurites of Alzheimer disease brains. Proc Natl Acad Sci U S A $\underline{84}$, 3033-3036

Pike CJ, Overman MJ, Cotman CW (1995): Amino-terminal deletions enhance aggregation of beta-amyloid peptides in vitro. J Biol Chem $\underline{270}$, 23895-23898

Poeck K, Hacke W: Neurologie. 12. Auflage; Springer Medizin, Heidelberg 2006

Prasher VP, Farrer MJ, Kessling AM, Fisher EM, West RJ, Barber PC, Butler AC (1998): Molecular mapping of Alzheimer-type dementia in Down's syndrome. Ann Neurol 43, 380383

Rogaeva E (2002): The solved and unsolved mysteries of the genetics of early-onset Alzheimer's disease. Neuromolecular Med 2, 1-10 
Rosen GD, Harry JD (1990): Brain volume estimation from serial section measurements: a comparison of methodologies. J Neurosci Methods $\underline{35}$, 115-124

Russo C, Violani E, Salis S, Venezia V, Dolcini V, Damonte G, Benatti U, D'Arrigo C, Patrone E, Carlo P et al (2002): Pyroglutamate-modified amyloid beta-peptides-AbetaN3(pE)--strongly affect cultured neuron and astrocyte survival. J Neurochem $\underline{82}$, 1480-1489

Salehi A, Delcroix JD, Belichenko PV, Zhan K, Wu C, Valletta JS, Takimoto-Kimura R, Kleschevnikov AM, Sambamurti K, Chung PP et al (2006): Increased App expression in a mouse model of Down's syndrome disrupts NGF transport and causes cholinergic neuron degeneration. Neuron $\underline{51}, 29-42$

Sandbrink R, Masters CL, Beyreuther K (1994): Similar alternative splicing of a non-homologous domain in beta A4-amyloid protein precursor-like proteins. J Biol Chem $\underline{269}$, 14227-14234

Saunders AM, Strittmatter WJ, Schmechel D, George-Hyslop PH, Pericak-Vance MA, Joo SH, Rosi BL, Gusella JF, Crapper-MacLachlan DR, Alberts MJ et al (1993): Association of apolipoprotein E allele epsilon 4 with late-onset familial and sporadic Alzheimer's disease. Neurology $\underline{43}, 1467-1472$

Schafer S, Wirths O, Multhaup G, Bayer TA (2007): Gender dependent APP processing in a transgenic mouse model of Alzheimer's disease. J Neural Transm 114, 387-394

Schellenberg GD, Bird TD, Wijsman EM, Orr HT, Anderson L, Nemens E, White JA, Bonnycastle L, Weber JL, Alonso ME et al (1992): Genetic linkage evidence for a familial Alzheimer's disease locus on chromosome 14. Science 258, 668-671

Scheuner D, Eckman C, Jensen M, Song X, Citron M, Suzuki N, Bird TD, Hardy J, Hutton M, Kukull W et al (1996): Secreted amyloid beta-protein similar to that in the senile plaques of Alzheimer's disease is increased in vivo by the presenilin 1 and 2 and APP mutations linked to familial Alzheimer's disease. Nat Med $\underline{2}, 864-870$

Schilling S, Hoffmann T, Manhart S, Hoffmann M, Demuth HU (2004): Glutaminyl cyclases unfold glutamyl cyclase activity under mild acid conditions. FEBS Lett $\underline{563}, 191-196$

Schilling S, Lauber T, Schaupp M, Manhart S, Scheel E, Bohm G, Demuth HU (2006): On the seeding and oligomerization of pGlu-amyloid peptides (in vitro). Biochemistry $\underline{45}, 12393$ 12399

Schilling S, Zeitschel U, Hoffmann T, Heiser U, Francke M, Kehlen A, Holzer M, Hutter-Paier B, Prokesch M, Windisch M et al (2008): Glutaminyl cyclase inhibition attenuates pyroglutamate Abeta and Alzheimer's disease-like pathology. Nat Med $\underline{14}, 1106-1111$

Schmechel DE, Saunders AM, Strittmatter WJ, Crain BJ, Hulette CM, Joo SH, Pericak-Vance MA, Goldgaber D, Roses AD (1993): Increased amyloid beta-peptide deposition in cerebral cortex as a consequence of apolipoprotein E genotype in late-onset Alzheimer disease. Proc Natl Acad Sci U S A 90, 9649-9653 
Schmitz C, Hof PR (2005): Design-based stereology in neuroscience. Neuroscience 130, 813-831

Schneider LS, Farlow MR, Henderson VW, Pogoda JM (1996): Effects of estrogen replacement therapy on response to tacrine in patients with Alzheimer's disease. Neurology $\underline{46}, 1580$ 1584

Schnieder A: Degenerative und symptomatische Demenzen; in: Neurologie in Praxis und Klinik Band I; hrsg v. Hopf HC, Deuschl G, Diener HC and Reichmann H; Georg Thieme Verlag, Stuttgart, New York 1999, 106-129

Selkoe DJ (2001): Alzheimer's disease: genes, proteins, and therapy. Physiol Rev $\underline{81,741-766}$

Selkoe DJ, Podlisny MB, Joachim CL, Vickers EA, Lee G, Fritz LC, Oltersdorf T (1988): Betaamyloid precursor protein of Alzheimer disease occurs as 110- to 135-kilodalton membraneassociated proteins in neural and nonneural tissues. Proc Natl Acad Sci U S A $\underline{85}, 7341-$ 7345

Shefer VF (1977): Hippocampal pathology as a possible factor in the pathogenesis of senile dementias. Neurosci Behav Physiol $\underline{8}, 236-239$

Sherrington R, Rogaev EI, Liang Y, Rogaeva EA, Levesque G, Ikeda M, Chi H, Lin C, Li G, Holman $\mathrm{K}$ et al (1995): Cloning of a gene bearing missense mutations in early-onset familial Alzheimer's disease. Nature $\underline{375}, 754-760$

Shumaker SA, Legault C, Kuller L, Rapp SR, Thal L, Lane DS, Fillit H, Stefanick ML, Hendrix SL, Lewis CE et al (2004): Conjugated equine estrogens and incidence of probable dementia and mild cognitive impairment in postmenopausal women: Women's Health Initiative Memory Study. JAMA 291, 2947-2958

Sisodia SS, Kim SH, Thinakaran G (1999): Function and dysfunction of the presenilins. Am J Hum Genet $\underline{65}, 7-12$

Stokin GB, Lillo C, Falzone TL, Brusch RG, Rockenstein E, Mount SL, Raman R, Davies P, Masliah E, Williams DS et al (2005): Axonopathy and transport deficits early in the pathogenesis of Alzheimer's disease. Science $\underline{307}$, 1282-1288

Strittmatter WJ, Saunders AM, Schmechel D, Pericak-Vance M, Enghild J, Salvesen GS, Roses AD (1993): Apolipoprotein E: high-avidity binding to beta-amyloid and increased frequency of type 4 allele in late-onset familial Alzheimer disease. Proc Natl Acad Sci U S A $\underline{90}, 1977-$ 1981

Suzuki K, Terry RD (1967): Fine structural localization of acid phosphatase in senile plaques in Alzheimer's presenile dementia. Acta Neuropathol $\underline{8}, 276-284$

Suzuki N, Iwatsubo T, Odaka A, Ishibashi Y, Kitada C, Ihara Y (1994): High tissue content of soluble beta 1-40 is linked to cerebral amyloid angiopathy. Am J Pathol $\underline{145}, 452-460$

Takahashi RH, Milner TA, Li F, Nam EE, Edgar MA, Yamaguchi H, Beal MF, Xu H, 
Greengard P, Gouras GK (2002): Intraneuronal Alzheimer abeta42 accumulates in multivesicular bodies and is associated with synaptic pathology. Am J Pathol 161, 18691879

Tang MX, Jacobs D, Stern Y, Marder K, Schofield P, Gurland B, Andrews H, Mayeux R (1996): Effect of oestrogen during menopause on risk and age at onset of Alzheimer's disease. Lancet $\underline{348}, 429-432$

Tang-Wai DF, Keith AJ, Petersen RC: Alzheimer's disease-overview; in: Neurodegenerative Diseases: Neurobiology, Pathogenesis and Therapeutics; hrsg v. Beal MF, Lang AE and Ludolph A; Cambrigde University Press, Cambridge 2005, 416-432

Tekirian TL, Cole GM, Russell MJ, Yang F, Wekstein DR, Patel E, Snowdon DA, Markesbery WR, Geddes JW (1996): Carboxy terminal of beta-amyloid deposits in aged human, canine, and polar bear brains. Neurobiol Aging 17, 249-257

Terry RD, Gonatas NK, Weiss M (1964): Ultrastructural Studies in Alzheimer's Presenile Dementia. Am J Pathol 44, 269-297

Terry RD, Hansen LA, DeTeresa R, Davies P, Tobias H, Katzman R (1987): Senile dementia of the Alzheimer type without neocortical neurofibrillary tangles. J Neuropathol Exp Neurol $\underline{46}, 262-268$

Thomas AJ, Morris CM, Ferrier IN, Kalaria RN (2000): Distribution of amyloid beta 42 in relation to the cerebral microvasculature in an elderly cohort with Alzheimer's disease. Ann N Y Acad Sci $\underline{903}, 83-88$

Tokuda T, Fukushima T, Ikeda S, Sekijima Y, Shoji S, Yanagisawa N, Tamaoka A (1997): Plasma levels of amyloid beta proteins Abeta1-40 and Abeta1-42(43) are elevated in Down's syndrome. Ann Neurol 41, 271-273

Tomlinson BE, Irving D, Blessed G (1981): Cell loss in the locus coeruleus in senile dementia of Alzheimer type. J Neurol Sci $\underline{49}, 419-428$

Vassar R, Bennett BD, Babu-Khan S, Kahn S, Mendiaz EA, Denis P, Teplow DB, Ross S, Amarante P, Loeloff R et al (1999): Beta-secretase cleavage of Alzheimer's amyloid precursor protein by the transmembrane aspartic protease BACE. Science $\underline{286}, 735-741$

Verbeek MM, Van Nostrand WE, Otte-Holler I, Wesseling P, De Waal RM (2000): Amyloidbeta-induced degeneration of human brain pericytes is dependent on the apolipoprotein $\mathrm{E}$ genotype. Ann N Y Acad Sci $\underline{903}$, 187-199

Vinters HV, Gilbert JJ (1983): Cerebral amyloid angiopathy: incidence and complications in the aging brain. II. The distribution of amyloid vascular changes. Stroke $\underline{14}, 924-928$

Wang J, Tanila H, Puolivali J, Kadish I, van Groen T (2003): Gender differences in the amount and deposition of amyloidbeta in APPswe and PS1 double transgenic mice. Neurobiol Dis $\underline{14}, 318-327$ 
Wertkin AM, Turner RS, Pleasure SJ, Golde TE, Younkin SG, Trojanowski JQ, Lee VM (1993): Human neurons derived from a teratocarcinoma cell line express solely the 695-amino acid amyloid precursor protein and produce intracellular beta-amyloid or A4 peptides. Proc Natl Acad Sci U S A $\underline{90}$, 9513-9517

West MJ, Slomianka L, Gundersen HJ (1991): Unbiased stereological estimation of the total number of neurons in thesubdivisions of the rat hippocampus using the optical fractionator. Anat Rec 231, 482-497

Weyerer S: Kosten der Demenz; in: Gesundheitsberichterstattung des Bundes - Heft 28; hrsg. v. Robert Koch Institut, Berlin 2005, 22-23

Whitehouse PJ, Price DL, Struble RG, Clark AW, Coyle JT, Delon MR (1982): Alzheimer's disease and senile dementia: loss of neurons in the basal forebrain. Science 215, 1237-1239

Wirths O, Multhaup G, Bayer TA (2004): A modified beta-amyloid hypothesis: intraneuronal accumulation of the beta-amyloid peptide--the first step of a fatal cascade. J Neurochem $\underline{91}$, 513-520

Wirths O, Bethge T, Marcello A, Harmeier A, Jawhar S, Lucassen PJ, Multhaup G, Brody DL, Esparza T, Ingelsson M et al (2010): Pyroglutamate Abeta pathology in APP/PS1KI mice, sporadic and familial Alzheimer's disease cases. J Neural Transm 117, 85-96

Wisniewski HM, Bancher C, Barcikowska M, Wen GY, Currie J (1989): Spectrum of morphological appearance of amyloid deposits in Alzheimer's disease. Acta Neuropathol $\underline{78}$, $337-347$

www.deutsche-alzheimer.de/fileadmin/alz/templates/template_images/Alois_Alzheimer.jpg $(07.10 .2009)$

www.hirnliga.de/images/augusteD.jpg (07.10.2009)

Xu H, Gouras GK, Greenfield JP, Vincent B, Naslund J, Mazzarelli L, Fried G, Jovanovic JN, Seeger M, Relkin NR et al (1998): Estrogen reduces neuronal generation of Alzheimer beta-amyloid peptides. Nat Med $\underline{4}, 447-451$

Yan R, Bienkowski MJ, Shuck ME, Miao H, Tory MC, Pauley AM, Brashier JR, Stratman NC, Mathews WR, Buhl AE et al (1999): Membrane-anchored aspartyl protease with Alzheimer's disease beta-secretase activity. Nature $\underline{402}, 533-537$

Yankner BA, Duffy LK, Kirschner DA (1990): Neurotrophic and neurotoxic effects of amyloid beta protein: reversal by tachykinin neuropeptides. Science $250,279-282$

Yen SH, Liu WK, Hall FL, Yan SD, Stern D, Dickson DW (1995): Alzheimer neurofibrillary lesions: molecular nature and potential roles of different components. Neurobiol Aging $\underline{16}$, 381-387

Zeyfang A, Hagg-Grün U, Nikolaus T: Basiswissen Medizin des Alterns und des alten Menschen. 1. Auflage; Springer Medizin, Heidelberg 2008 


\section{Danksagung}

Ich danke Herrn Prof. Dr. rer. nat. Thomas Bayer für die Ermöglichung dieser Arbeit in seiner Arbeitsgruppe und der Vergabe dieses interessanten Themas. Weiter möchte ich mich bei dem gesamten Team der Arbeitsgruppe „Molekulare Psychiatrie“ bedanken, namentlich bei Dr. rer. nat. Oliver Wirths, Marie Cotel und Ditte Christensen, die mir jederzeit mit Hilfe, Rat und Geduld zur Seite standen 